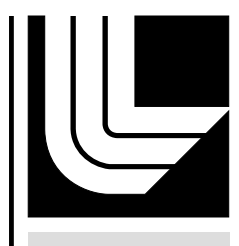

LAWRENCE LIVERMORE N A TIO NAL LABORATORY

\section{LIFE Reactor Study Fiscal Year 2013 Contract Report}

R. Sacks, G. Moses

October 29, 2013 
This document was prepared as an account of work sponsored by an agency of the United States government. Neither the United States government nor Lawrence Livermore National Security, LLC, nor any of their employees makes any warranty, expressed or implied, or assumes any legal liability or responsibility for the accuracy, completeness, or usefulness of any information, apparatus, product, or process disclosed, or represents that its use would not infringe privately owned rights. Reference herein to any specific commercial product, process, or service by trade name, trademark, manufacturer, or otherwise does not necessarily constitute or imply its endorsement, recommendation, or favoring by the United States government or Lawrence Livermore National Security, LLC. The views and opinions of authors expressed herein do not necessarily state or reflect those of the United States government or Lawrence Livermore National Security, LLC, and shall not be used for advertising or product endorsement purposes.

This work performed under the auspices of the U.S. Department of Energy by Lawrence Livermore National Laboratory under Contract DE-AC52-07NA27344. 
LIFE Reactor Study

Fiscal Year 2013 Contract Report

Submitted to

Lawrence Livermore National Laboratory

by

Ryan F. Sacks and Gregory A. Moses

Fusion Technology Institute

Department of Engineering Physics

University of Wisconsin - Madison

September 26, 2013 


\section{Statement of Work and Summary}

1. Sensitivity study of LIFE Chamber dynamics with BUCKY radiation hydrodynamics simulation code: We will continue to model the interaction of ICF target ion and X-ray output with the LIFE reactor cavity and first wall using the BUCKY 1-D radiation hydrodynamics code. We specifically will address the approach to a cyclic steady state condition, blast conditions for the final optics, and the first wall temperature. We will interface BUCKY output with LLNL and UIUC codes for long time analysis of chamber conditions. We will perform sensitivity studies of the chamber as directed by LLNL through varying parameters such as the xenon opacities.

Task 1 was accomplished. "Hand off" parameters produced by BUCKY were sent to UIUC for use as the source term in VTF 3-D simulations of the LIFE chamber. A number of parameter sweeps were done with the BUCKY code to see the influence on engineering quantities such as first surface maximum temperature and overpressure.

2. Improvements to the BUCKY models: BUCKY is an integrated multi-physics code with many models of varying degrees of accuracy. In some cases the accuracy has been dictated by past applications of the code. For the LIFE design we will improve BUCKY models of the following phenomena: we will incorporate xenon opacity data from improved models provided by LLNL into BUCKY and compare the effect of different opacity models on the chamber dynamics.

Task 2 was accomplished. The BUCKY code was modified to read FAC opacity and equation of state files and use this data in the radiation hydrodynamics simulations.

3. Conceptual reactor design participation: We will participate in the conceptual reactor design activity providing trade-offs between reactor cavity conditions, first wall conditions, and other design features such as cavity gas pumping, laser beam propagation to the target and first wall radius. We will participate in LLNL activities under the direction of LLNL scientists.

Task 3 was accomplished. Periodic teleconferences with LLNL and UIUC scientists guided the research plan. Results were periodically shared with all participants.

4. Miscellaneous tasks as specified: We will support the LIFE reactor design with additional tasks as requested by LLNL and upon mutual agreement. These additional tasks may supersede portions of tasks I to 3 to remain consistent with level of effort.

Task 4 was accomplished. It was decided that UW should acquire the export controlled CRETIN code from LLNL to study the effect of non-local thermodynamic equilibrium conditions on the dynamics of the gas filled LIFE chamber. Export control documents were filed and appropriate measures taken to ensure export control guidelines were met. CRETIN was acquired and installed on our local computer cluster. Determination of non-LTE effects is work in progress. Under the direction of LLNL scientists, it was decided to study noble gas mixtures. The process 
for generating these opacities with CRETIN was undertaken and accomplished. These opacities are now being evaluated and compared to FAC opacities.

\section{Deliverables:}

1. Weekly progress reports and/or email interactions

2. Rad-hydro simulations of LIFE chamber dynamics

3. Other code enhancements and simulations as mutually agreed

4. Final report summarizing work

All deliverables were delivered. 


\section{IFE Reactor Chamber Parameter Study}

A parameter study pursuant to the statement of work was conducted on the LIFE IFE reactor chamber. The parameters of interest were fill gas type, fill gas density and chamber radius. The simulations were performed using a $132 \mathrm{MJ}$ high gain indirect drive inertial confinement fusion target with $22 \%$ of the output energy split between $\mathrm{x}$-rays and ions. The new $\mathrm{x}$-ray spectrum (see Figure 1 for comparison of new spectrum in red vs old spectrum in blue) is in general harder than the previous spectrum used in studies in past years. The spectrum was inputted into the BUCKY simulation group-wise in accordance with the 121 group FAC opacities generated by Howard Scott at LLNL. The FAC data also includes equation of state data for the Xenon gas while the temperature dependence in the wall was calculated using thermal conductivity and heat capacity data from 409 Stainless Steel from the AK Steel company as a representative surrogate for a first wall material.

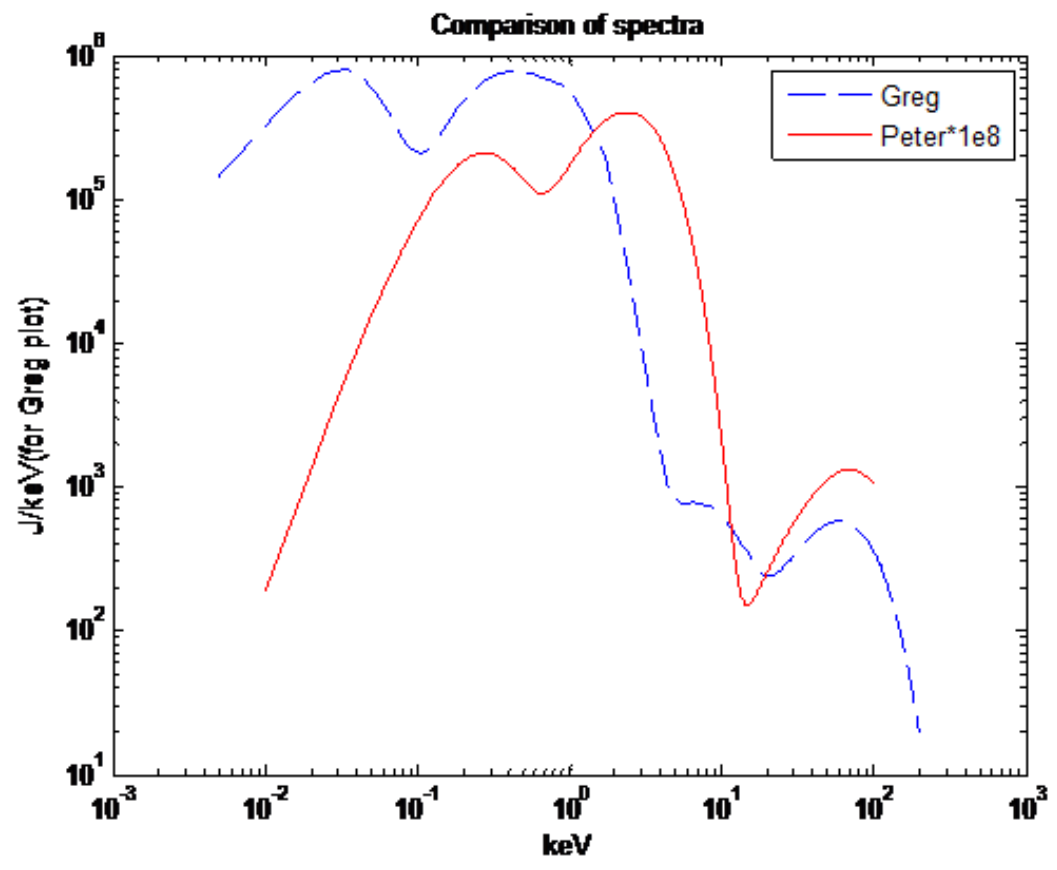

Figure 1: Comparison of the old spectra (blue dashed) with the new (red solid). In each case the spectra is multiplied to reach the appropriate energy output of $15 \mathrm{MJ}$.

Each simulation consists of 400 spatial finite difference lagrangian zones in the gas and 70 zones in the wall. Studies performed in the past and with the current FAC data (please see draft paper sent to Kevin Kramer on 9/11/2013) show an insensitivity to the engineering parameter values based on the number of gas zones selected. For the gas zones, all simulations use a $28.79 \mathrm{~cm}$ central zone, as this at $6 \mu \mathrm{g} / \mathrm{cm}^{3}$ is equal to 1 gram which is the approximate mass of an ICF target. The following 299 zones are allowed to increase in mass by a constant rate until the final 100 zones, which are held at a constant mass leading up to the wall zones. The first 30 zones in the wall are a constant thickness of $0.673 \mathrm{~nm}$. This is required by the simulation as a limit due to 
the smallest time step used during initial x-ray deposition $\left(10^{-13}\right.$ seconds $)$ and the corresponding physical values of the steel wall used according to the relationship:

$$
\Delta t=\left(\frac{\rho C_{v}}{\kappa}\right)(\Delta x)^{2}
$$

This zone thickness ensures that the transient temperature response of the surface is numerically accurate. The next 40 wall zones are allowed to increase in mass by $38.5 \%$, leading to a wall thickness of $1.1 \mathrm{~mm}$, which is approximately the correct wall thickness communicated by LLNL. The outer boundary of the wall is held at a constant temperature boundary condition which allows for heat to flow out of the system. The same zoning scheme is used for each simulation, with the only difference being the percentage of increase from zone to zone in the gas to allow for differing chamber radii.

The parameters of study for this are the fill gas, gas density and chamber radius. The two gases studied are Xenon and Argon, with opacities generated by the FAC code from LLNL. The radii studied are 4, 5, 6, 8, 10, 12 and 14 meters. First wall temperature rise and maximum overpressure at the first wall are analyzed as a function of radius using simulation results at these radii. The gas densities are $6 \mu \mathrm{g} / \mathrm{cc}$ for both Xe and Ar, $2 \mu \mathrm{g} / \mathrm{cc}$ for Xe and $1.83 \mu \mathrm{g} / \mathrm{cc}$ for Ar. The $1.83 \mu \mathrm{g} / \mathrm{cc}$ for Ar was chosen as it is the same number density as $6 \mu \mathrm{g} / \mathrm{cc}$ for Xe. The other values of interest are the arrival time of the shock wave at the first wall, the propagation dynamics of the Marshak wave, the cyclic steady state gas temperature at $62.5 \mathrm{~ms}$ and the gas temperature time dependence half way from the chamber center. The "base case" that is considered as the standard for the simulations is the $6 \mu \mathrm{g} / \mathrm{cc}$ Xe filled 6 meter chamber. The simulations of the base case reveal two distinct shock waves (see section III for more discussion on this) impinge on the wall (see Figure 2). The first arrival is at $\sim 2.6 \mathrm{~ms}$ and the second time is at $\sim 4.5 \mathrm{~ms}$. The two shock waves are a result of the target ionic debris expanding and slowing down and the attenuation of the prompt target x-rays (the inner shock), and the Marshak wave slowing down (the outer shock that starts at $\sim 350 \mathrm{~cm}$ ). The Marshak wave generated shock is a new phenomenon first seen with use of the FAC opacities. The FAC opacities are significantly smaller at low gas temperatures ahead of the Marshak wave compared to the IONMIX opacities used previously (see March 5 update). The RT plot (Figure 2) distinctly shows both of the shock waves and Figure 3 shows the slowing down and dissipation of the Marshak wave as it travels through the chamber. 


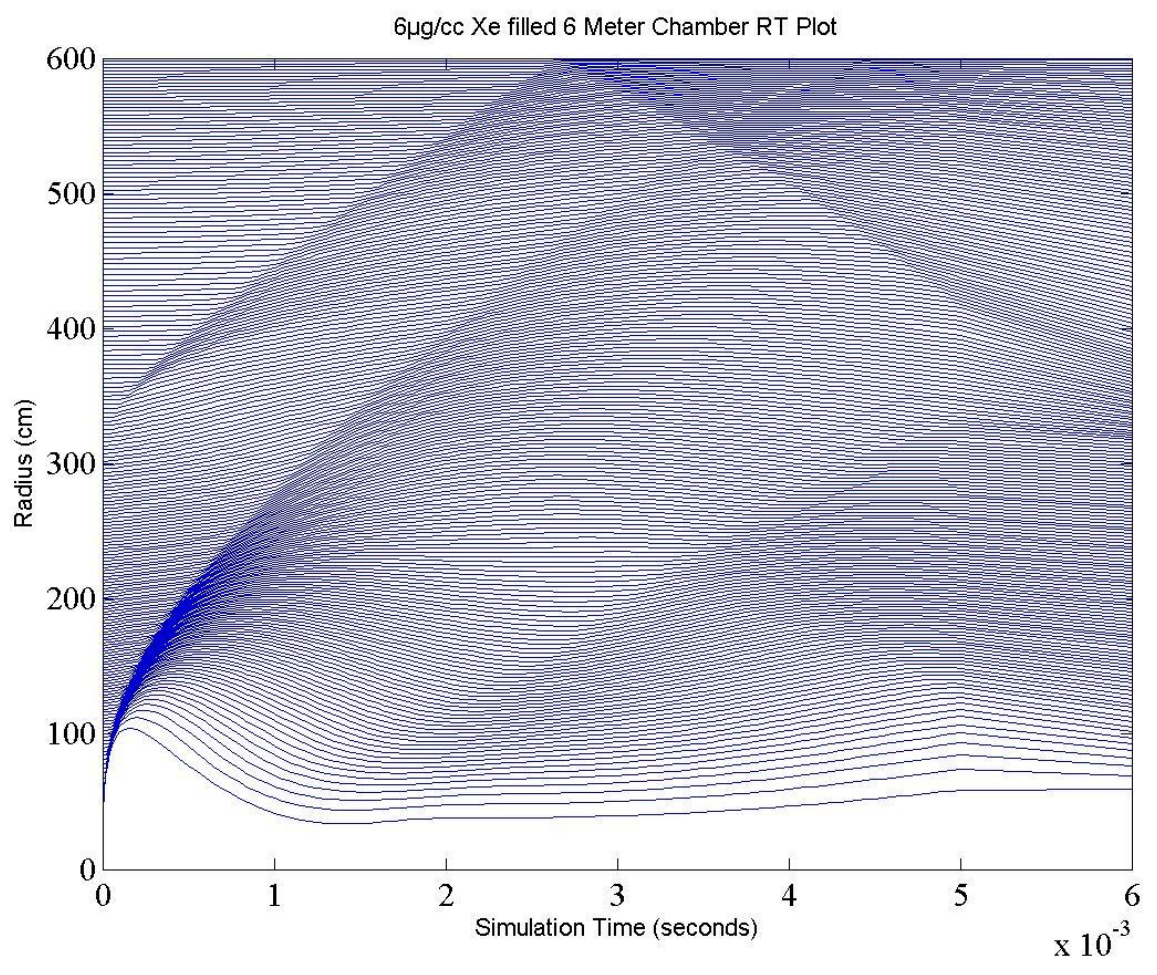

Figure 2: RT plot for the $6 \mu \mathrm{g} / \mathrm{cc}$ Xe filled 6 meter chamber. Note the two distinct shocks that form and arrive at the wall.

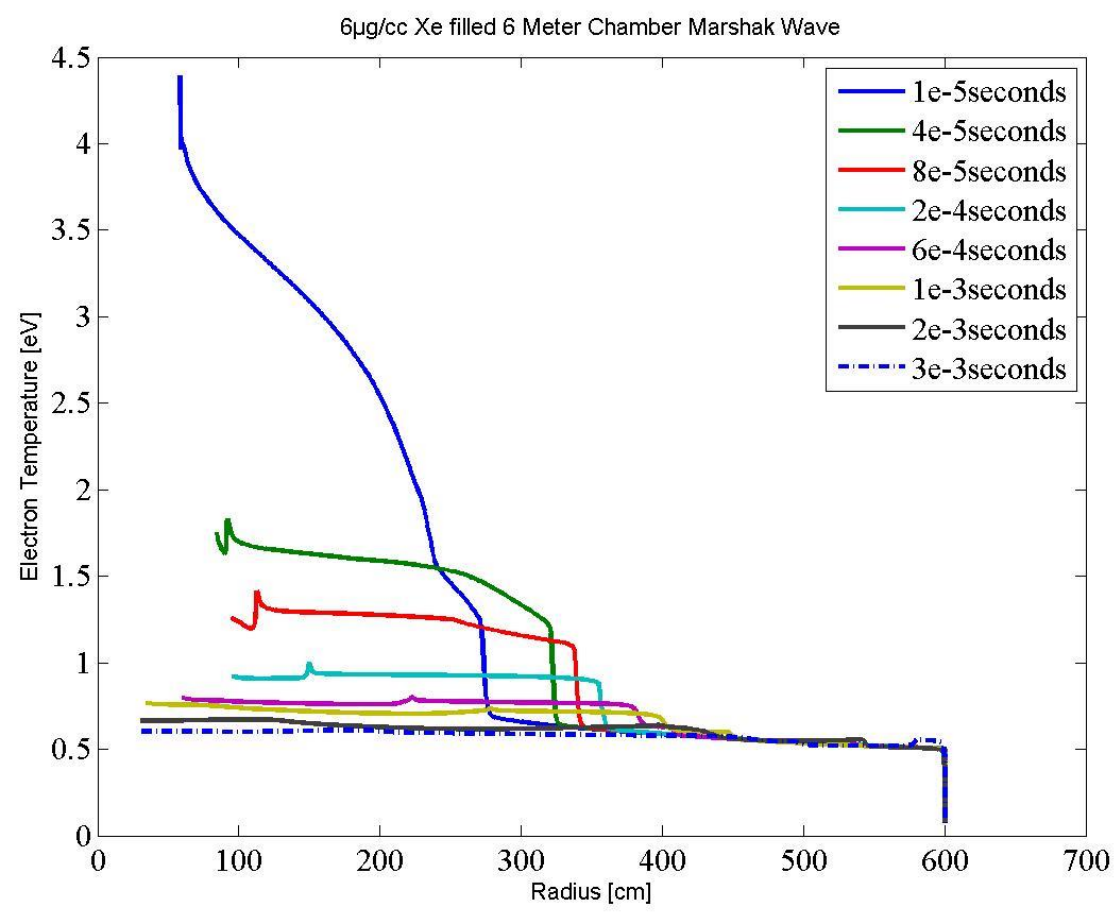

Figure 3: Marshak wave propagation in the $6 \mu \mathrm{g} / \mathrm{cc}$ Xe filled 6 meter chamber. The wave propagates through the chamber and dissipates around $350 \mathrm{~cm}$, the position where on the RT plot where the outer shock begins. 
The base case also has a few other values of interest for the chamber study which can be seen in Table 1. As seen in Figure 3, the Marshak wave slows to the sound speed at $\sim 350 \mathrm{~cm}$, which in turn launches the second shock seen in the RT plot (Figure 2). The final chamber temperature at the end of the first shot $(62.5 \mathrm{~ms})$ is $0.39 \mathrm{eV}$ according to a mass weighted average. These results show the overpressure on the wall is not a concern for the chamber design as the reactor chamber is essentially a vacuum. According to the ASM Specialty Handbook 409 Stainless steel has an upper melting point of $1530^{\circ} \mathrm{C}\left(1803^{\circ} \mathrm{K}\right)$. Previous studies have put the design limit of the wall maximum temperature at $2 / 3$ the melting temperature, which in this case is $1202{ }^{\circ} \mathrm{K}$. The base case gives a $\sim 100{ }^{\circ} \mathrm{K}$ safety factor on the first wall temperature.

The parameter sweep was done by varying the radius of the chamber, the fill gas type and density. The overall results of the sweep are shown in Table 1 and the figures in the appendix. The results in Table 2 show an interesting, although not unexpected relationship between the overpressure and first wall temperature vs radius. Each density fill is used to generate a functional fit for both of those engineering parameters vs independent variables, $1 / R^{3}$ and $1 / R^{2}$. This makes sense as the total volume of gas is what affects the overpressure, as the more gas there is, the more the outgoing shocks are dampened before they reach the first wall. The first wall temperature is most affected by the total surface area of the chamber wall as the heat flux incident on the wall is the same, and the only thing that changes is the amount of surface area that can absorb the flux. The fits presented in the table are produced as plots in Figures 4-11.

The simulations show that the smaller radius chambers have wall surface temperatures that are too high for the use of the chosen 409 stainless steel. The fill gas density and type also have a large effect on the final temperature of the first wall. The Ar filled chambers have a higher first wall temperature, with the $1.83 \mu \mathrm{g} / \mathrm{cm}^{3}$ filled chamber having the highest first surface temperature. This is understandable as the opacities for the Ar are lower than that of Xe, allowing for more of the prompt $\mathrm{X}$-rays emitted by the target to reach the first wall and induce heating. Interestingly though the Ar chambers have their secondary shocks start closer to chamber center than the Xe filled chambers. The density also affects the start of the secondary shock, with the less dense chambers having the secondary shock starting further from the center. In general the $1.83 \mu \mathrm{g} / \mathrm{cm}^{3}$ Ar filled chamber requires the largest radius to meet the material requirements of the 409 stainless steel while the denser chamber gas fills work with all but the smallest chamber radii. 
Table 1: Engineering Parameters of Interest for Parameter Sweep

\begin{tabular}{|c|c|c|c|c|}
\hline $\begin{array}{l}\text { Gas Type and } \\
\text { Density }\end{array}$ & Radius [m] & $\begin{array}{l}1^{\text {st }} \text { Wall Max } \\
\text { Temperature }{ }^{\mathrm{o}} \mathrm{K}\end{array}$ & $\begin{array}{l}\text { Overpressure } \\
{\left[\mathrm{J} / \mathrm{cm}^{3}\right]}\end{array}$ & $\begin{array}{l}\text { Shock Arrival } \\
{[\mathrm{ms}]}\end{array}$ \\
\hline \multirow[t]{7}{*}{ Xenon $6 \mu \mathrm{g} / \mathrm{cm}^{3}$} & 4 & 1365 & $1.237 \mathrm{e}-2$ & 0.75 \\
\hline & 5 & 1185 & $7.066 \mathrm{e}-3$ & 1.75 \\
\hline & 6 & 1092 & $5.373 \mathrm{e}-3$ & 2.7 \\
\hline & 8 & 1000 & $3.899 \mathrm{e}-3$ & 5 \\
\hline & 10 & 955 & $3.270 \mathrm{e}-3$ & 7.5 \\
\hline & 12 & 929 & $2.917 \mathrm{e}-3$ & 8 \\
\hline & 14 & 914 & $2.697 \mathrm{e}-3$ & 13 \\
\hline \multirow[t]{5}{*}{ Xenon $2 \mu \mathrm{g} / \mathrm{cm}^{3}$} & 6 & 1259 & $3.432 \mathrm{e}-3$ & 1 \\
\hline & 8 & 1046 & $1.833 \mathrm{e}-3$ & 3 \\
\hline & 10 & 983 & $1.417 \mathrm{e}-3$ & 5.25 \\
\hline & 12 & 948 & $1.200 \mathrm{e}-3$ & 7.75 \\
\hline & 14 & 927 & $1.063 \mathrm{e}-3$ & 12 \\
\hline \multirow[t]{7}{*}{ Argon $6 \mu \mathrm{g} / \mathrm{cm}^{3}$} & 4 & 2129 & $2.196 \mathrm{e}-2$ & 1 \\
\hline & 5 & 1507 & $1.673 \mathrm{e}-2$ & 1.5 \\
\hline & 6 & 1227 & $1.414 \mathrm{e}-2$ & 2.25 \\
\hline & 8 & 1012 & $1.148 \mathrm{e}-2$ & 3.25 \\
\hline & 10 & 941 & $1.010 \mathrm{e}-2$ & 4.75 \\
\hline & 12 & 919 & $9.375 \mathrm{e}-3$ & 6 \\
\hline & 14 & 906 & $8.786 e-3$ & 7.5 \\
\hline \multirow[t]{5}{*}{ Argon $1.83 \mu \mathrm{g} / \mathrm{cm}^{3}$} & 6 & 1907 & $5.036 \mathrm{e}-3$ & 1.5 \\
\hline & 8 & 1349 & $3.744 \mathrm{e}-3$ & 3 \\
\hline & 10 & 1127 & $3.198 \mathrm{e}-3$ & 4.5 \\
\hline & 12 & 1025 & $2.877 \mathrm{e}-3$ & 5.5 \\
\hline & 14 & 972 & $2.681 \mathrm{e}-3$ & 7 \\
\hline
\end{tabular}

Table 2: Fits for Temperature in the Wall and Overpressure Incident on Wall

\begin{tabular}{|l|l|l|}
\hline Gas Type and Density & Fit & $\mathrm{R}^{2}$ value \\
\hline Xenon $6 \mu \mathrm{g} / \mathrm{cm}^{3}$ & Temperature: $\mathrm{y}=\frac{7.811 e+7}{R^{2}}+875.45$ & 0.9999 \\
\cline { 2 - 2 } & Overpressure: $\mathrm{y}=\frac{6.175 e+5}{R^{3}}+0.0025$ & \\
\hline Xenon $2 \mu \mathrm{g} / \mathrm{cm}^{3}$ & Temperature: $\mathrm{y}=\frac{1.463 e+8}{R^{2}}+841.091$ & 0.988 \\
\cline { 2 - 2 } & Overpressure: $\mathrm{y}=\frac{5.5243 e+5}{R^{3}}+8.547 e-4$ & \\
\hline Argon $6 \mu \mathrm{g} / \mathrm{cm}^{3}$ & Temperature: $\mathrm{y}=\frac{2.112 e+8}{R^{3}}+727$ & 0.9773 \\
\cline { 2 - 2 } & Overpressure: $\mathrm{y}=\frac{8.462 e+5}{R^{2}}+0.0093$ & \\
\hline Argon $1.83 \mu \mathrm{g} / \mathrm{cm}^{3}$ & Temperature: $\mathrm{y}=\frac{4.166 e+8}{R^{3}}+730.68$ & 0.9954 \\
\cline { 2 - 2 } & Overpressure: $\mathrm{y}=\frac{5.93 e+5}{R^{2}}+0.0026$ & \\
\hline
\end{tabular}




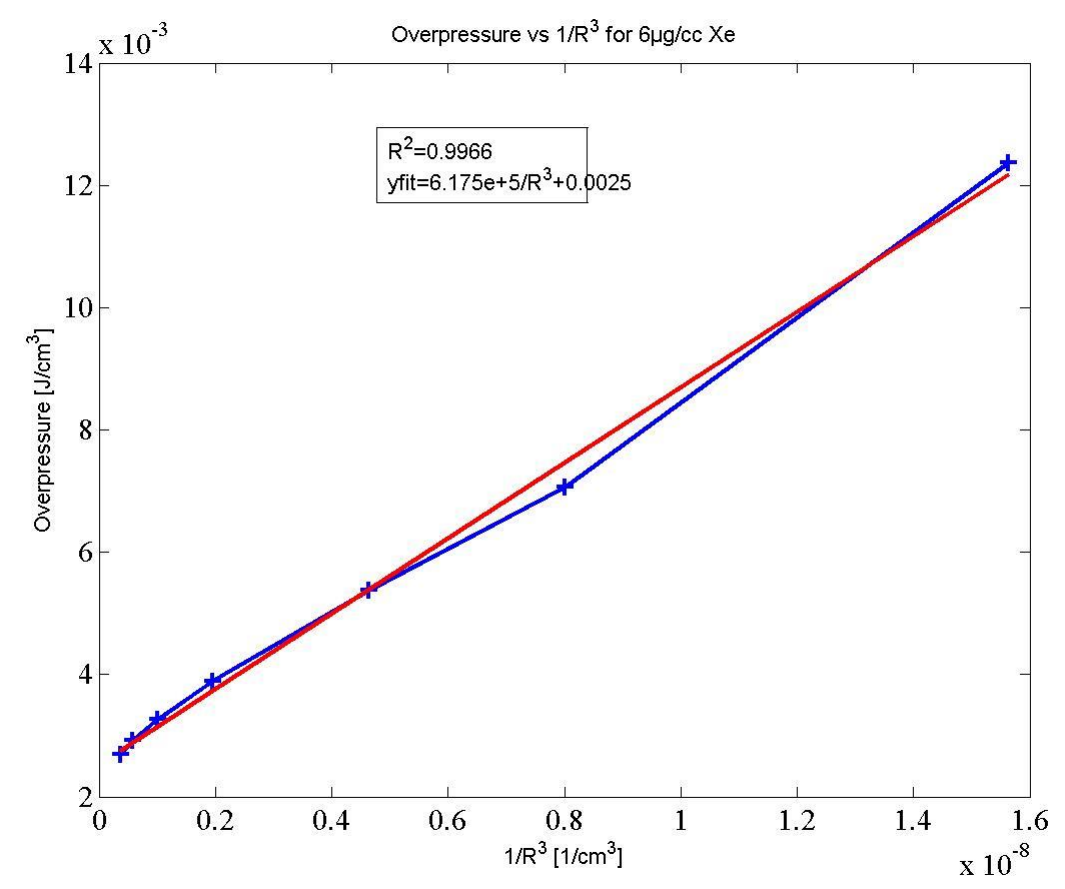

Figure 4: Fit for the $6 \mu \mathrm{g} / \mathrm{cc} \mathrm{Xe}$ chamber overpressure vs. radius

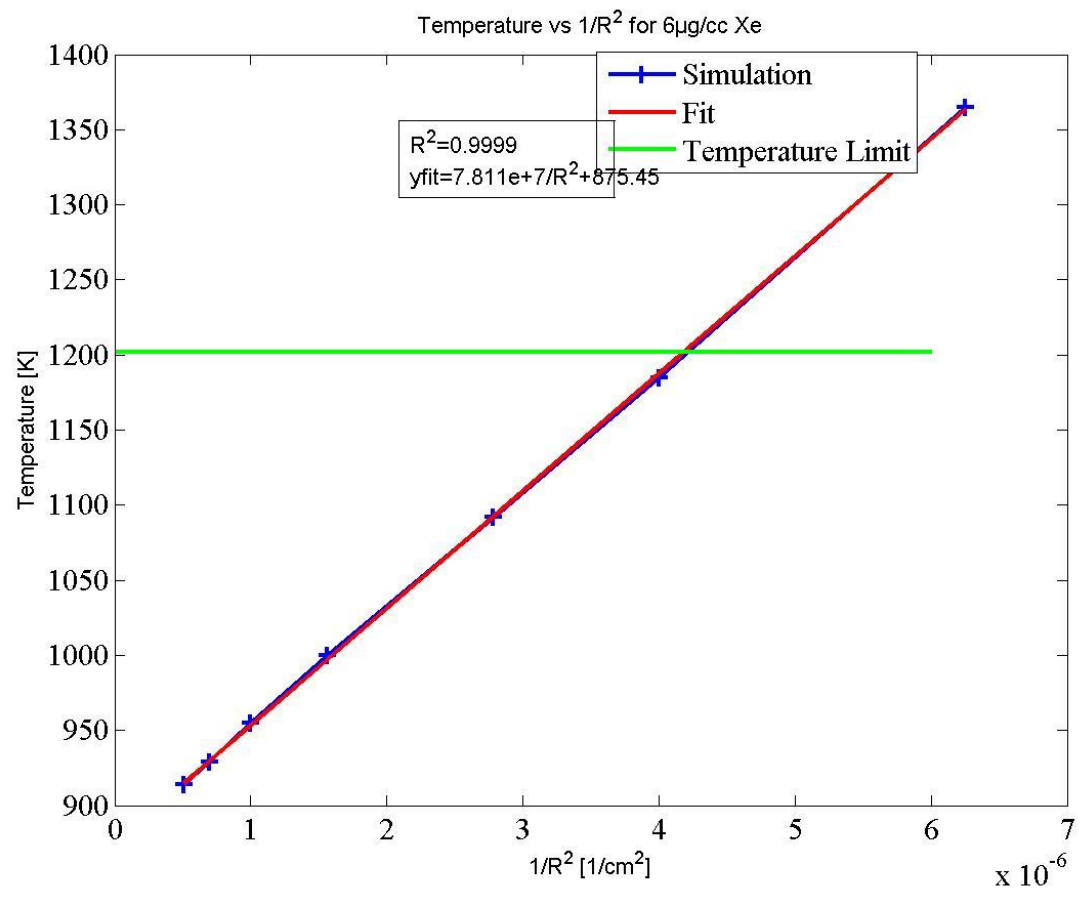

Figure 5: Fit for the $6 \mu \mathrm{g} / \mathrm{cc}$ Xe chamber first wall temperature vs. radius. The 4 meter case has a temperature above the safety limit. 


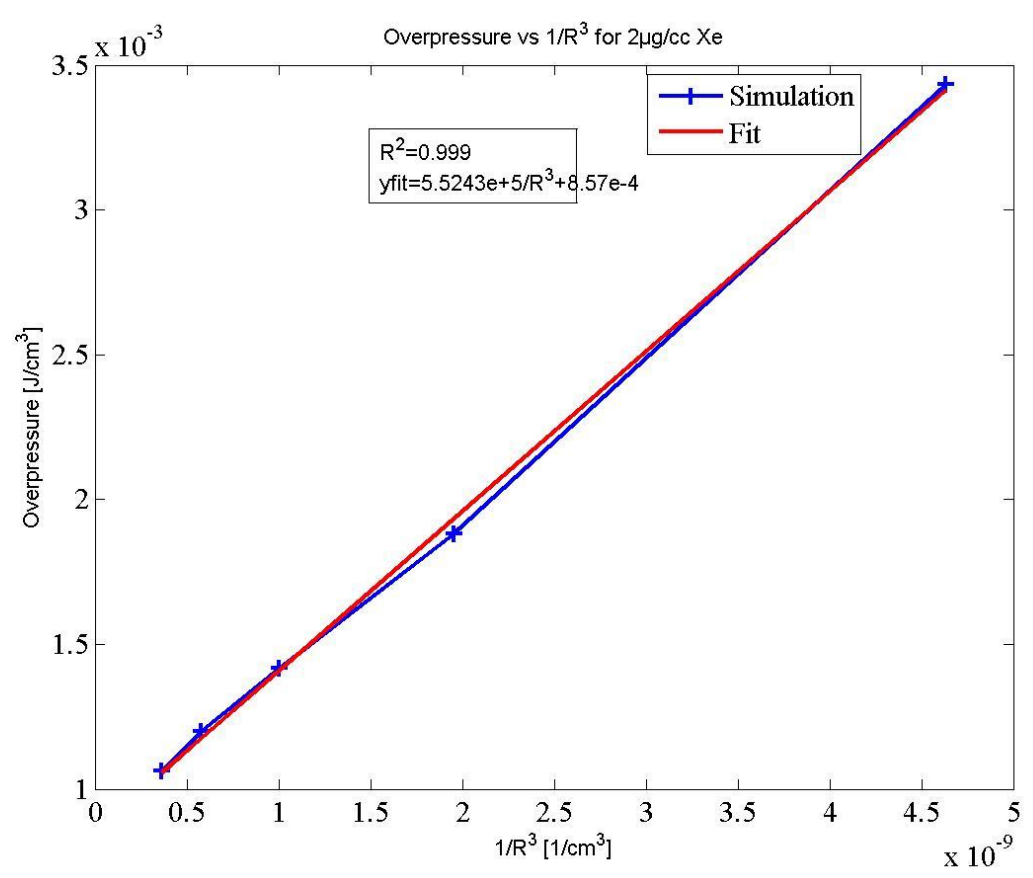

Figure 6: Fit for the $2 \mu \mathrm{g} / \mathrm{cc}$ Xe chamber overpressure vs. radius

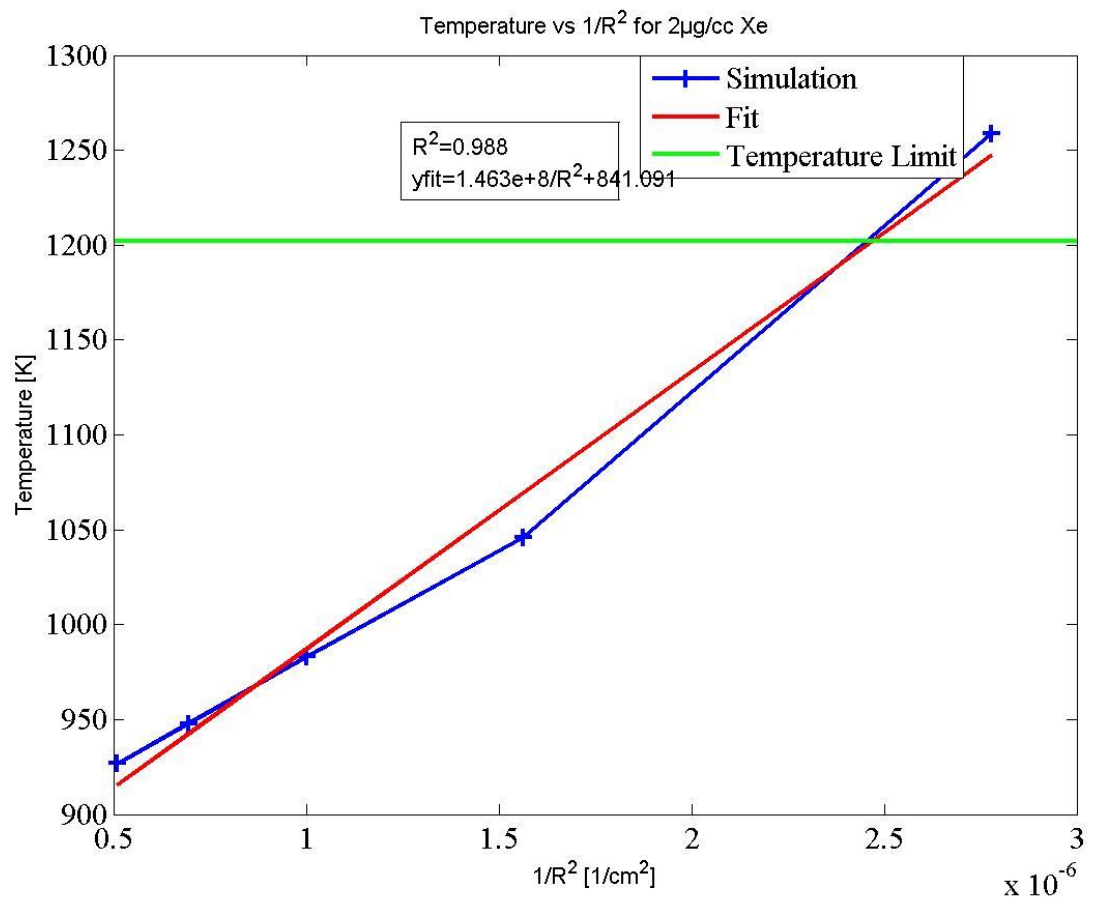

Figure 7: Fit for the $2 \mu \mathrm{g} / \mathrm{cc}$ Xe chamber first wall temperature vs.radius. The 6 meter case has a temperature above the safety limit. 


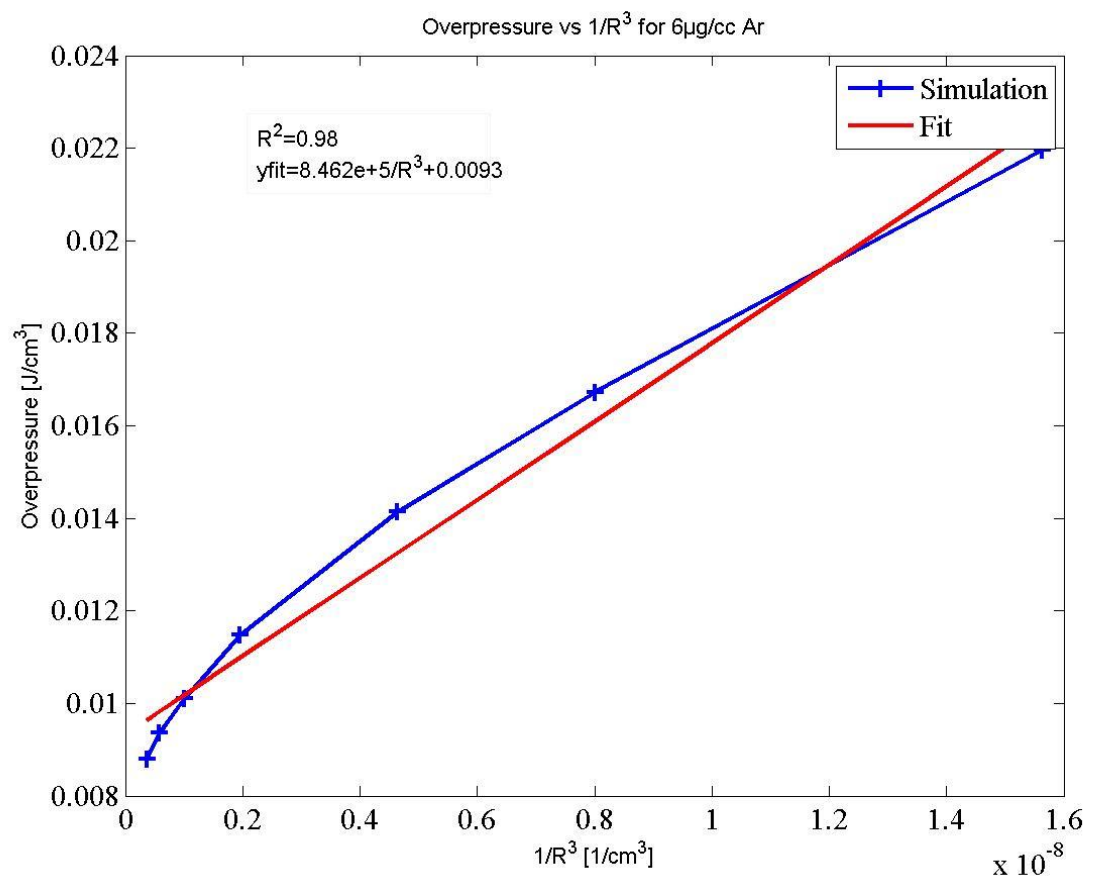

Figure 8: Fit for the $6 \mu \mathrm{g} / \mathrm{cc}$ Ar chamber simulations with respect to overpressure

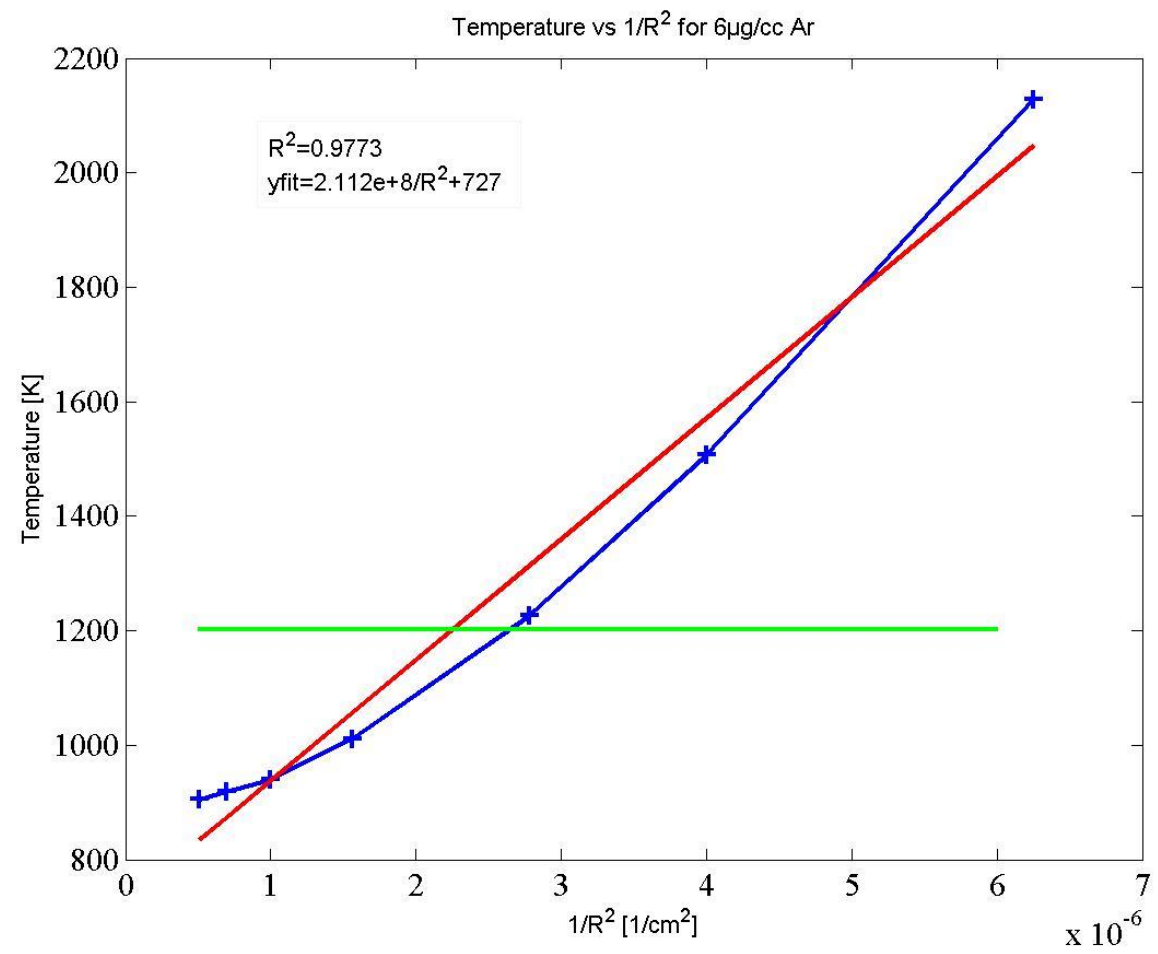

Figure 9: Fit for the $6 \mu \mathrm{g} / \mathrm{cc}$ Ar chamber first wall temperature vs. radius. The 4, 5 and 6 meter cases have a temperature above the safety limit. 


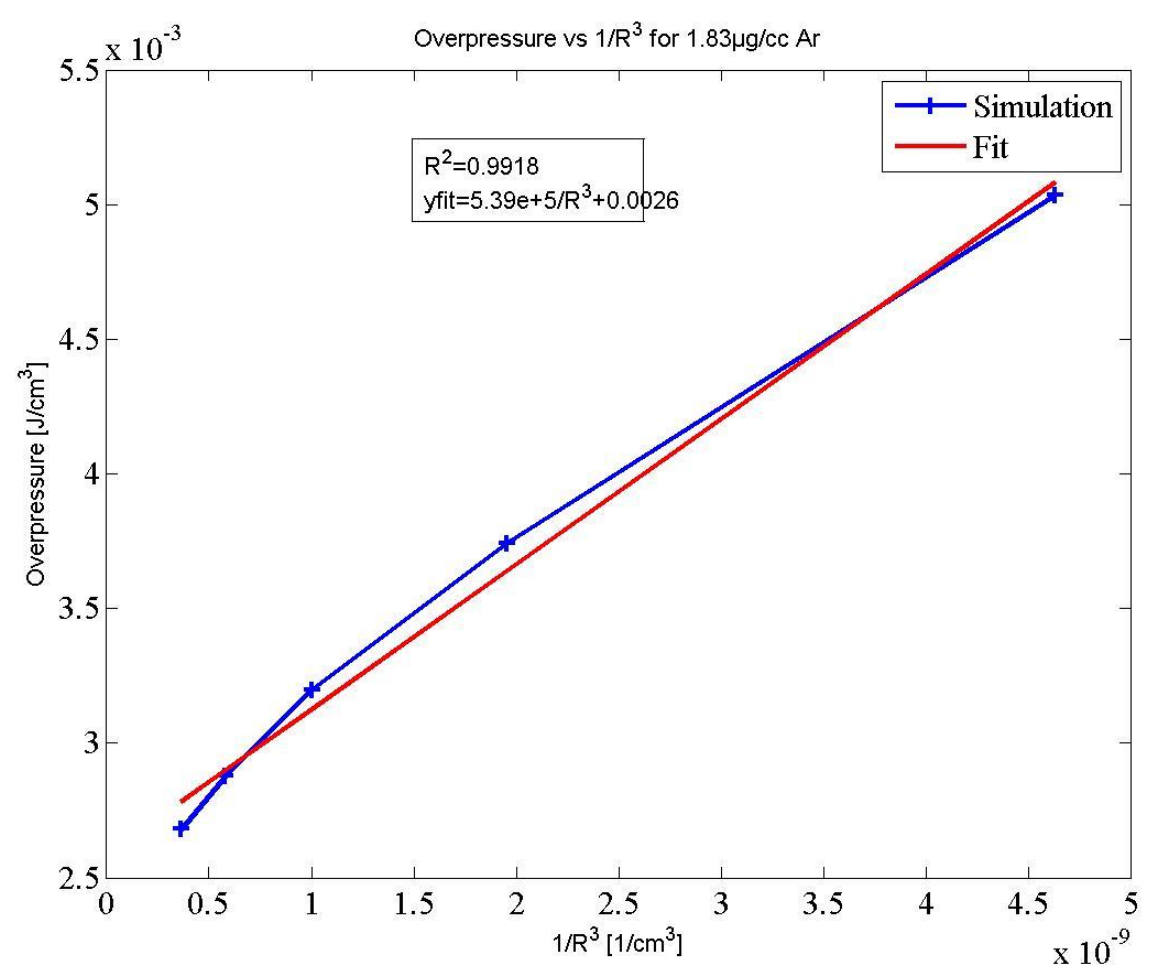

Figure 10: Fit for the $1.83 \mu \mathrm{g} / \mathrm{cc}$ Ar chamber overpressure vs. radius

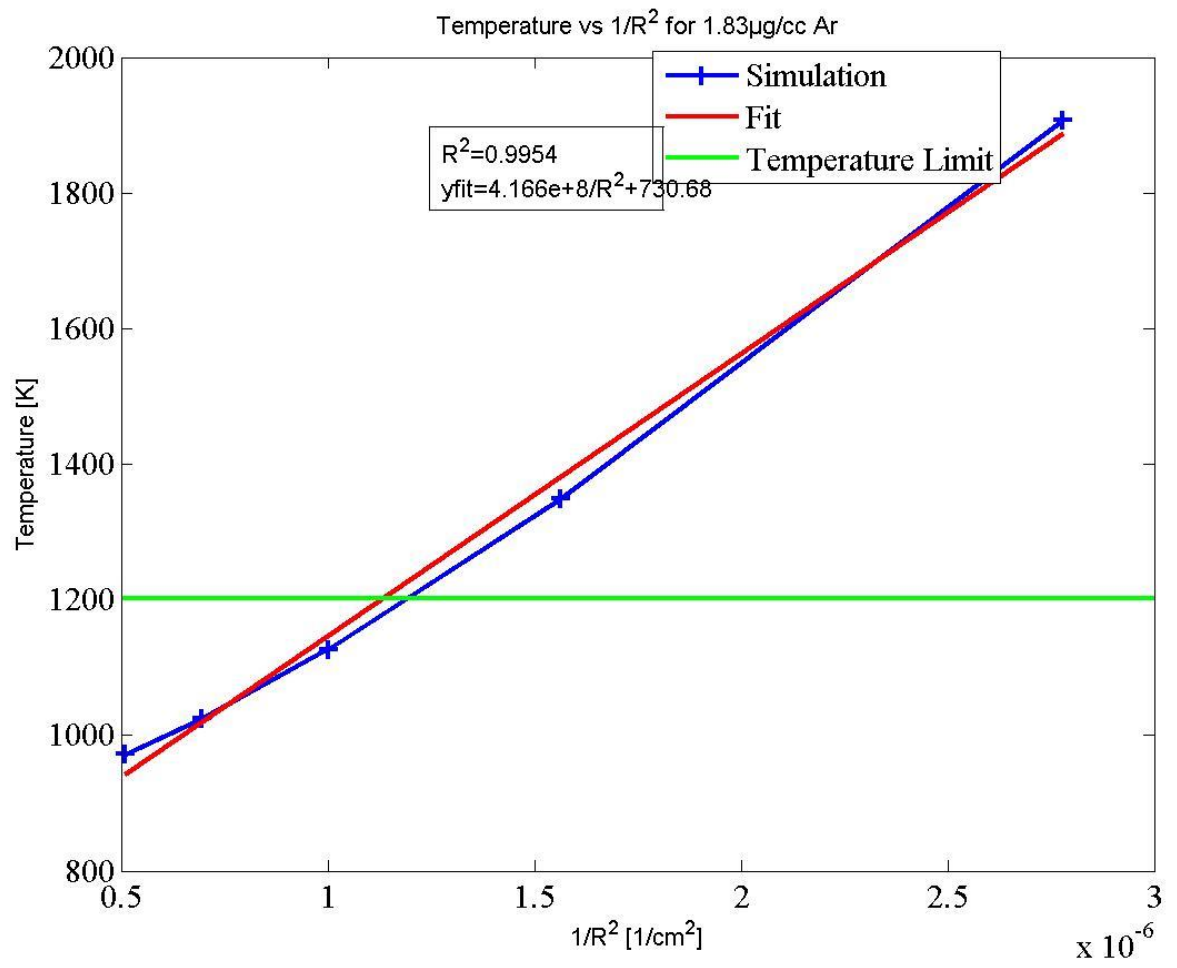

Figure 11: Fit for the $1.83 \mu \mathrm{g} / \mathrm{cc}$ Ar chamber first wall temperature vs. radius. The 6 and 8 meter cases have a temperature above the safety limit. 


\section{BUCKY - VTF Handshake Procedure}

Working with LLNL scientists and UIUC scientists to perform fully 3-D simulations required using the 1-D BUCKY radiation hydrodynamics simulations as a starting point for the 3-D VTF pure hydrodynamics simulations. Transferring this intermediate BUCKY output to the VTF code is called the handshake procedure. The UIUC VTF code uses a source input derived from the 1$\mathrm{D}$ simulations. As the VTF code is purely a hydrodynamics code with no radiation there is no need to send separate temperatures for the radiation or electrons nor is there a reason to send any information about the x-ray spectra excepting the total amount of energy deposited by the x-rays and ions (15 MJ each for the BUCKY simulations). The information passed off in the handshake includes the zone widths, the zone densities, the zone velocities and zone ion temperatures.

These values are given for the entire chamber and are tied to the position of the outermost shock. The values are recorded when the shock is at 3 different positions; $200 \mathrm{~cm}$ from chamber center, $400 \mathrm{~cm}$ from chamber center and the arrival at the first wall. This information is transmitted to UIUC in a table derived directly from the BUCKY output with the only change being converting the temperature from electron volts to kelvin. 


\section{Double Shock Phenomenon}

Four additional BUCKY simulations are run to ascertain the origin of the double shock, first seen when using the FAC opacities. Figure 12 shows an RT plot for the nominal base case of target xray and ion debris sources and FAC opacities. To understand this sequence of results the BUCKY simulation model is reviewed. LLNL target implosion and burn simulations produce $\mathrm{x}$ ray and ion output spectra. These output spectra are introduced into BUCKY as a point $\mathrm{x}$-ray source and point ion source at the origin of a 1-D spherical simulation. These source terms are energy dependent and time dependent. The ion source is species dependent. Therefore BUCKY does not include the actual target implosion or explosion radiation hydrodynamics. The result of the target explosion is modeled as these point source terms in a one dimensional spherical radiation hydrodynamics simulation of Xe response and first wall response to the point sources. In Figure 13 are shown the results of a BUCKY simulation where the prompt target $\mathrm{x}$-ray source term is "turned on" and the ion source term is "turned off" and the radiation diffusion in the Xe that uses the FAC opacities is turned off. There is no second shock and the primary shock originating at the origin is quite strong because there is no radiation dissipation. This shock is generated by energy deposition in the Xe by attenuation of the prompt target $\mathrm{X}$-rays from the point source. In Figure 14 are shown the results of a BUCKY simulation where the prompt target $\mathrm{x}$-ray source term is turned on and ion source term is turned off and the radiation diffusion in the $\mathrm{Xe}$ that uses the FAC opacities is turned on. There is a second shock and the primary shock originating at the origin is much weaker because the multi-group radiation diffusion dissipates the energy. This phenomenon is generated by only the prompt target x-ray source term. Comparing Figures 13 and 14 with Figure 12 we see that the source of the second shock is the Marshak wave that is intrinsic to the radiation diffusion model. Finally in Figure 15 we show a BUCKY simulation where the UW's IONMIX2 opacities are reduced by a factor of $10^{-4}$. Once again, we see the second shock. Noting that IONMIX2 predicts opacities at low plasma temperatures ahead of the Marshak wave that are $10^{4}$ larger than FAC opacities, we conclude that it is the more accurate FAC opacities at low plasma temperatures that lead to the second shock. This must be further explored to determine the exact dynamics of the second shock. However, the evidence presented above serves as a good indication that the second shock phenomenon is real and can be reproduced with scaled IONMIX2 opacities.

\section{FAC opacity scaling}

While FAC may be the best available opacity model for this research, there remains significant uncertainty in the FAC opacities. Therefore an opacity scaling parameter study is done to determine if uncertainty in the opacities has significant effects on the engineering quantities of the LIFE reactor chamber. FAC opacities are scaled by factors of $0.1,0.3,3.0$ and 10.0 and compared to the nominal case. Full physics target explosion simulations are run to determine the outcomes of this parameter study. The results are tabulated in Table 3. Figures 16-30 show the individual results and are labeled accordingly and the engineering values of interest and their changes from the base case are shown in Table 3. 
Table 3 Engineering results of opacity scaling parameter study

\begin{tabular}{|l|l|l|l|}
\hline Opacity multiplier & $\begin{array}{l}\text { Wall overpressure } \\
\left(\mathrm{J} / \mathrm{cm}^{3}\right)\end{array}$ & $\begin{array}{l}\text { Cyclic temperature } \\
(\mathrm{eV})\end{array}$ & $\begin{array}{l}\text { Change in Wall } \Delta \mathrm{T} \\
\text { from nominal }(\mathrm{K})\end{array}$ \\
\hline 0.1 & $9.14 \mathrm{e}-3$ & 0.5 & -101 \\
\hline 0.3 & $6.58 \mathrm{e}-3$ & 0.44 & -2 \\
\hline 1.0 & $5.12 \mathrm{e}-3$ & 0.40 & 0 \\
\hline 3.0 & $3.92 \mathrm{e}-3$ & 0.38 & 0 \\
\hline 10.0 & $3.44 \mathrm{e}-3$ & 0.36 & -37 \\
\hline
\end{tabular}

The maximum wall overpressure from the reflected shock decreases monotonically with increasing opacity. This is likely due to the increased radiation loss to the wall. The cyclic steady state temperature of the Xe decreases monotonically with increasing opacity. This again is likely due to increased radiation energy loss to the wall, thus cooling the Xe gas. However, the peak wall surface temperature does not vary monotonically. We don't yet have an explanation for this. The wall surface temperature is lower for both higher and lower opacities when compared to the nominal case. However the amount of variation is not large considering the large scaling of opacities.

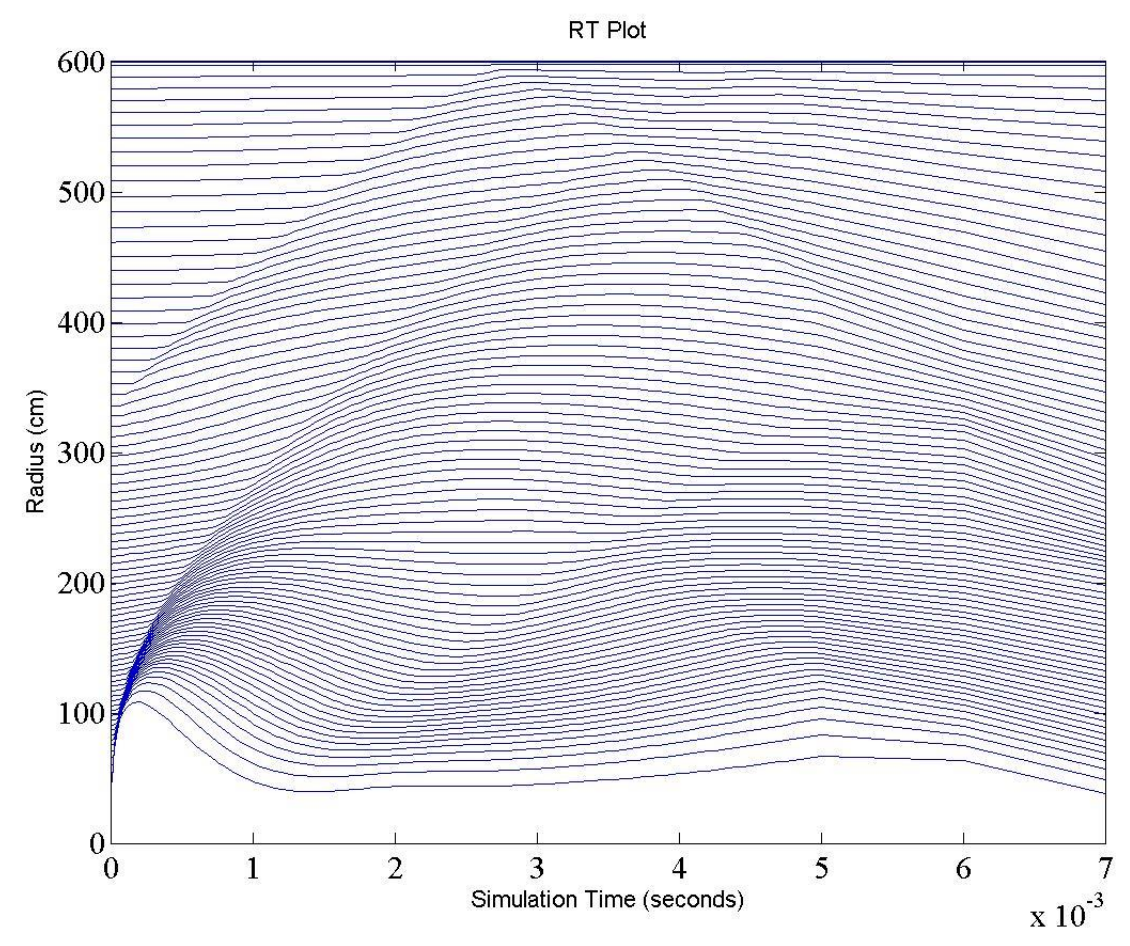

Figure 12 Nominal 132 MJ target yield, Xe response RT plot 


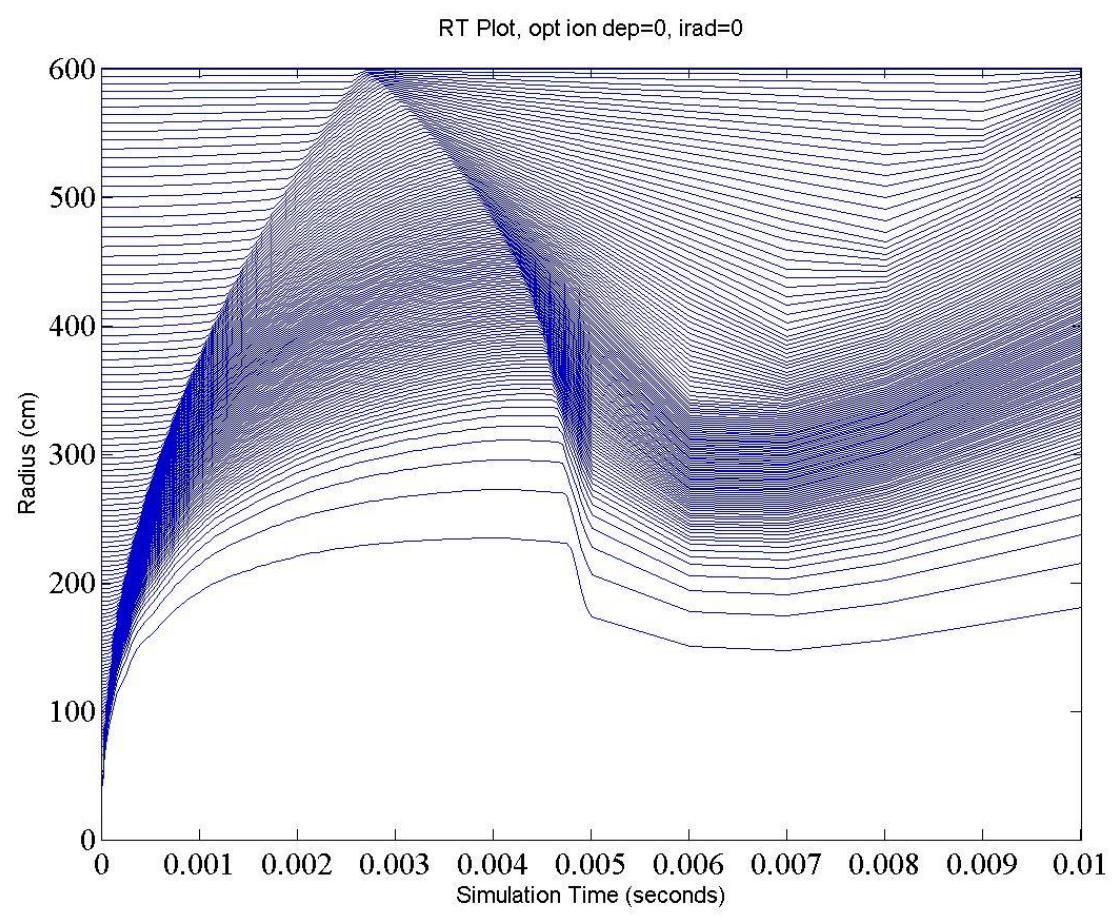

Figure $13 \mathrm{X}$-ray source, no ion source, no radiation diffusion

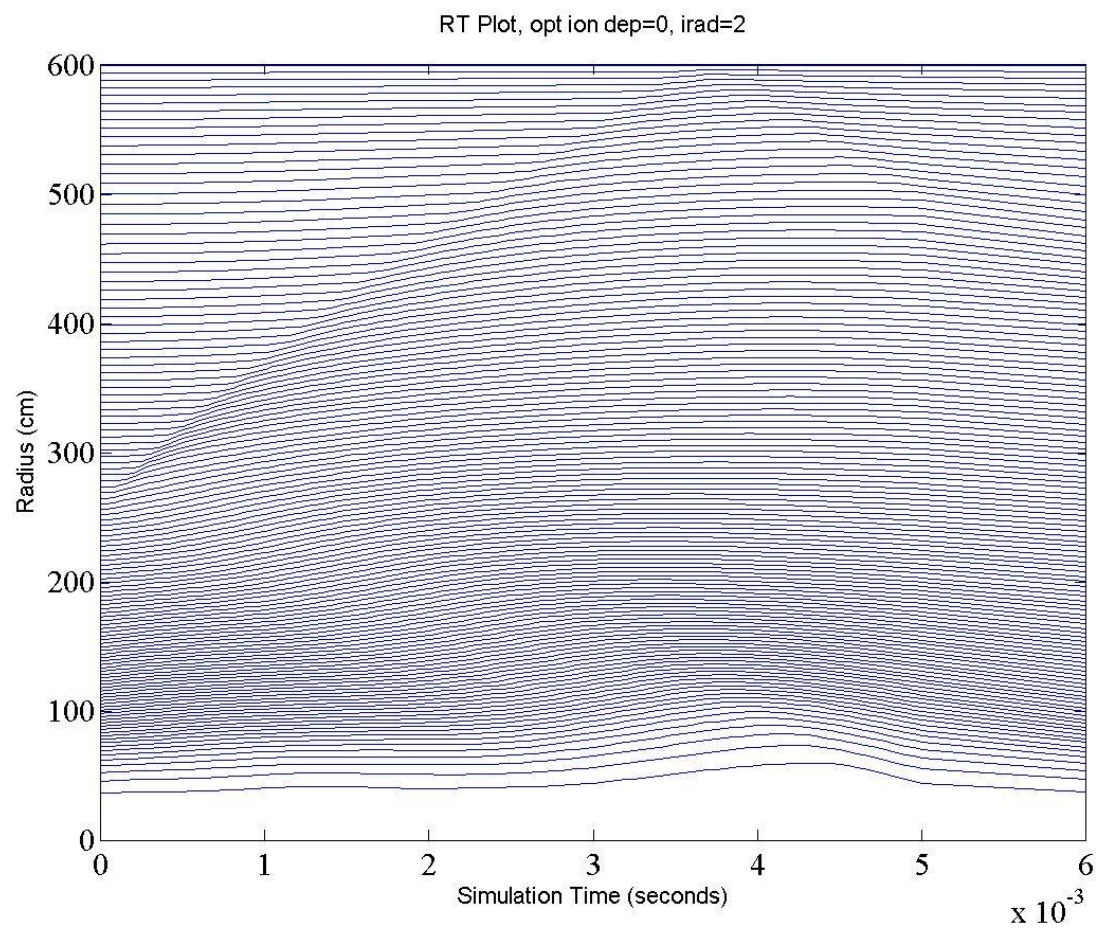

Figure $14 \mathrm{X}$-ray source, no ion source, with radiation diffusion 


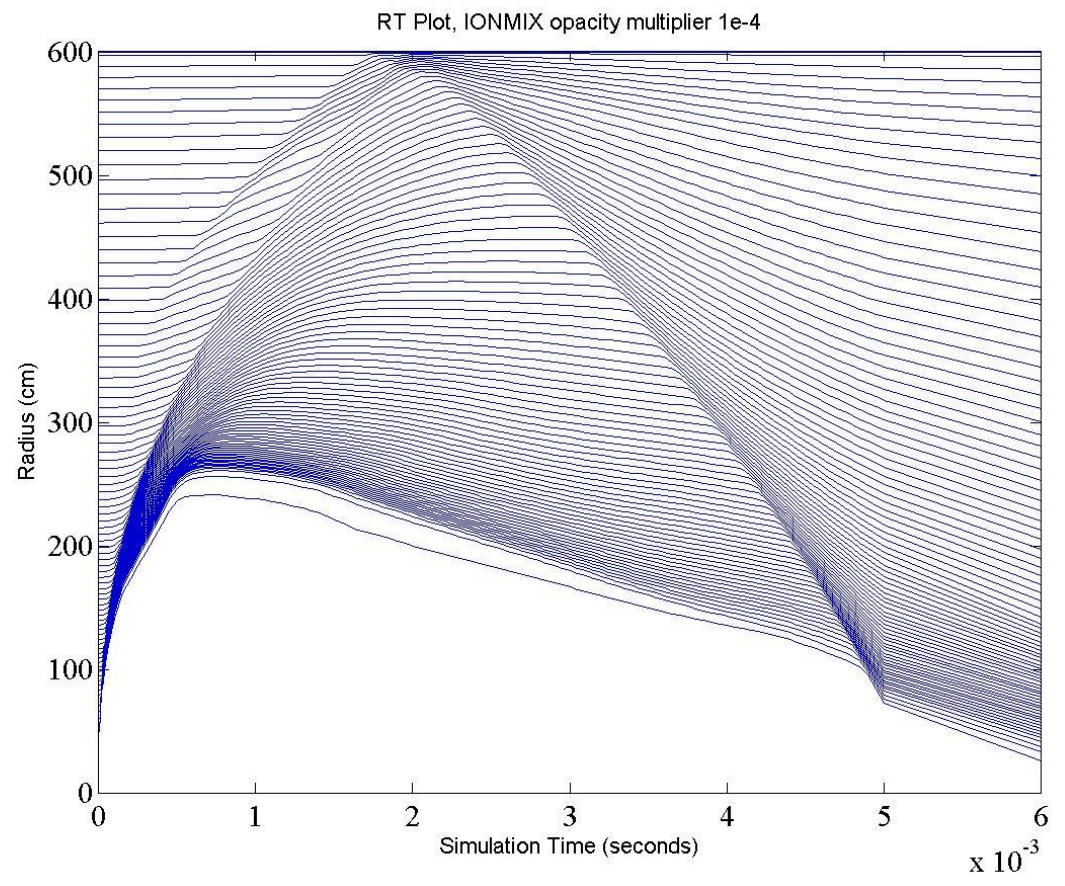

Figure 15 X-ray source, no ion source, with radiation diffusion, $10^{-4}$ IONMIX2 opacity

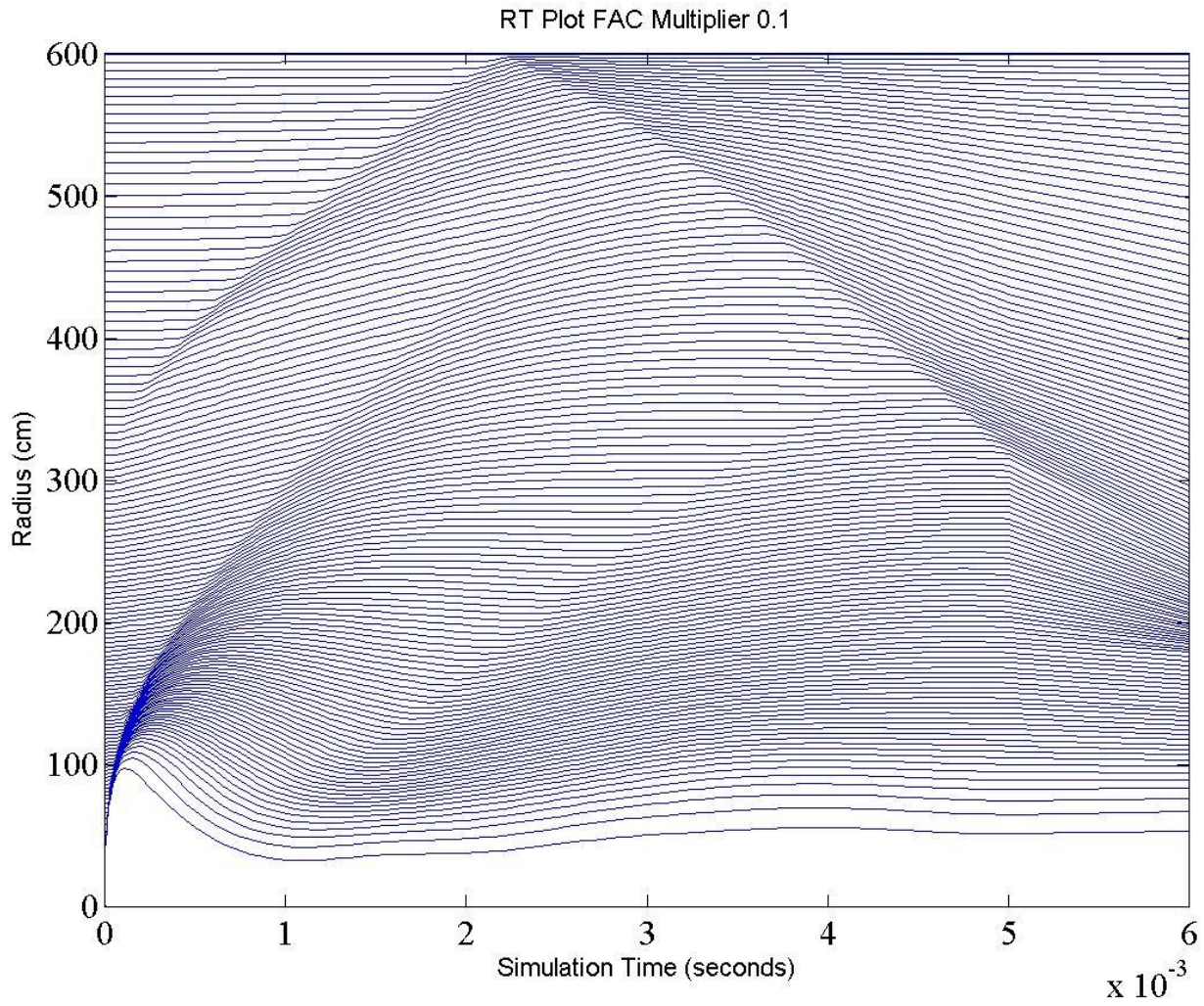

Figure 16 RT plot for FAC 0.1 x opacity 


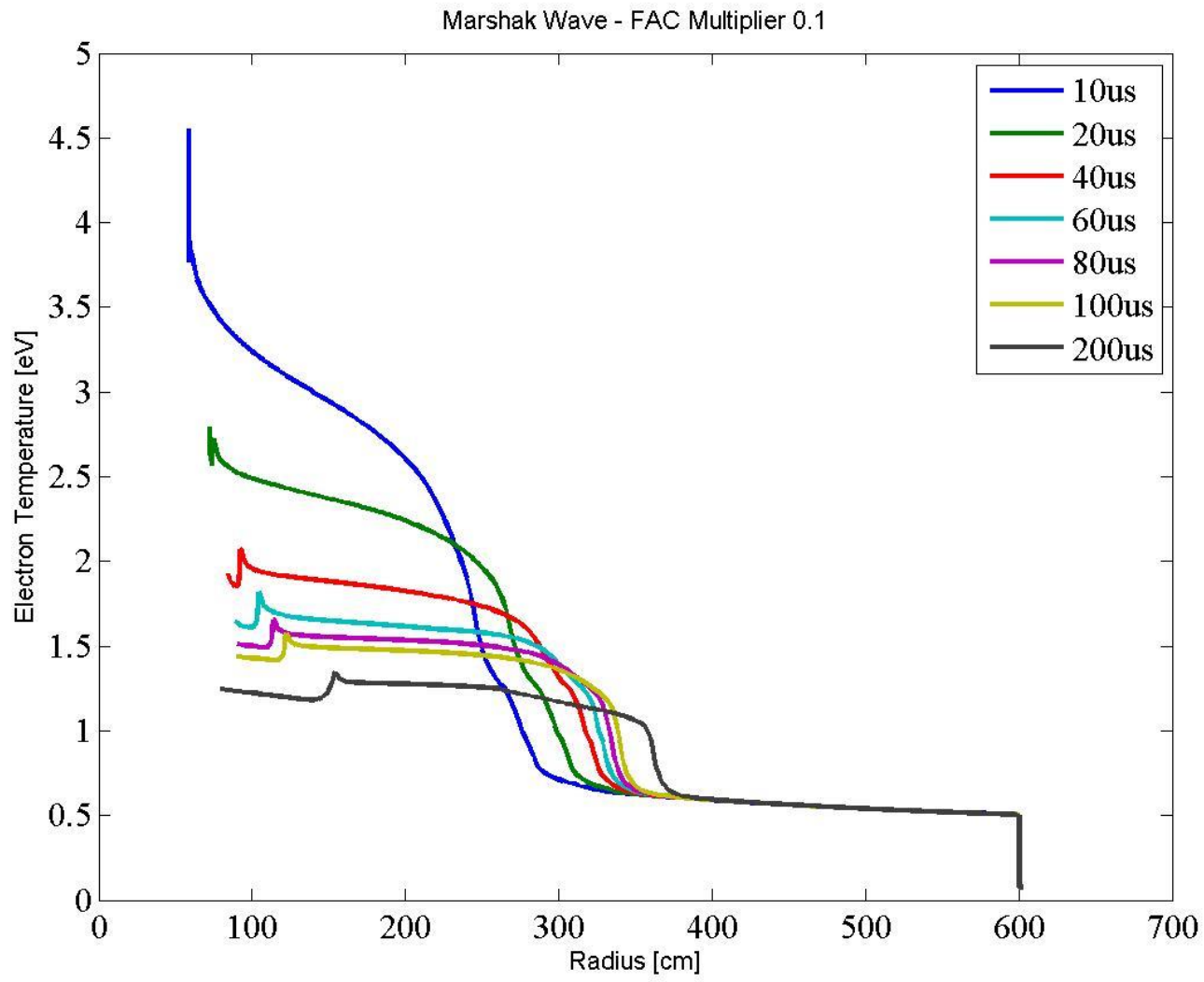

Figure 17 Marshak wave for FAC 0.1 x opacity

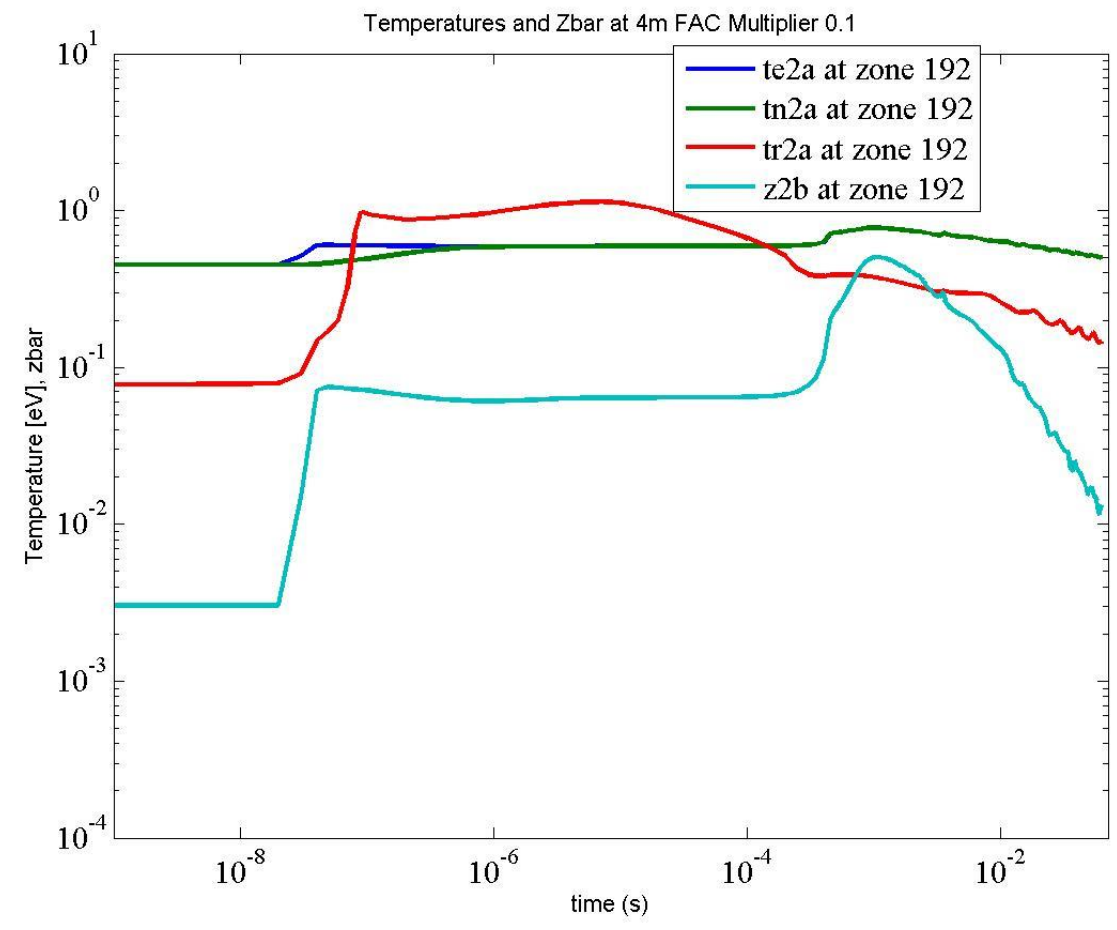

Figure 18 Temperatures and Zbar at $\mathrm{R}=400 \mathrm{~cm}$ vs time for FAC $0.1 \mathrm{x}$ opacity 


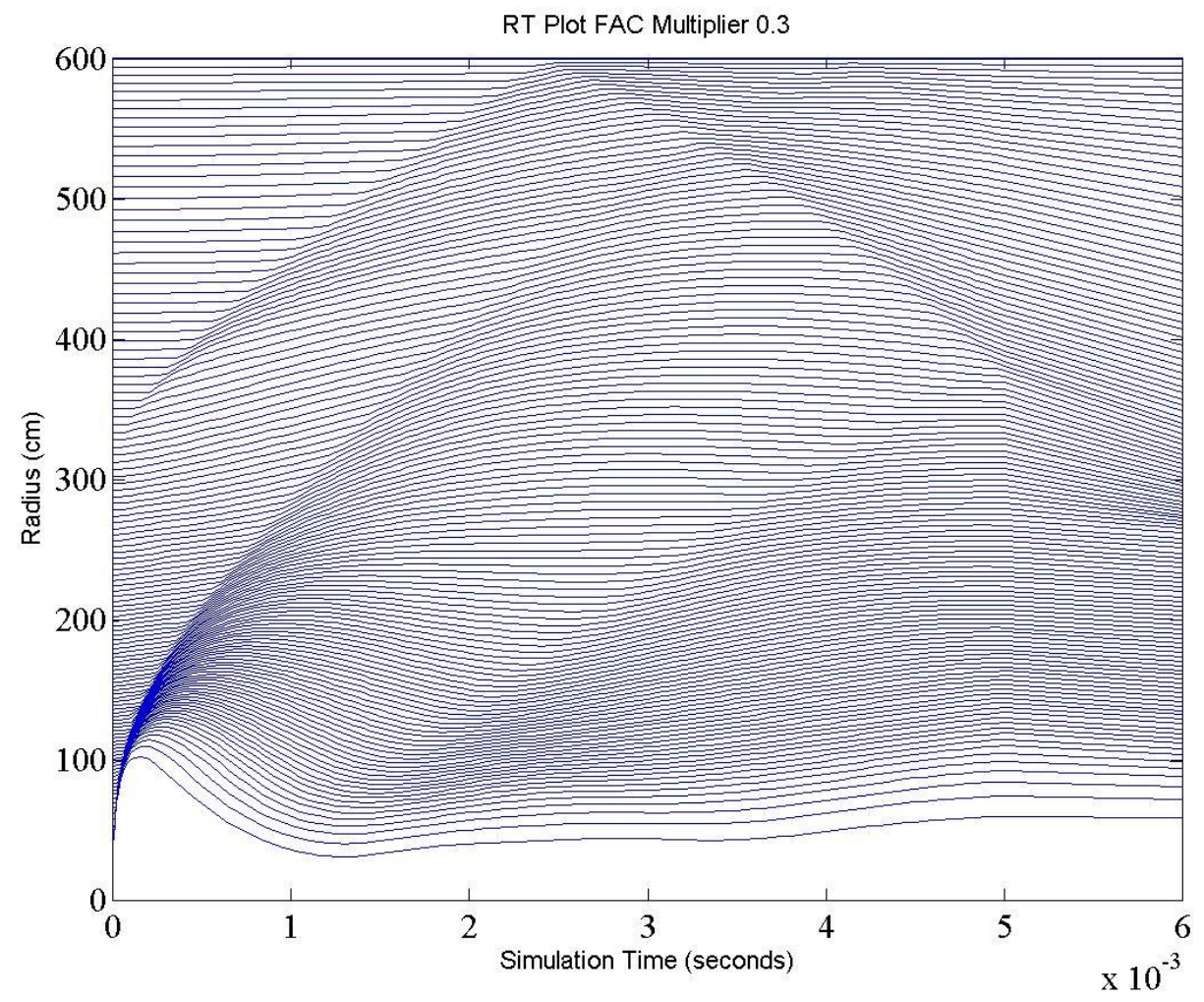

Figure 19 RT plot for FAC 0.3 x opacity

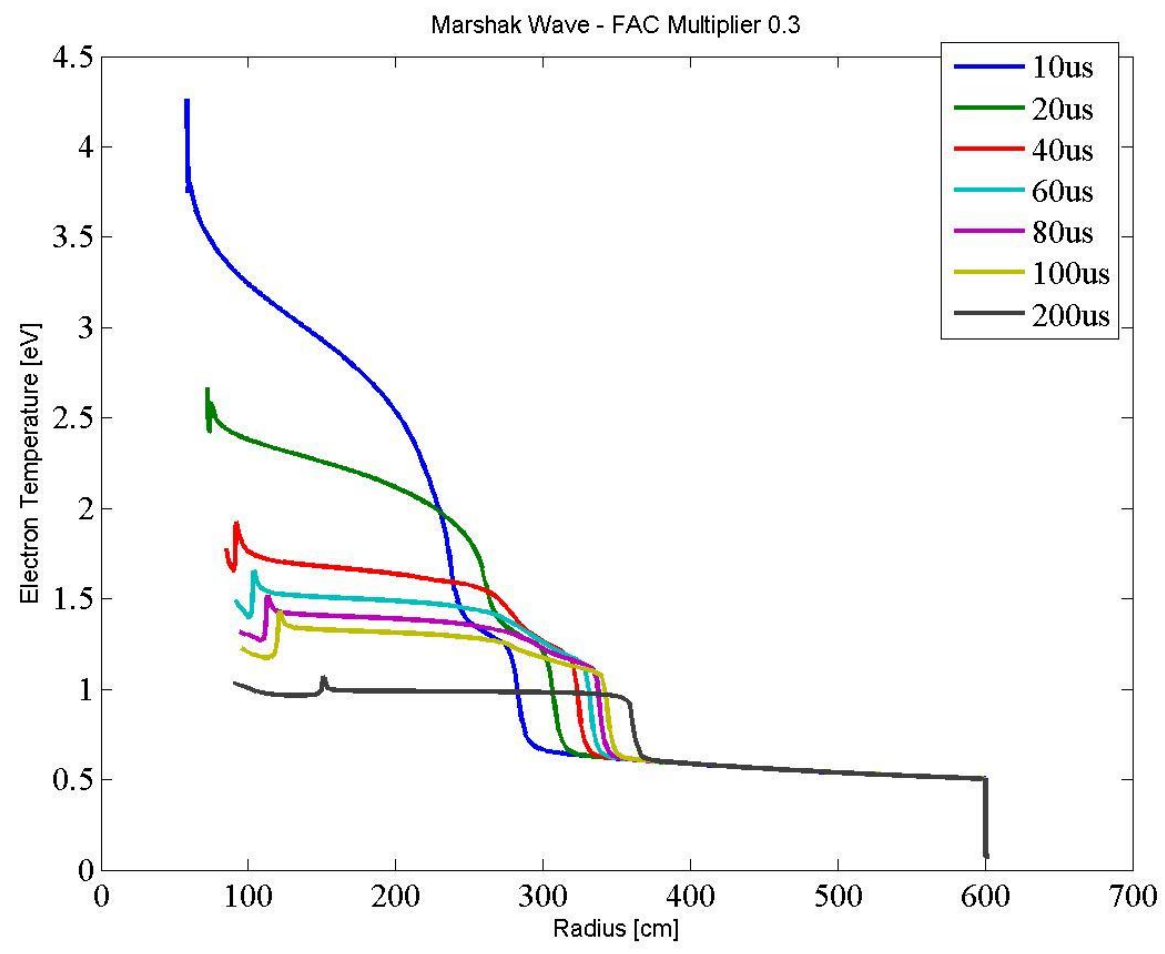

Figure 20 Marshak wave for FAC 0.3 x opacity 


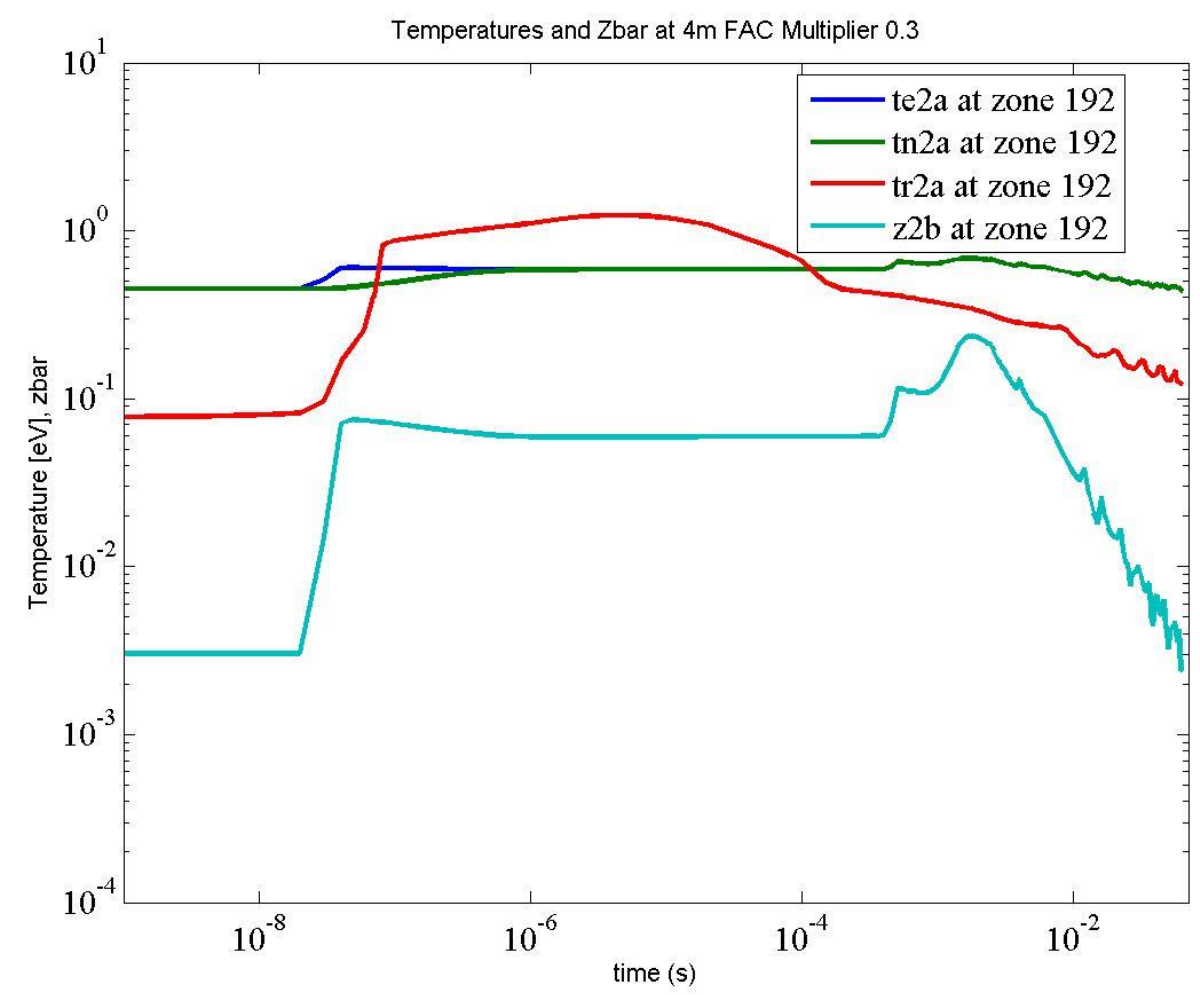

Figure 21 Temperatures and Zbar at $\mathrm{R}=400 \mathrm{~cm}$ vs time for FAC $0.3 \mathrm{x}$ opacity

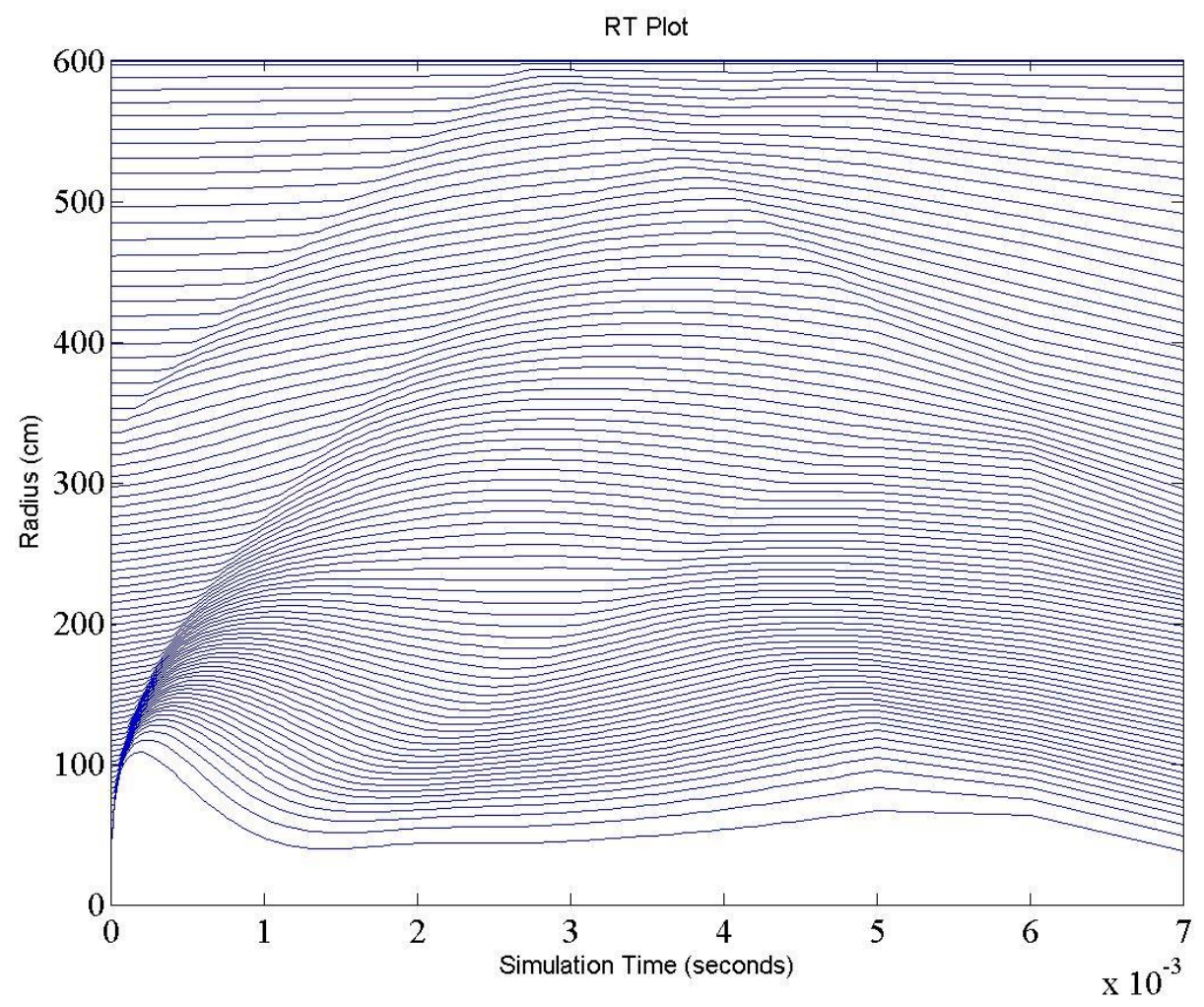

Figure $22 \mathrm{RT}$ plot for FAC $1.0 \mathrm{x}$ opacity 


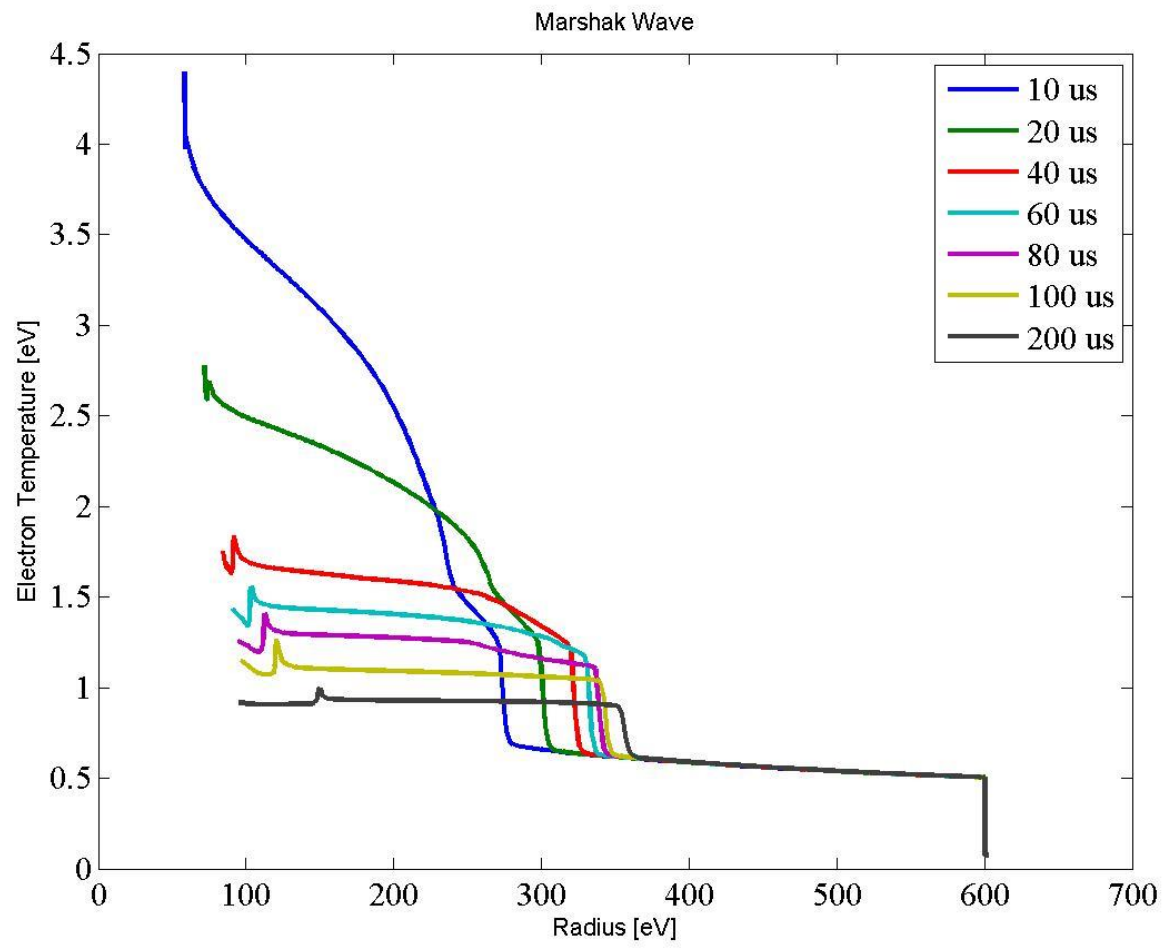

Figure 23 Marshak wave for FAC 1.0 x opacity

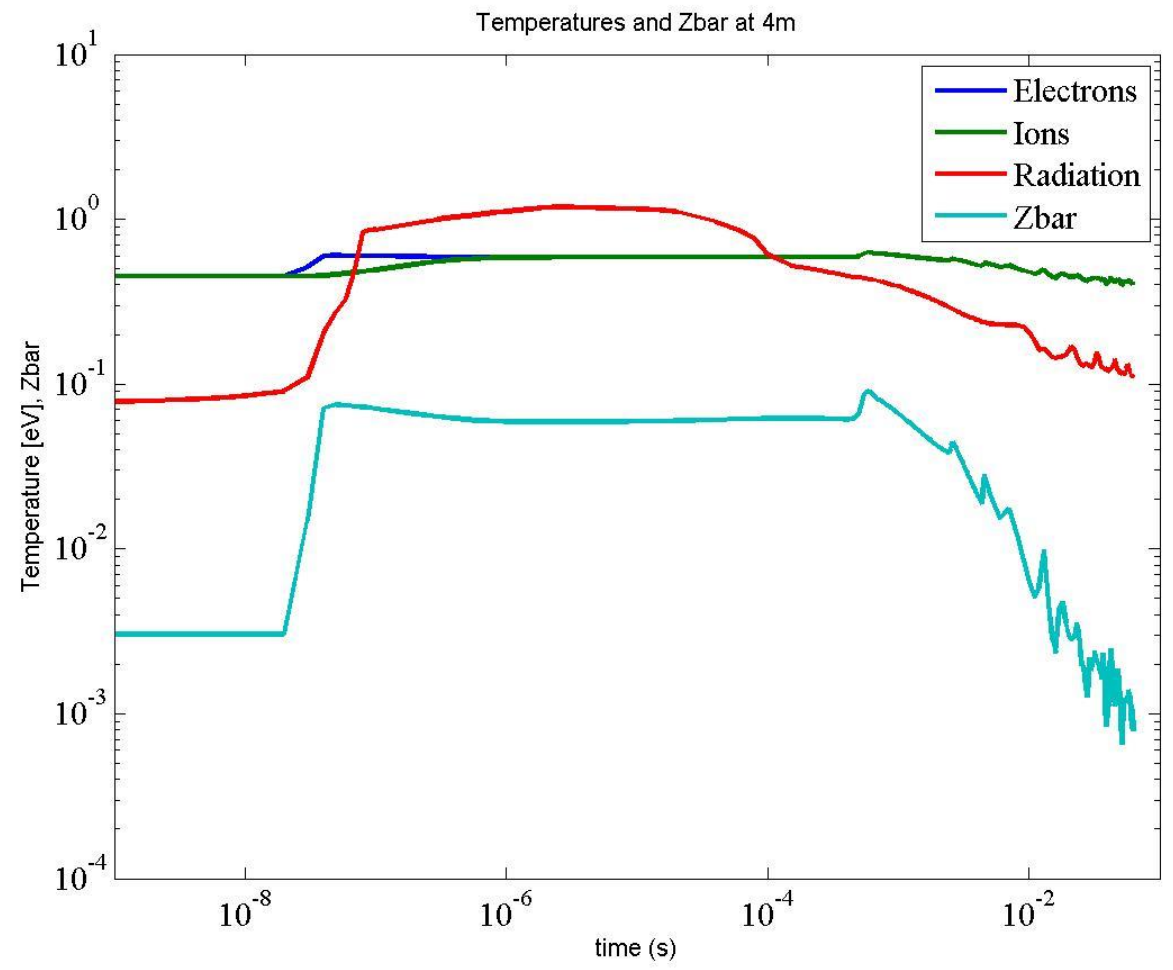

Figure 24 Temperatures and $\mathrm{Zbar}$ at $\mathrm{R}=400 \mathrm{~cm}$ vs time for FAC $1.0 \mathrm{x}$ opacity 


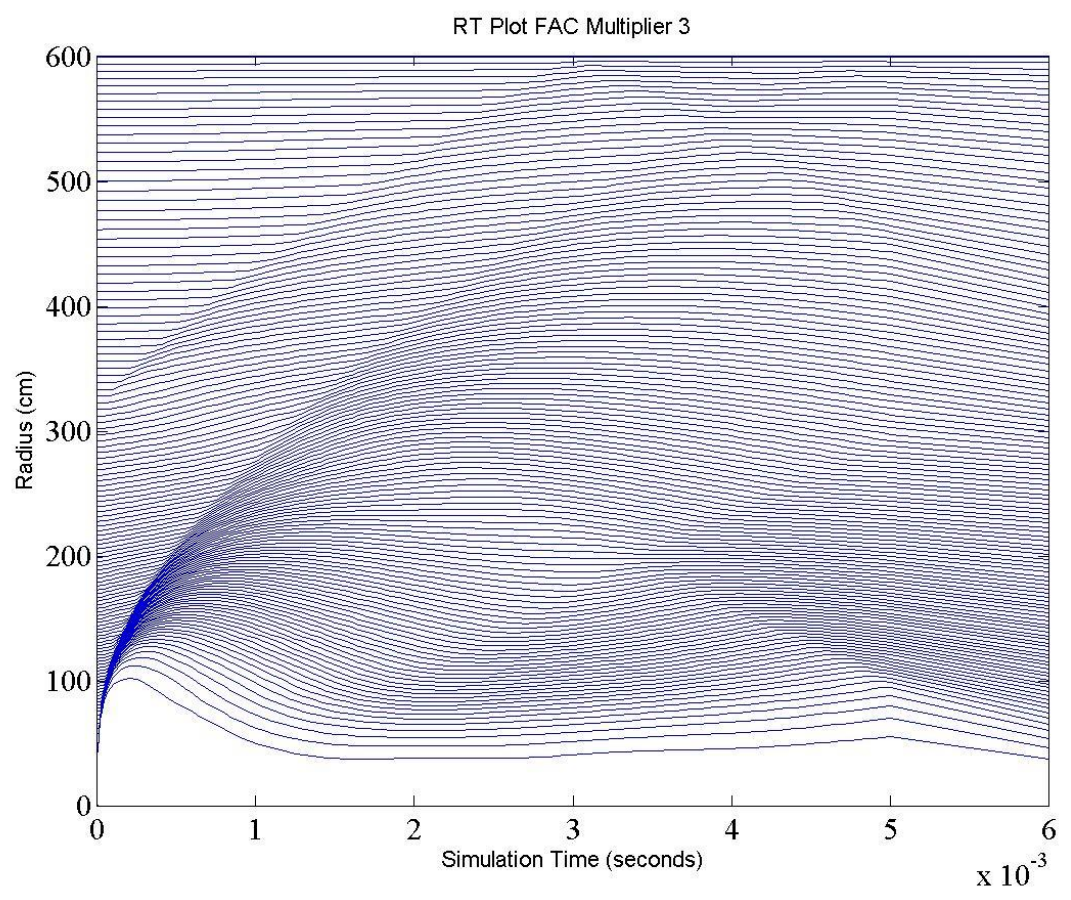

Figure 25 RT plot for FAC 3.0 x opacity

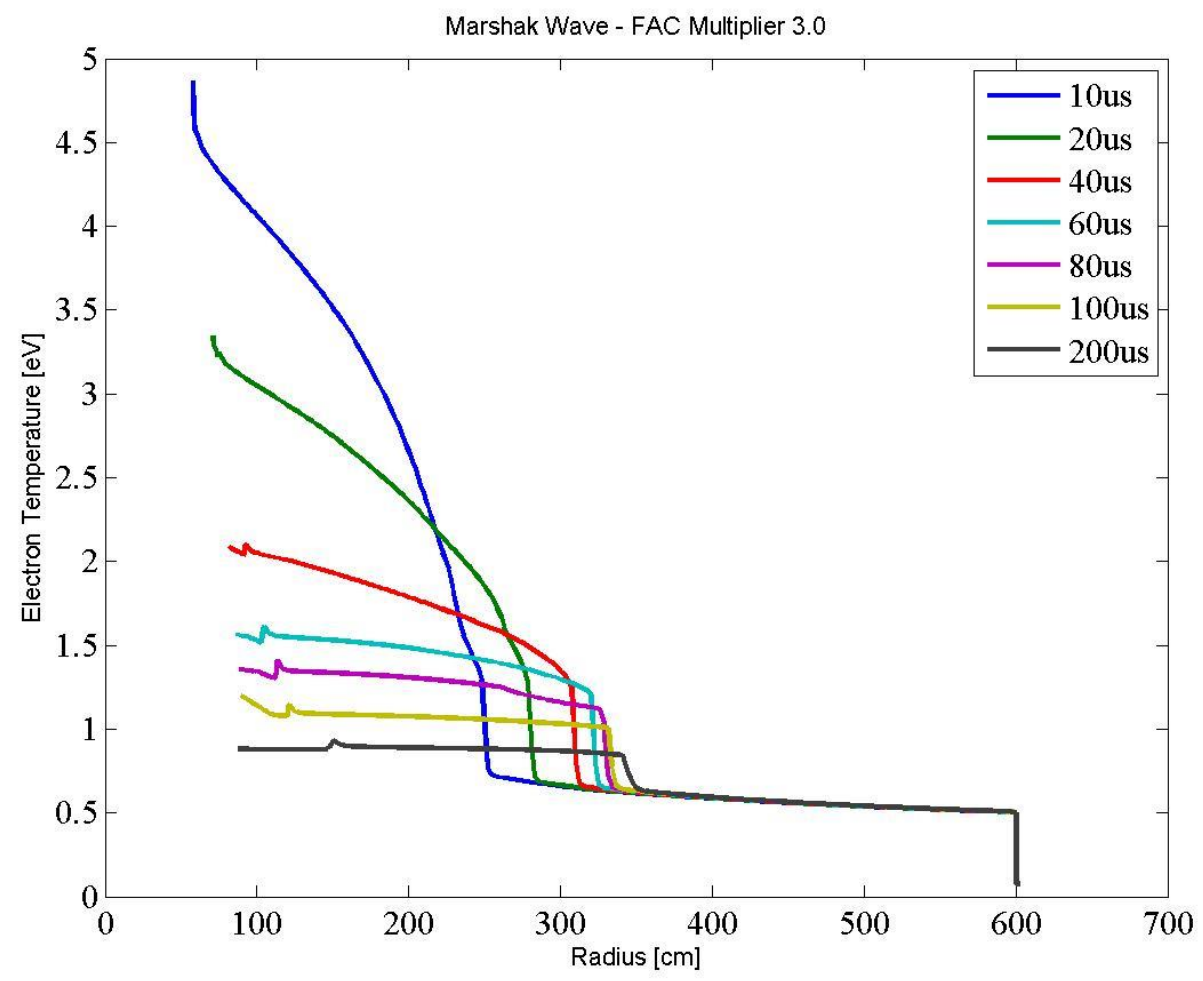

Figure 26 Marshak wave for FAC 3.0 x opacity 


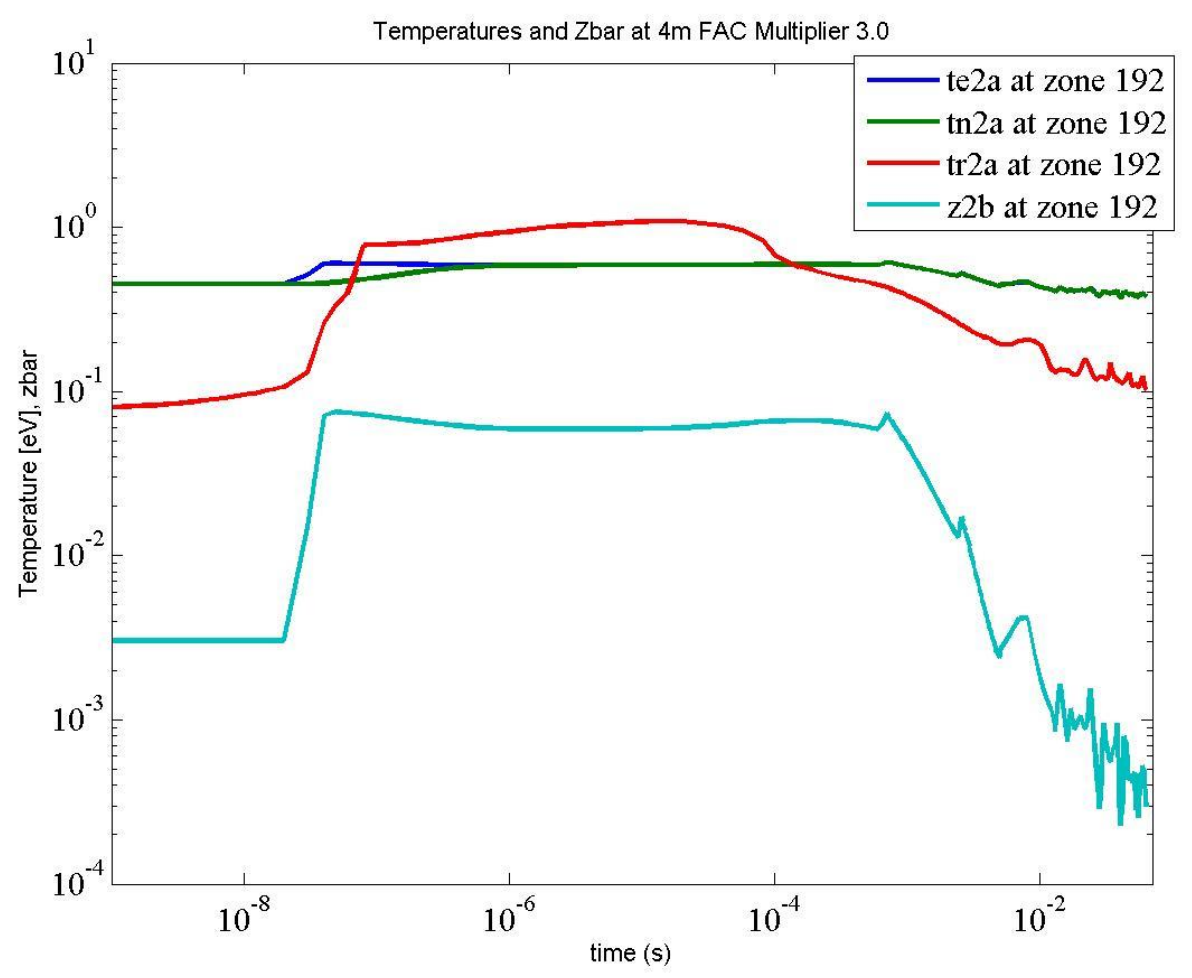

Figure 27 Temperatures and Zbar at $\mathrm{R}=400 \mathrm{~cm}$ vs time for FAC $3.0 \mathrm{x}$ opacity

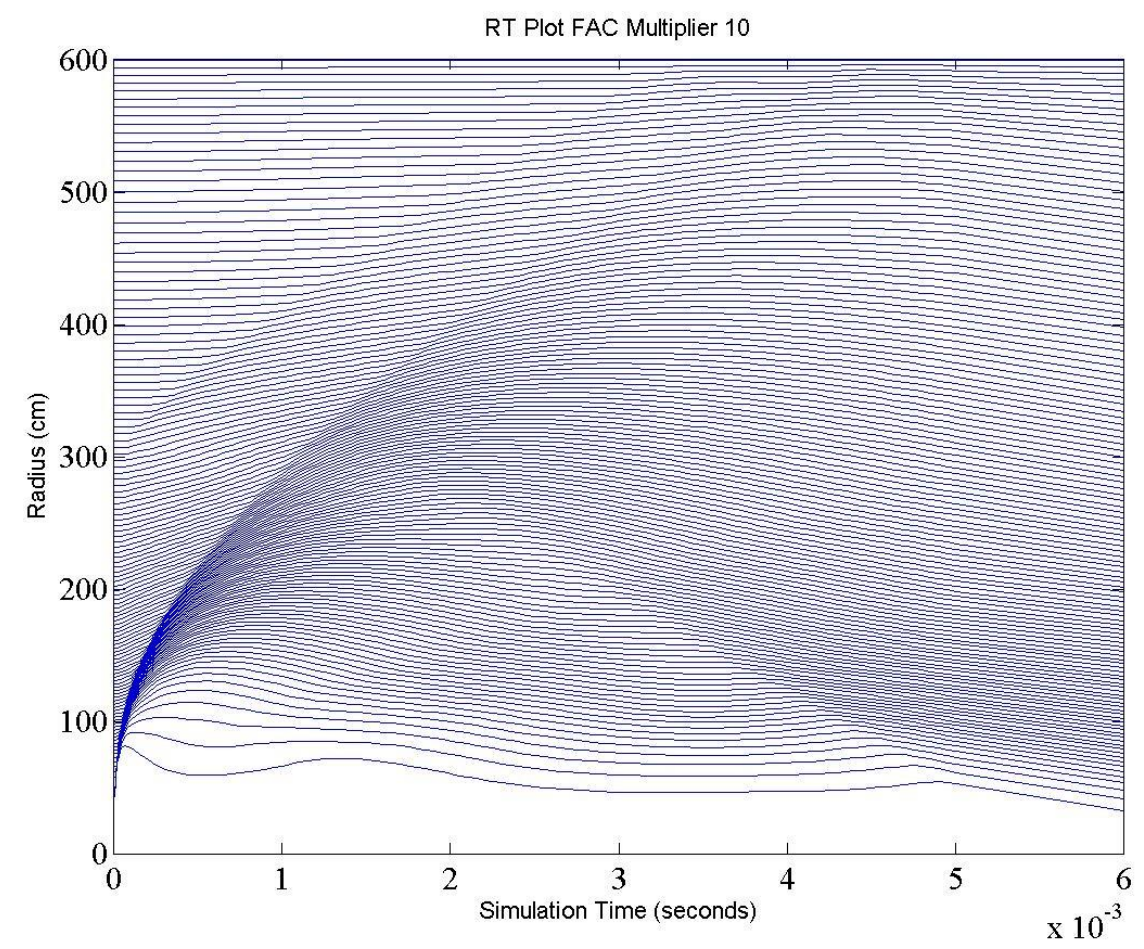

Figure 28 RT plot for FAC 10.0 x opacity 


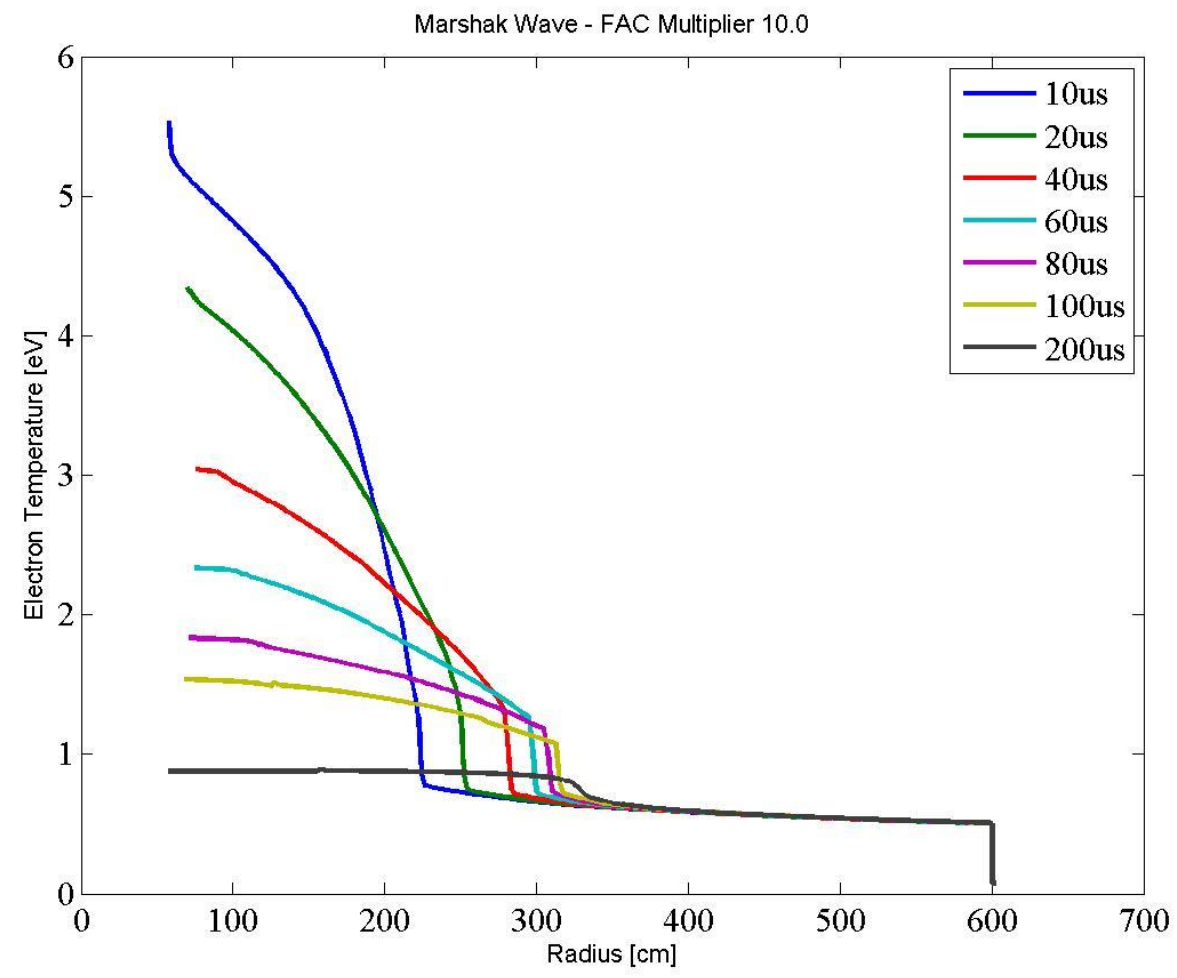

Figure 29 Marshak wave for FAC 10.0 x opacity

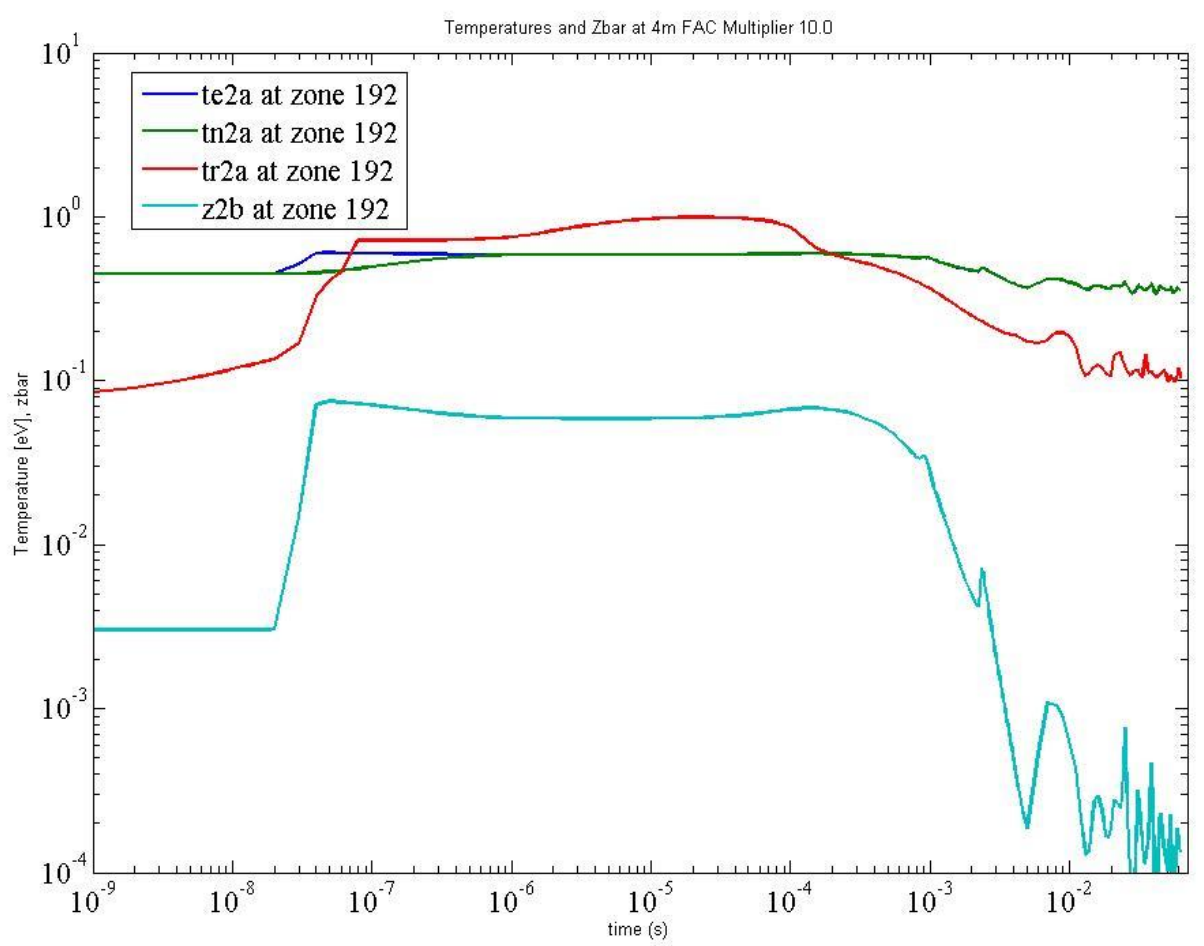

Figure 30 Temperatures and Zbar at $\mathrm{R}=400 \mathrm{~cm}$ vs time for FAC $10.0 \mathrm{x}$ opacity 


\section{CRETIN Code Simulations}

The CRETIN code was provided to UW by Howard Scott from LLNL. Efforts with this code are ongoing. The initial intention was creating a CRETIN simulation of the base case chamber (see section II of this report for details of the base case) to see the differences due to non-local thermodynamic equilibrium effects. This will be of prime importance to validate or invalidate previous LTE simulations. In addition, with the appropriate tables of atomic information, opacity tables of both pure and mixed gases can be produced by CRETIN. This has already been attempted and the attempt can be seen in Figure 79 at the end of the appendix.

\section{Future Studies}

Use of the CRETIN code to generate mixed gas opacities opens the door to another parameter study to see if the gas mixtures have superior properties compared to pure gas fills. Further development with the CRETIN code and understanding of the input decks will lead to the capability to run simulations of the reactor chamber with non-local thermodynamic equilibrium physics included. This will show if the previous studies done with LTE physics are reliable or if the NLTE effects are large enough impact to require modifications of the engineering design of the target chamber.

BUCKY simulations of the exploding target simulated from bang time, surrounded by Xe gas would verify the current model of using an X-ray and ion point source to represent the radiating and exploding target. This would require modification of BUCKY to implicitly couple the multigroup radiation diffusion to the electron energy equation in order to numerically simulate the tight coupling found in such high opacity systems. This is a straightforward numerical procedure in the one dimensional model used in BUCKY.

Using 1-D results as a guide, simulation of the exploding target into surrounding Xe using a multi-dimensional Eulerian code would elucidate the mixing of the expanding target material with the Xe. This will be important for the details of chamber clearing. 


\section{Appendix of Figures}

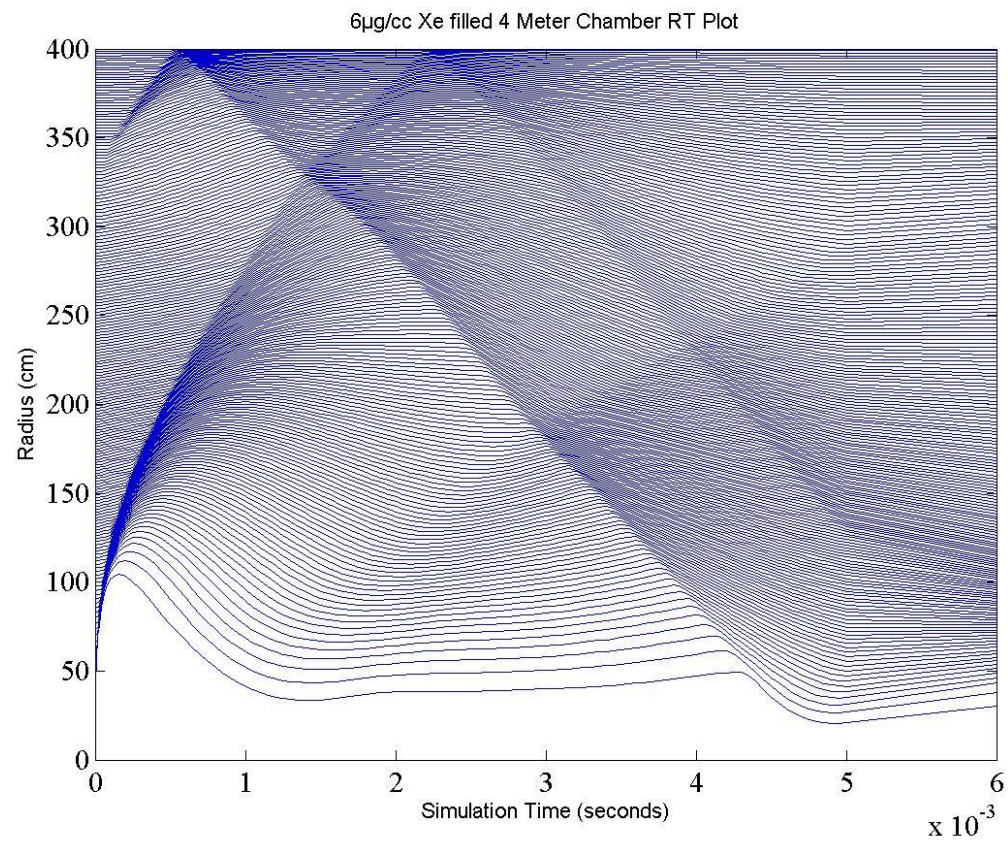

Figure 31: RT plot of the $6 \mu \mathrm{g} / \mathrm{cc}$ Xe filled chamber with 4 meter radius. The double shock starts at $\sim 350 \mathrm{~cm}$ and shocks arrive at the wall at $\sim 0.75 \mathrm{~ms}$ and $\sim 2.25 \mathrm{~ms}$.

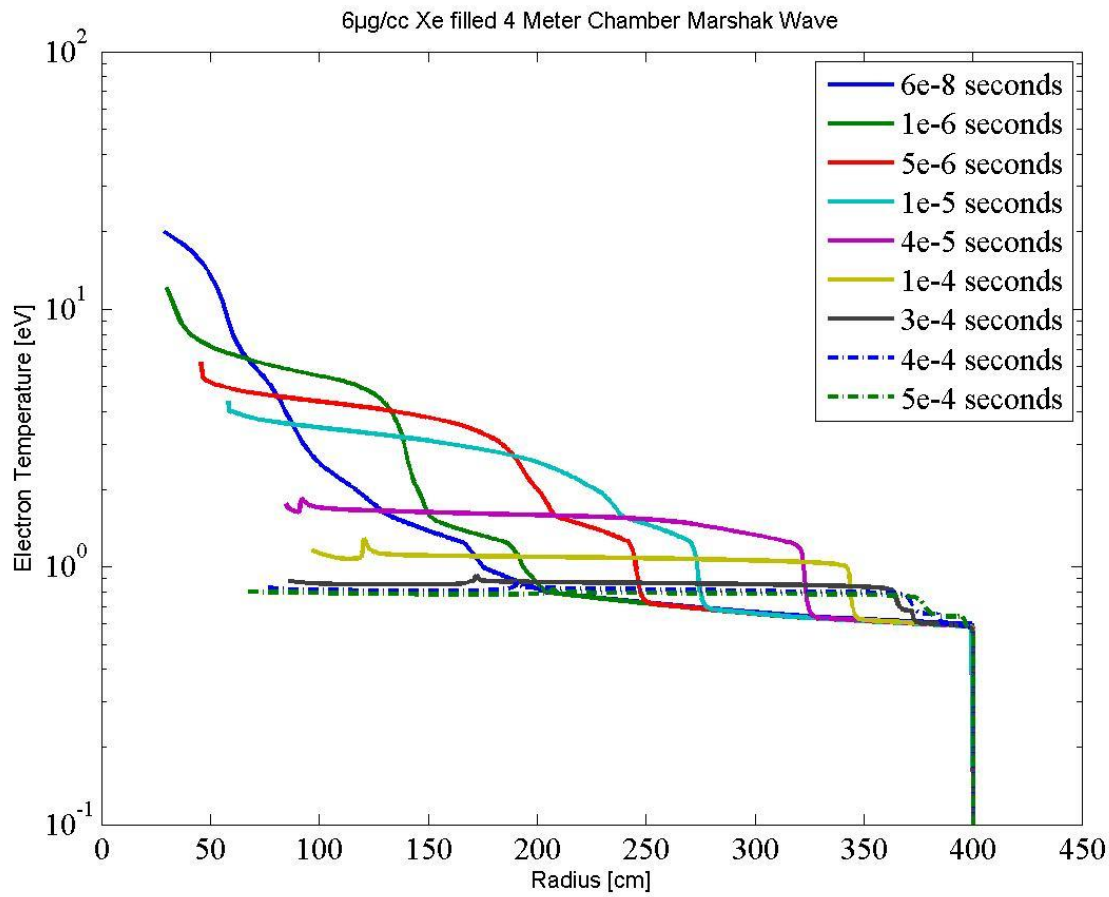

Figure 32: Marshak Wave for 4 meter $6 \mu \mathrm{g} / \mathrm{cc}$ Xe filled chamber. As this is a smaller chamber the wave nearly reaches the wall but still dissipates. 


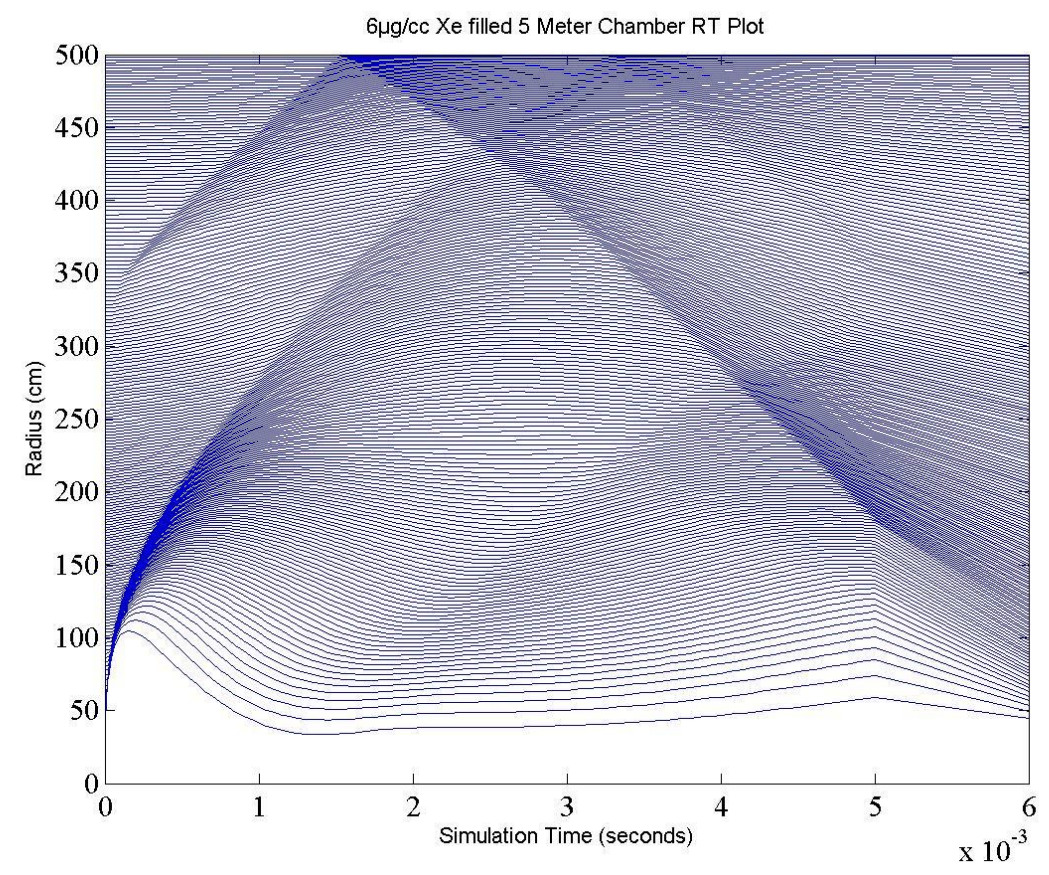

Figure 33: RT plot of the $6 \mu \mathrm{g} / \mathrm{cc}$ Xe filled chamber with 5 meter radius. The double shock starts at $\sim 350 \mathrm{~cm}$ and shocks arrive at the wall at $\sim 1.75 \mathrm{~ms}$ and $\sim 3.5 \mathrm{~ms}$.

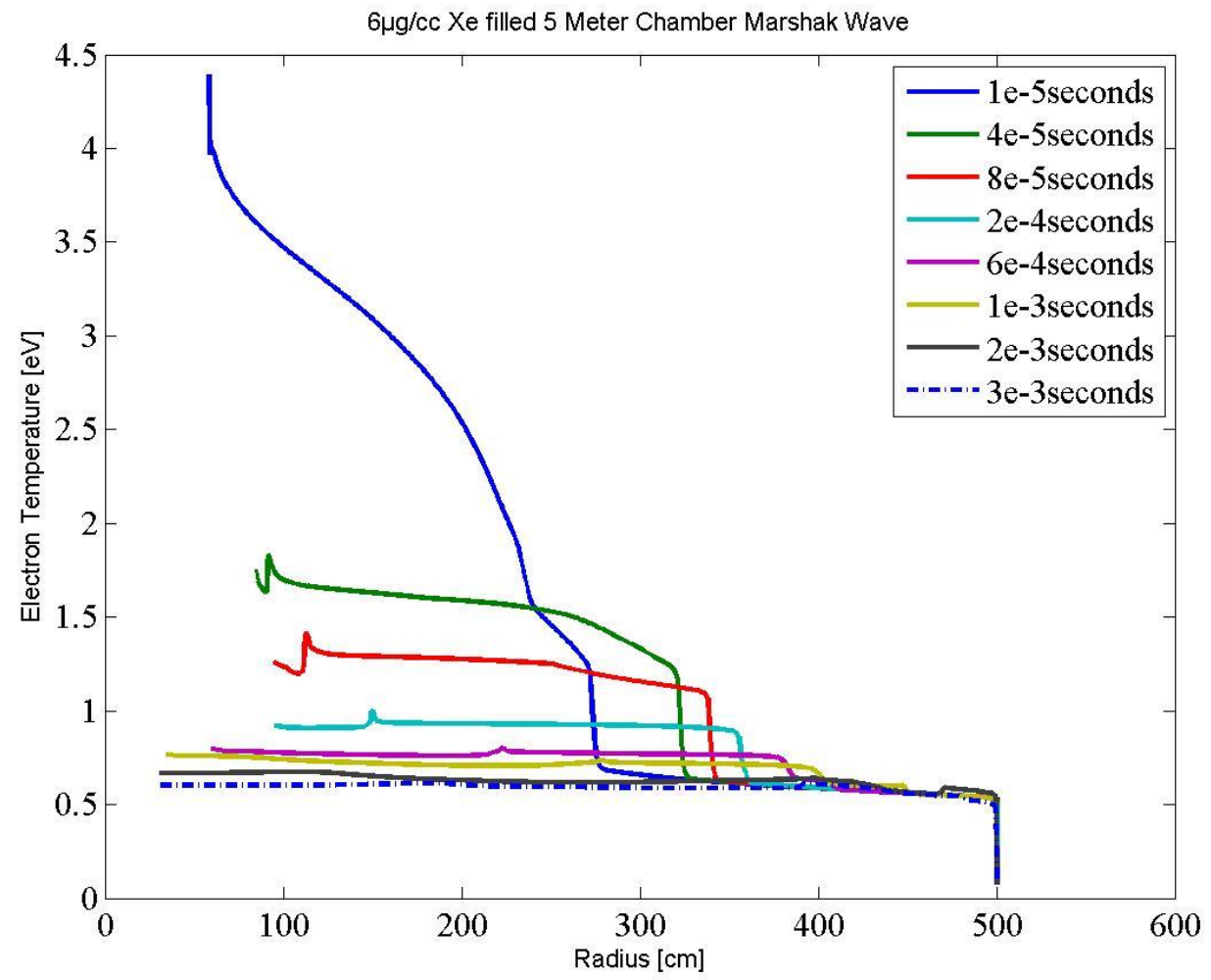

Figure 34: Marshak Wave for 5 meter $6 \mu \mathrm{g} / \mathrm{cc}$ Xe filled chamber. The wave dissipates at about $350 \mathrm{~cm}$. 


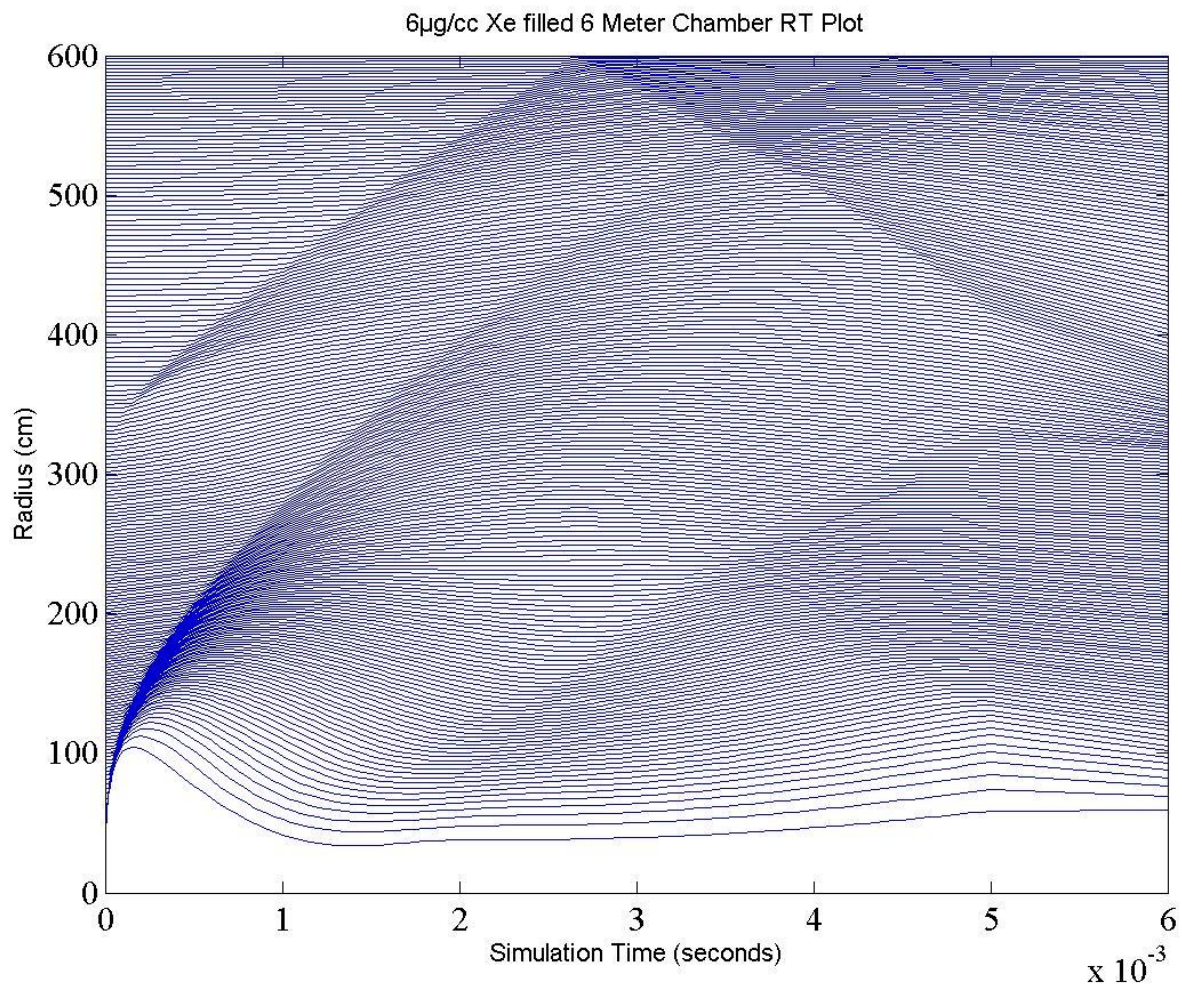

Figure 35: RT plot of the $6 \mu \mathrm{g} / \mathrm{cc}$ Xe filled chamber with 6 meter radius. The double shock starts at $\sim 350 \mathrm{~cm}$ and shocks arrive at the wall at $\sim 2.6 \mathrm{~ms}$ and $\sim 4.5 \mathrm{~ms}$.

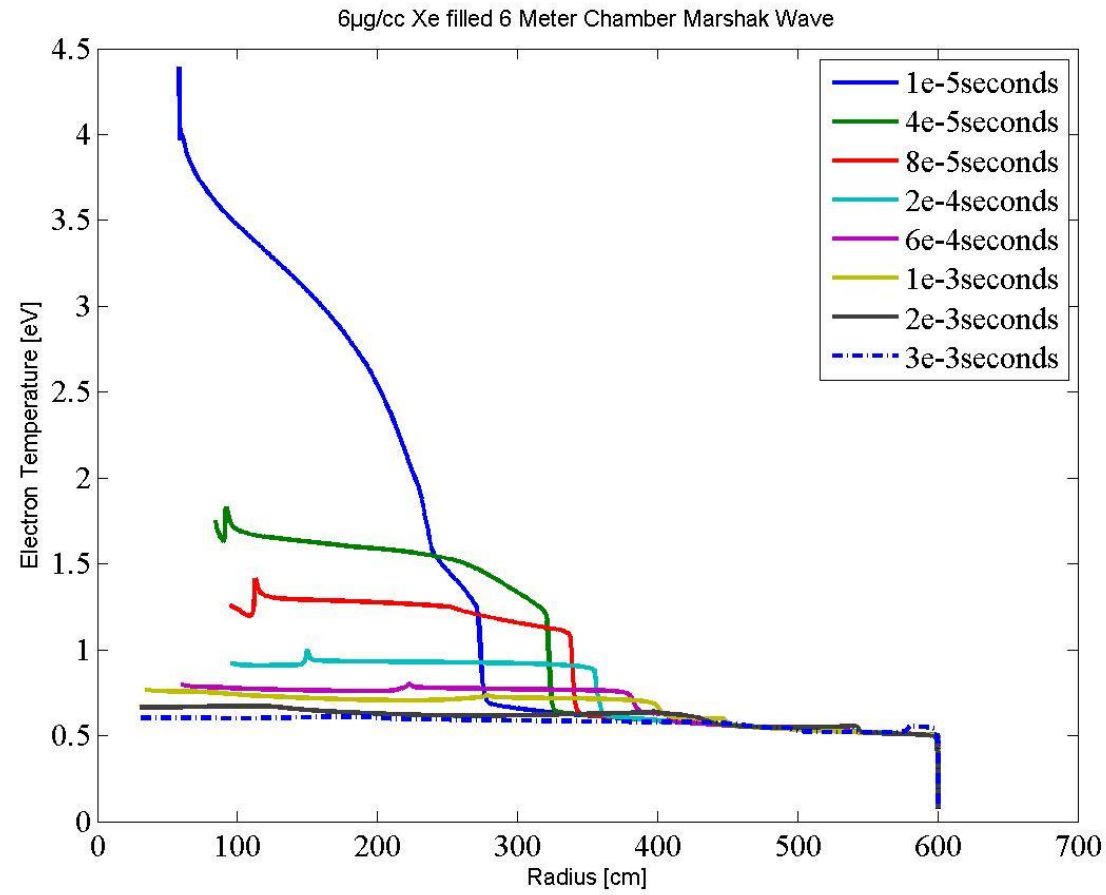

Figure 36: Marshak Wave for 6 meter $6 \mu \mathrm{g} / \mathrm{cc}$ Xe filled chamber. The wave dissipates at about $350 \mathrm{~cm}$. 


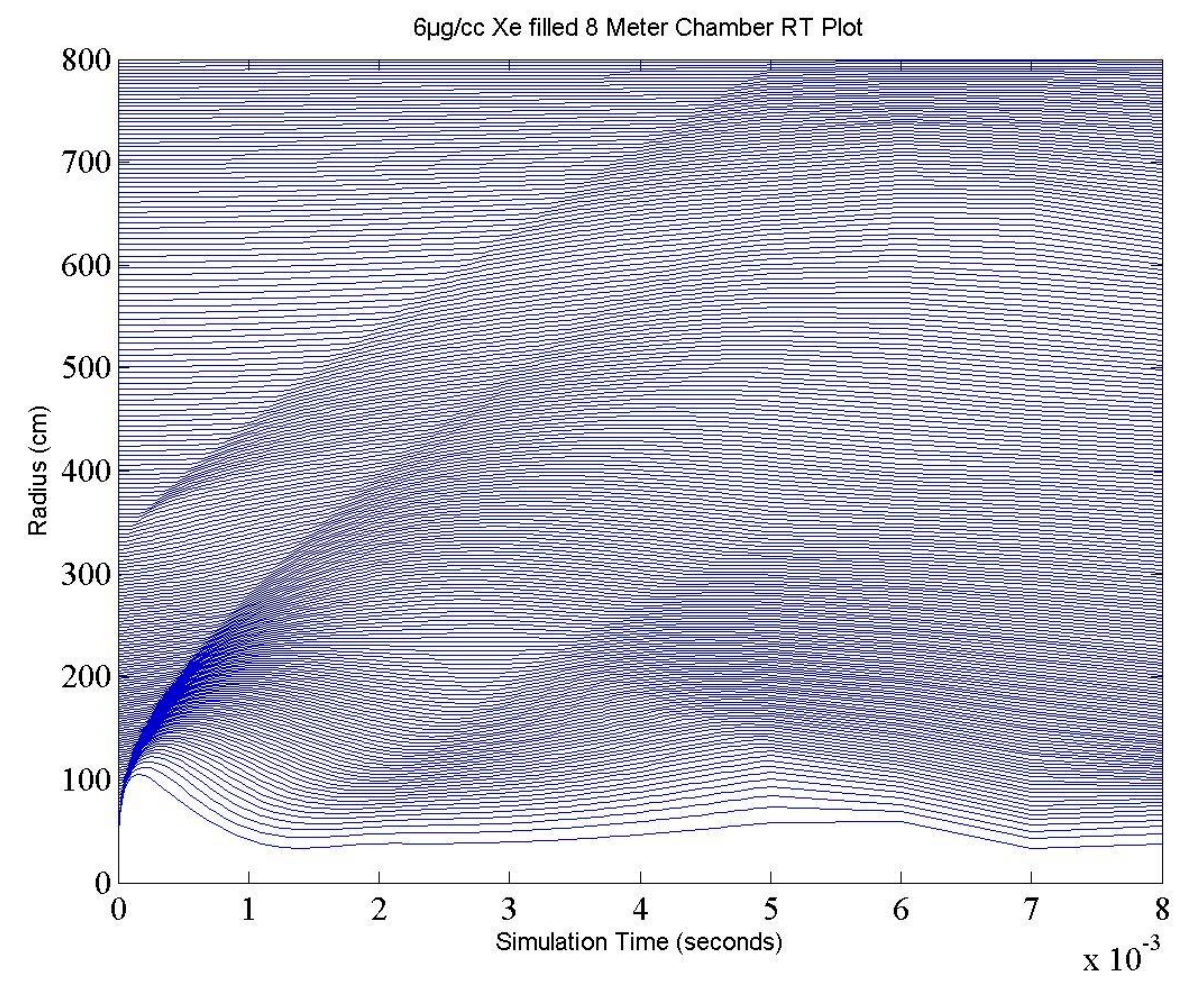

Figure 37: RT plot of the $6 \mu \mathrm{g} / \mathrm{cc}$ Xe filled chamber with 8 meter radius. The double shock starts at $\sim 350 \mathrm{~cm}$. The outer shock arrives at $\sim 5 \mathrm{~ms}$ but the inner shock is lost in the rebound of the outer shock.

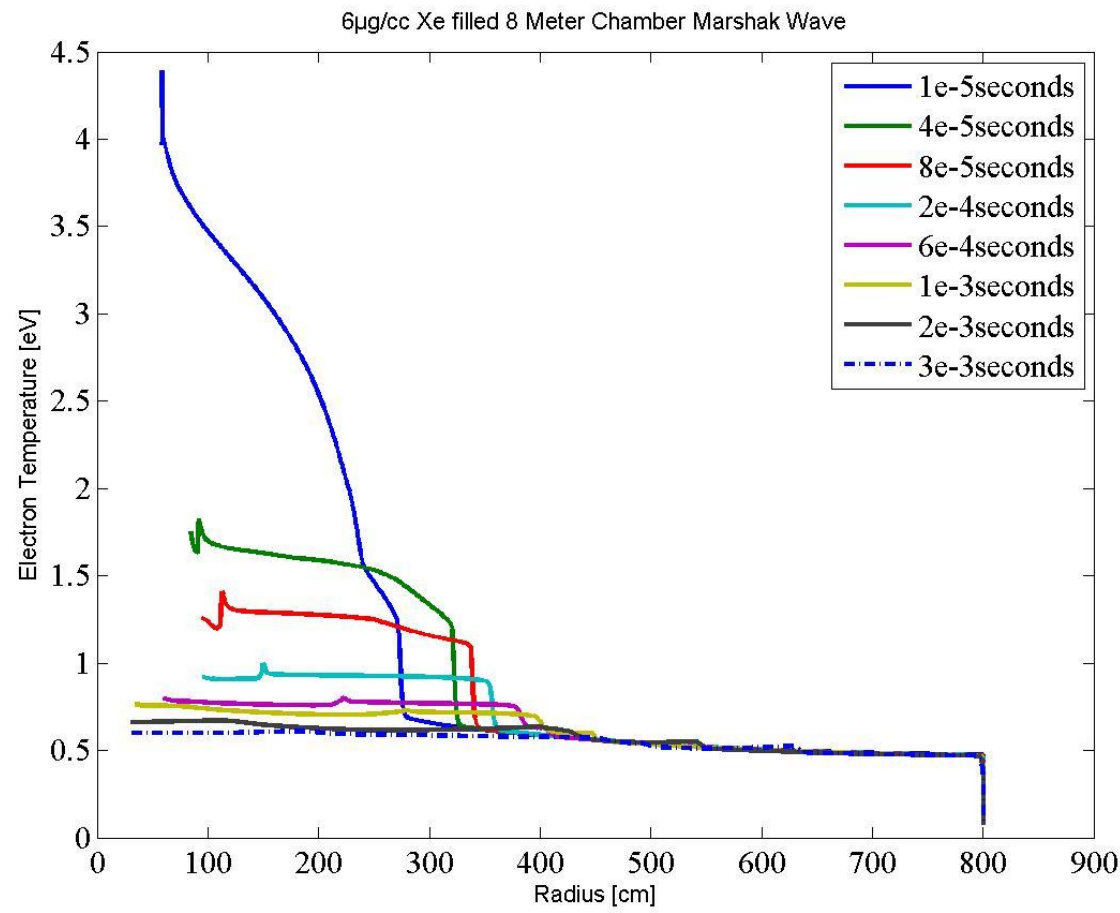

Figure 38: Marshak Wave for 8 meter $6 \mu \mathrm{g} / \mathrm{cc}$ Xe filled chamber. The wave dissipates at about $350 \mathrm{~cm}$. 


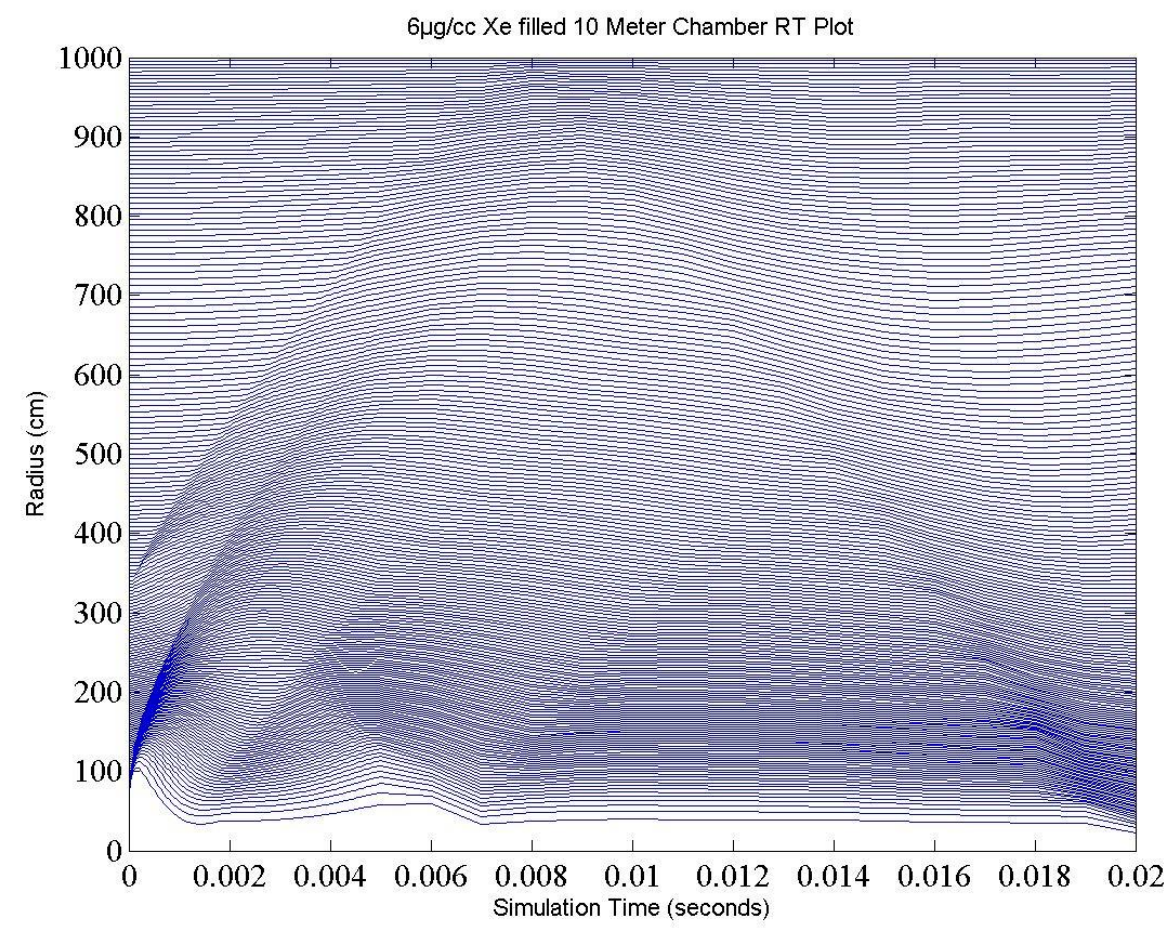

Figure 39: RT plot of the $6 \mu \mathrm{g} / \mathrm{cc}$ Xe filled chamber with 10 meter radius. The double shock starts at $\sim 350 \mathrm{~cm}$. The outer shock arrives at $\sim 7.5 \mathrm{~ms}$ but the inner shock is lost in the rebound of the outer shock.

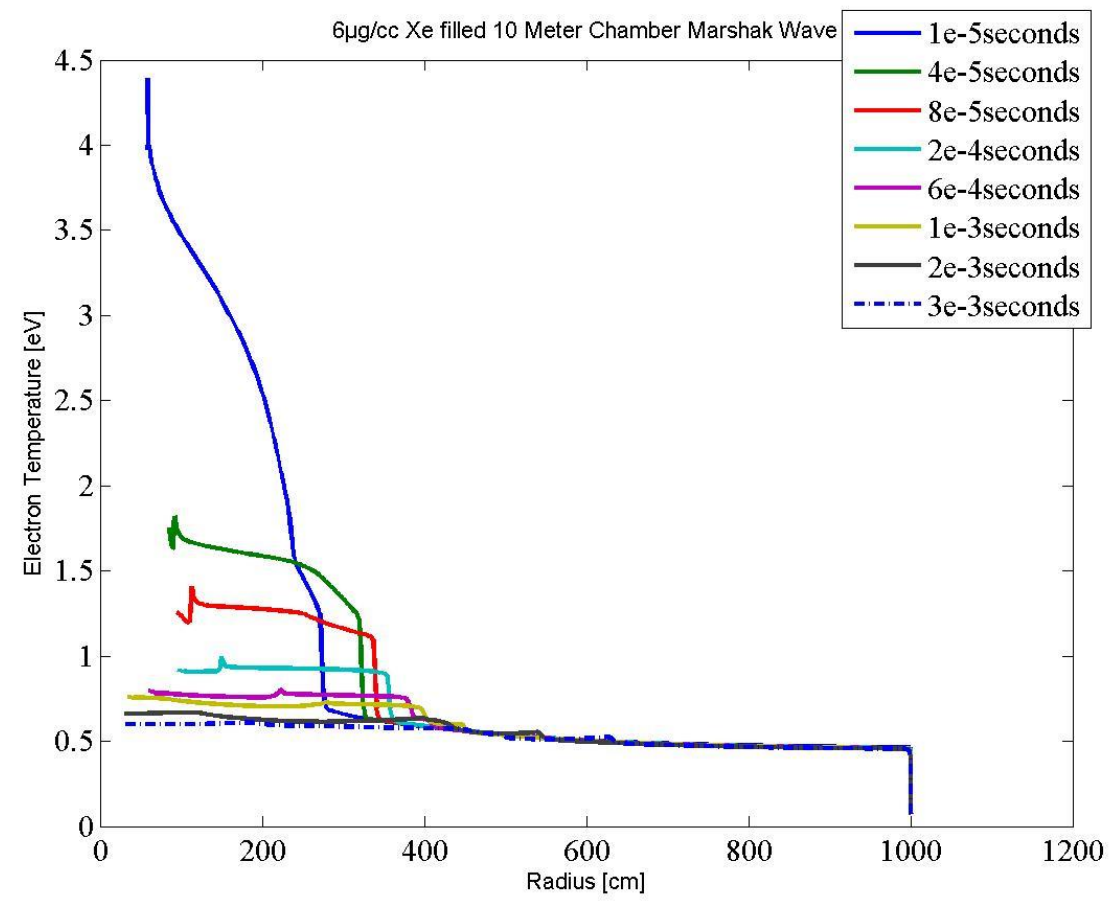

Figure 40: Marshak Wave for 10 meter $6 \mu \mathrm{g} / \mathrm{cc}$ Xe filled chamber. The wave dissipates at about $350 \mathrm{~cm}$. 


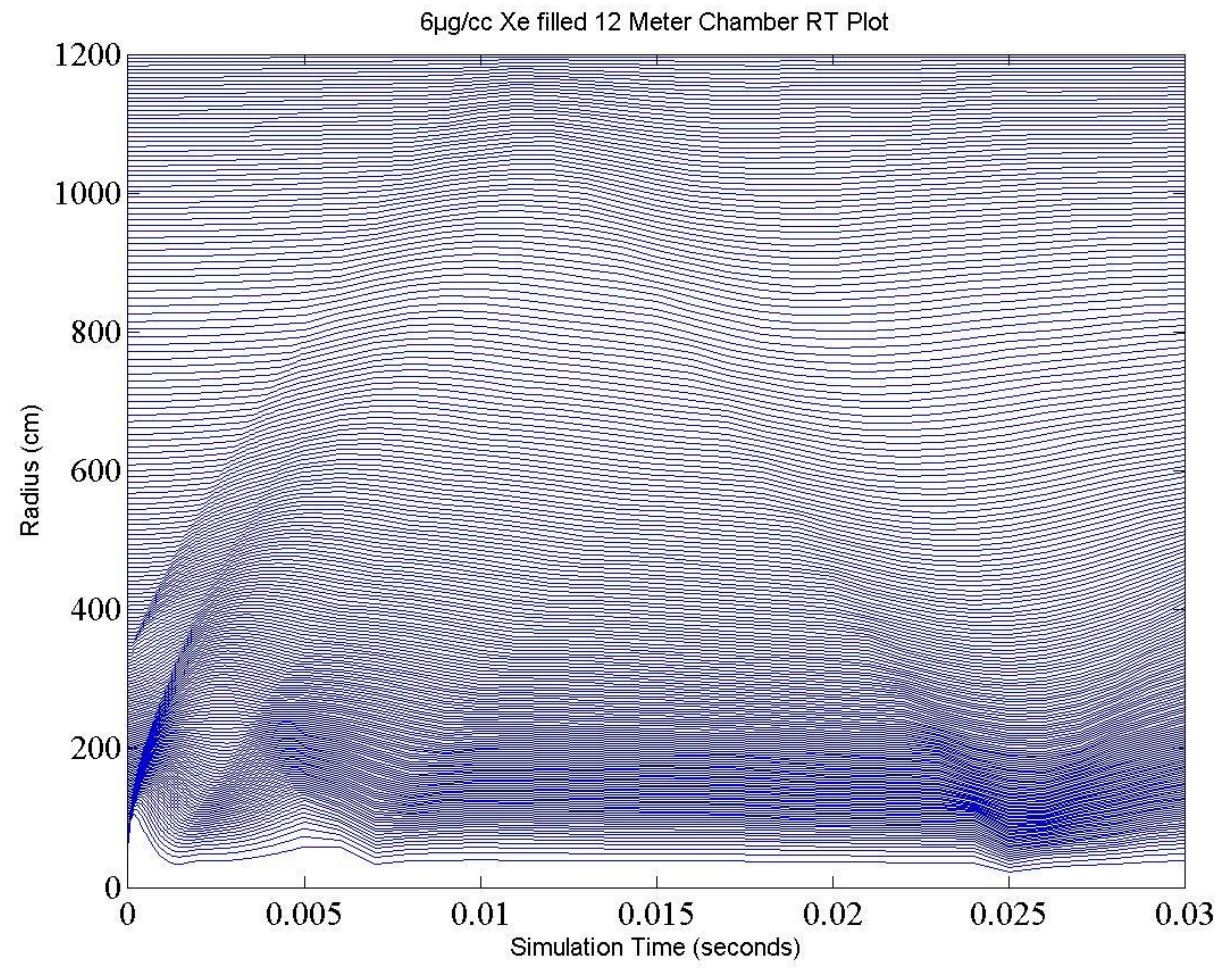

Figure 41: RT plot of the $6 \mu \mathrm{g} / \mathrm{cc}$ Xe filled chamber with 12 meter radius. The double shock starts at $\sim 350 \mathrm{~cm}$. The outer shock arrives at $\sim 7.5 \mathrm{~ms}$ but the inner shock is lost in the rebound of the outer shock.

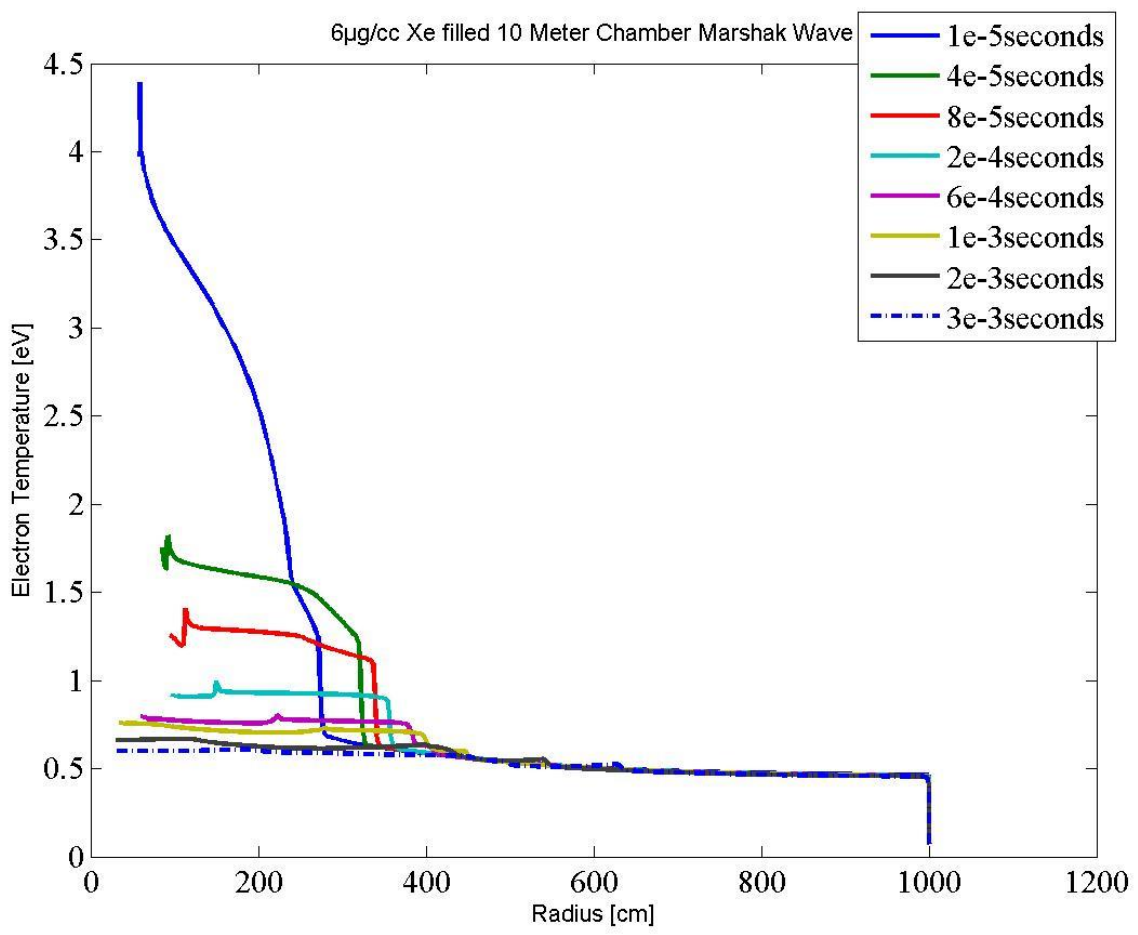

Figure 42: Marshak Wave for 12 meter $6 \mu \mathrm{g} / \mathrm{cc}$ Xe filled chamber. The wave dissipates at about $350 \mathrm{~cm}$. 


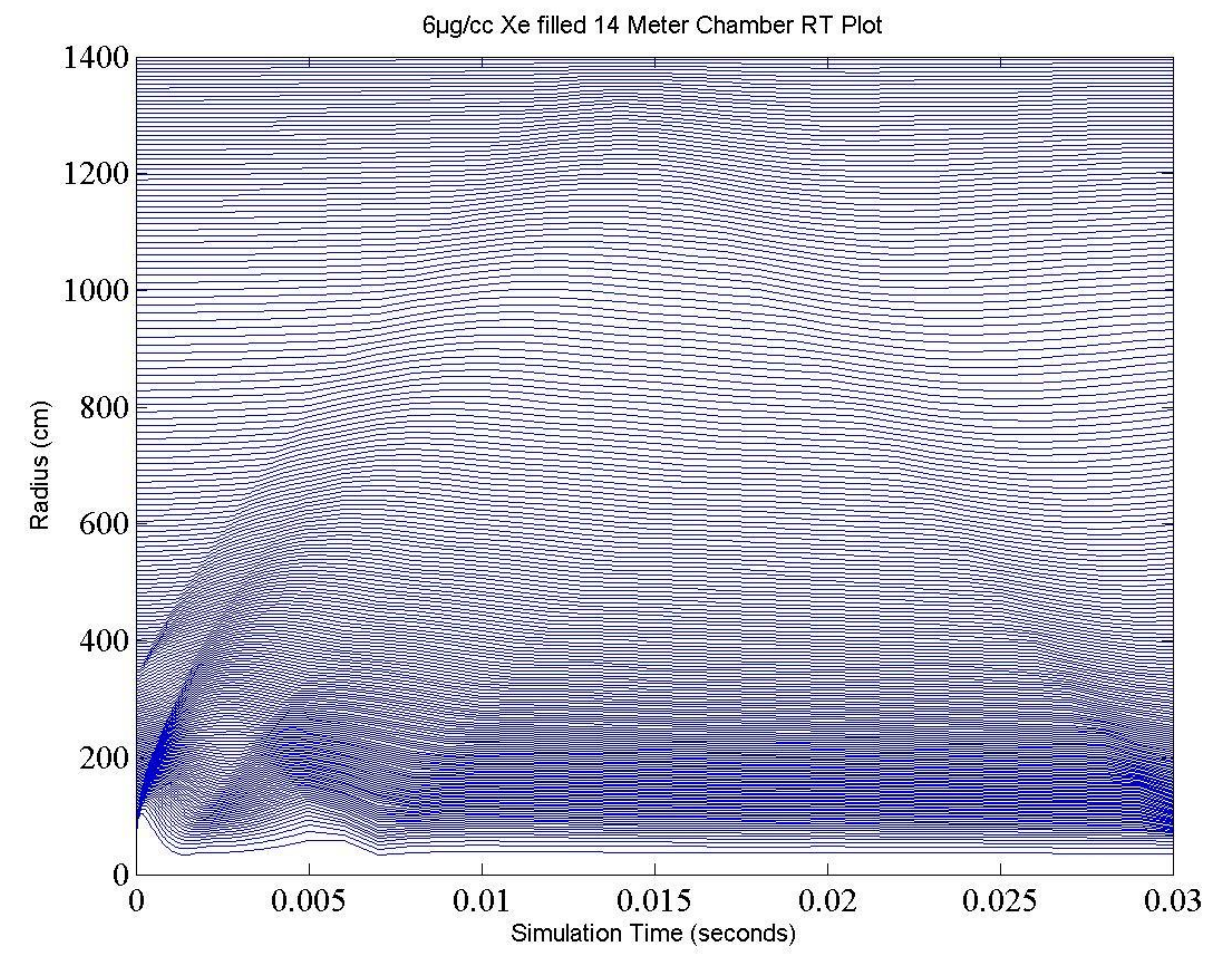

Figure 43: RT plot of the $6 \mu \mathrm{g} / \mathrm{cc}$ Xe filled chamber with 14 meter radius. The double shock starts at $\sim 350 \mathrm{~cm}$. The outer shock arrives at $\sim 13 \mathrm{~ms}$ but the inner shock is lost in the rebound of the outer shock.

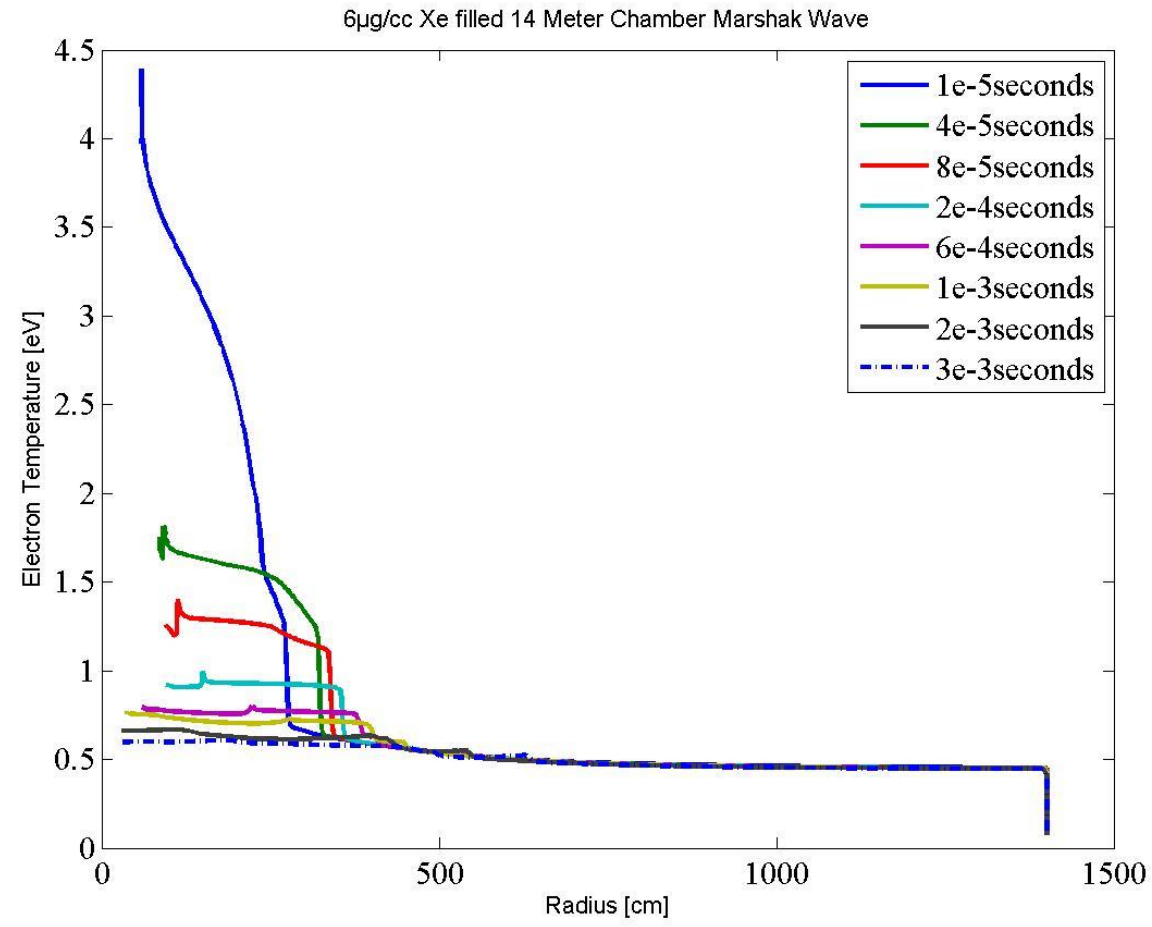

Figure 44: Marshak Wave for 12 meter $6 \mu \mathrm{g} / \mathrm{cc}$ Xe filled chamber. The wave dissipates at about $350 \mathrm{~cm}$. 


\section{$2 \mu \mathrm{g} / \mathrm{cc}$ Xe filled 6 Meter Chamber RT Plot}

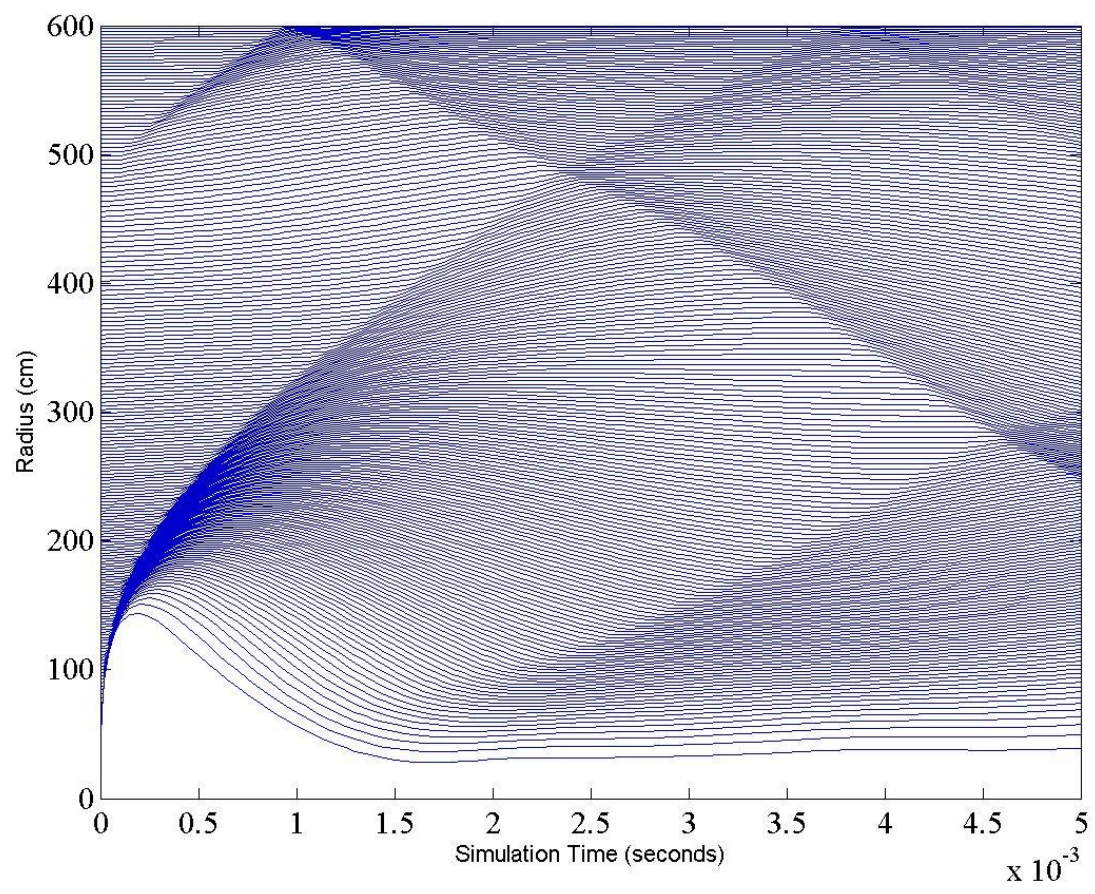

Figure 45: RT plot of the $2 \mu \mathrm{g} / \mathrm{cc}$ Xe filled chamber with 6 meter radius. The double shock starts at $\sim 500 \mathrm{~cm}$ and shocks arrive at the wall at $\sim 1 \mathrm{~ms}$ and $\sim 3.75 \mathrm{~ms}$.

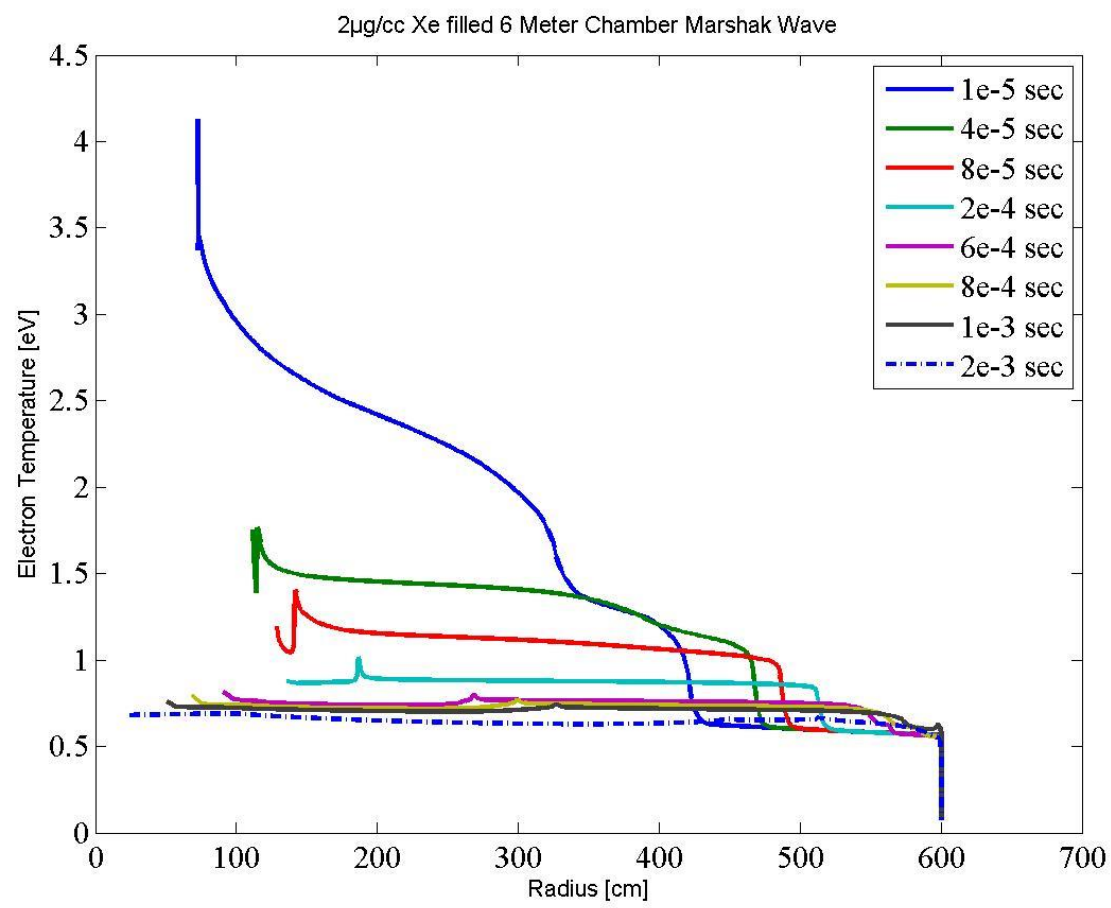

Figure 46: Wave for 6 meter $2 \mu \mathrm{g} / \mathrm{cc}$ Xe filled chamber. The wave dissipates at about $530 \mathrm{~cm}$. 


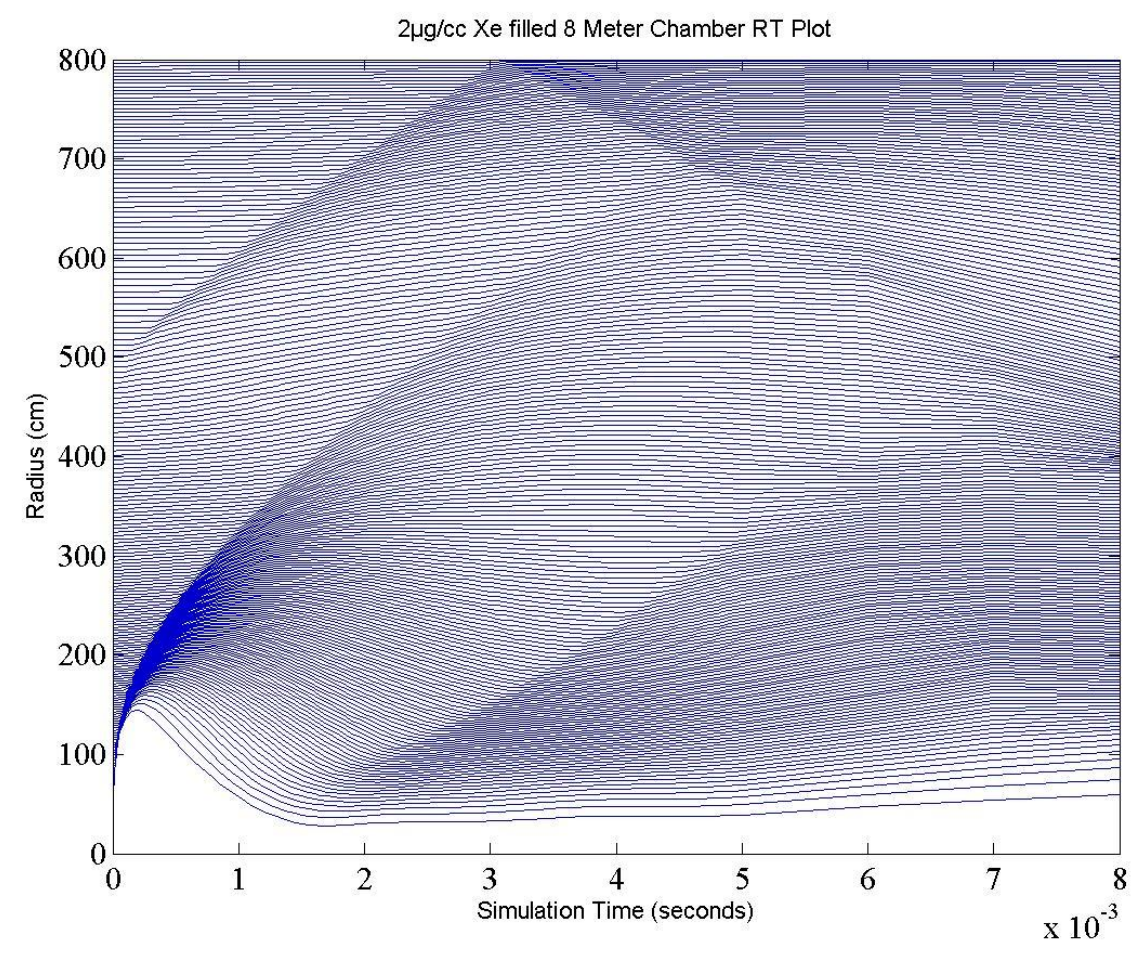

Figure 47: RT plot of the $2 \mu \mathrm{g} / \mathrm{cc}$ Xe filled chamber with 8 meter radius. The double shock starts at $\sim 500 \mathrm{~cm}$ and shocks arrive at the wall at $\sim 3 \mathrm{~ms}$ and $\sim 6 \mathrm{~ms}$.

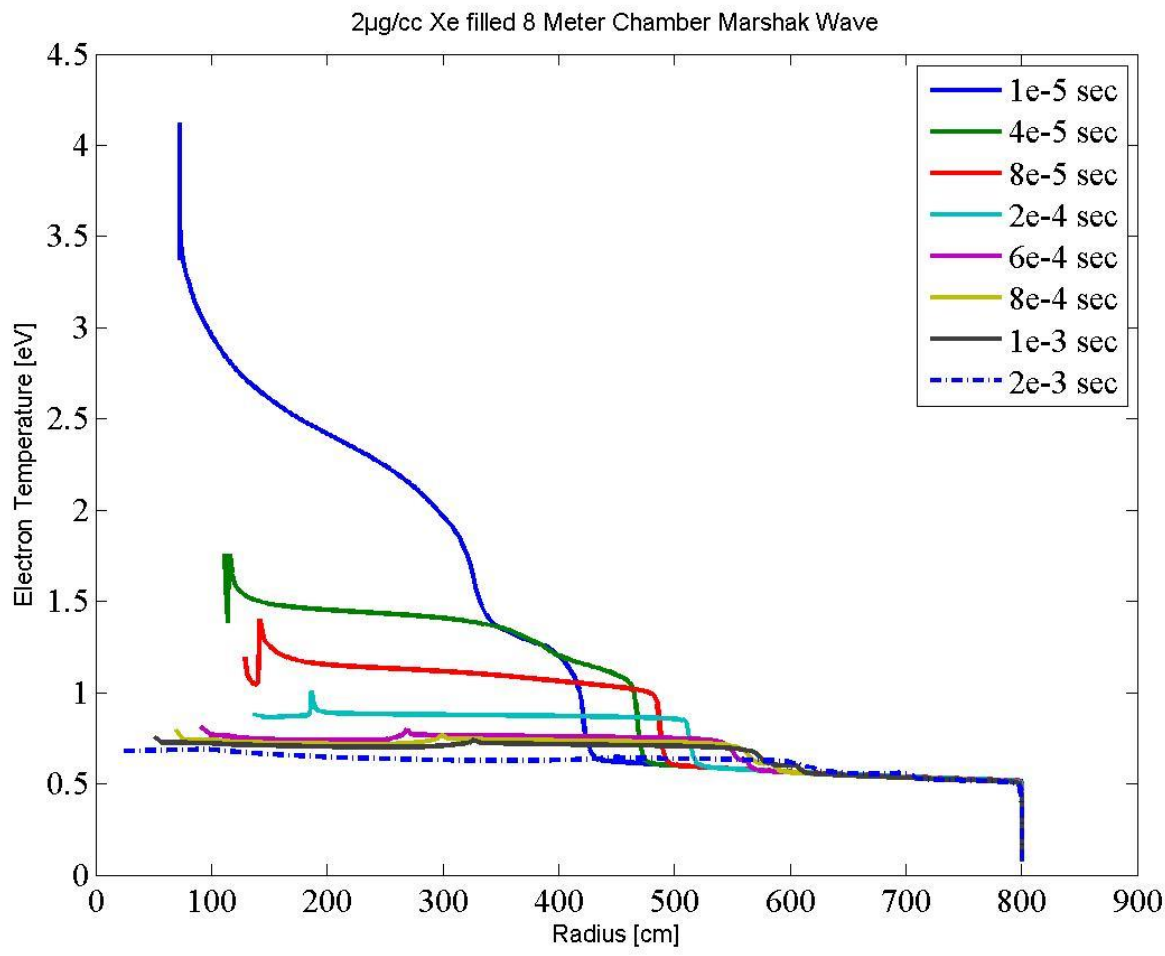

Figure 48: Marshak Wave for 8 meter $2 \mu \mathrm{g} / \mathrm{cc}$ Xe filled chamber. The wave dissipates at about $530 \mathrm{~cm}$. 


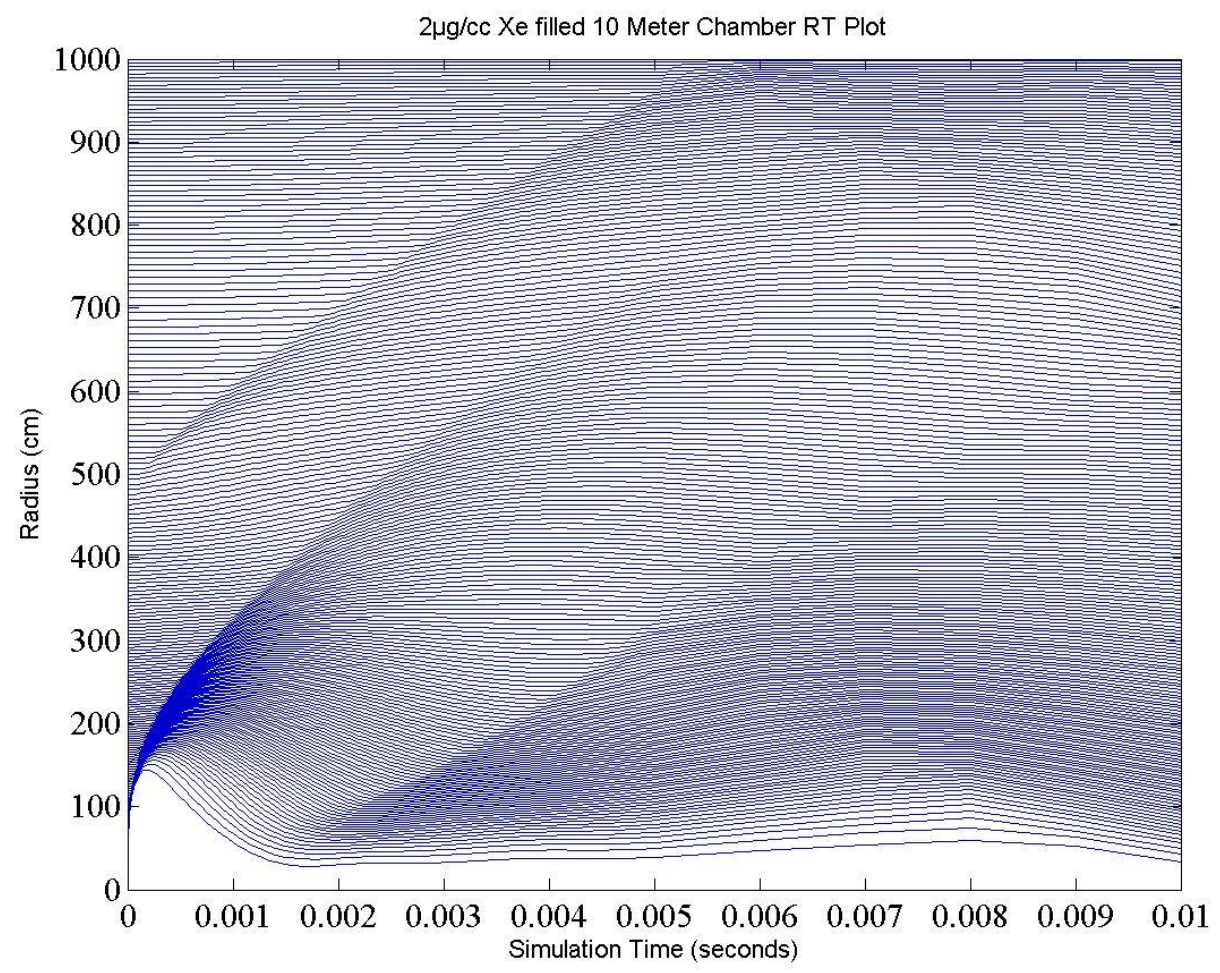

Figure 49: RT plot of the $2 \mu \mathrm{g} / \mathrm{cc}$ Xe filled chamber with 10 meter radius. The double shock starts at $\sim 500 \mathrm{~cm}$. The outer shock arrives at $\sim 5.25 \mathrm{~ms}$ but the inner shock is lost in the rebound of the outer shock.

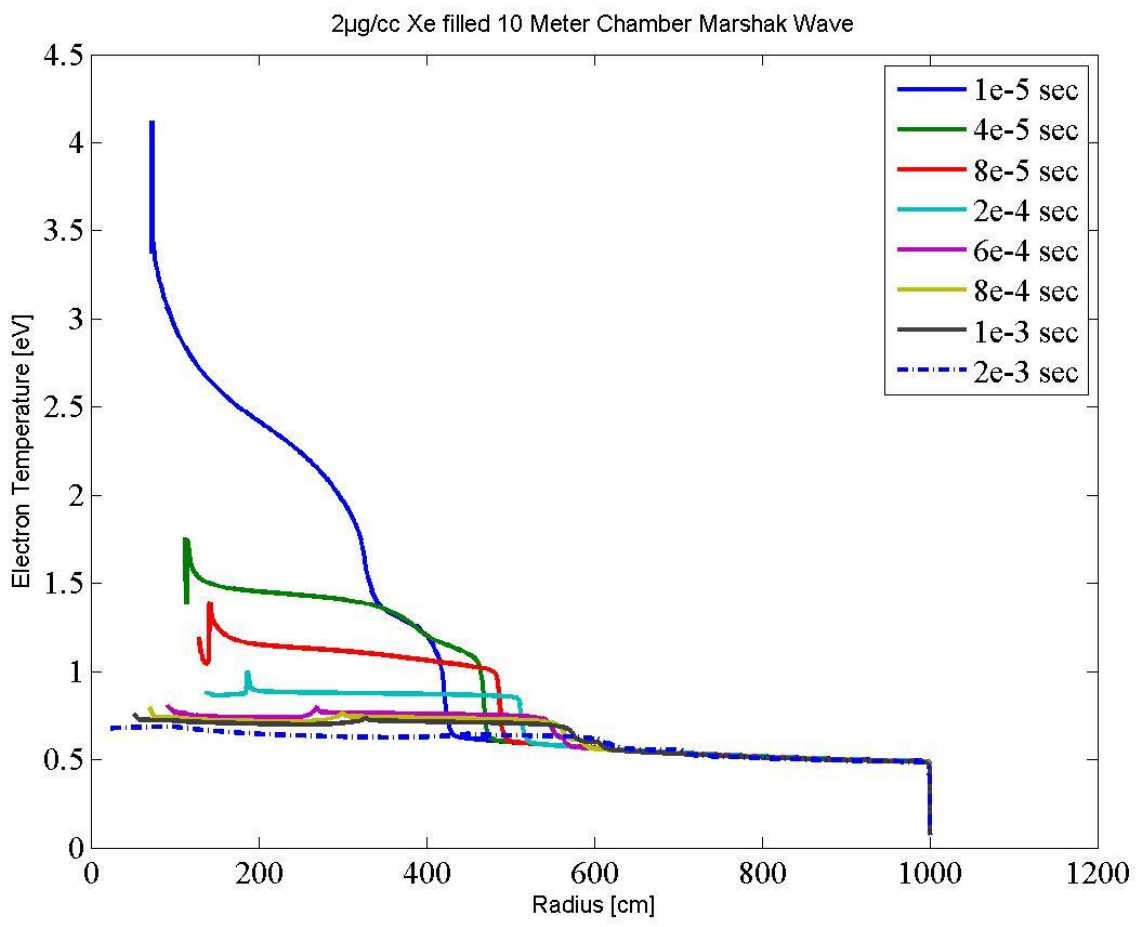

Figure 50: Marshak Wave for 10 meter $2 \mu \mathrm{g} / \mathrm{cc}$ Xe filled chamber. The wave dissipates at about $530 \mathrm{~cm}$. 


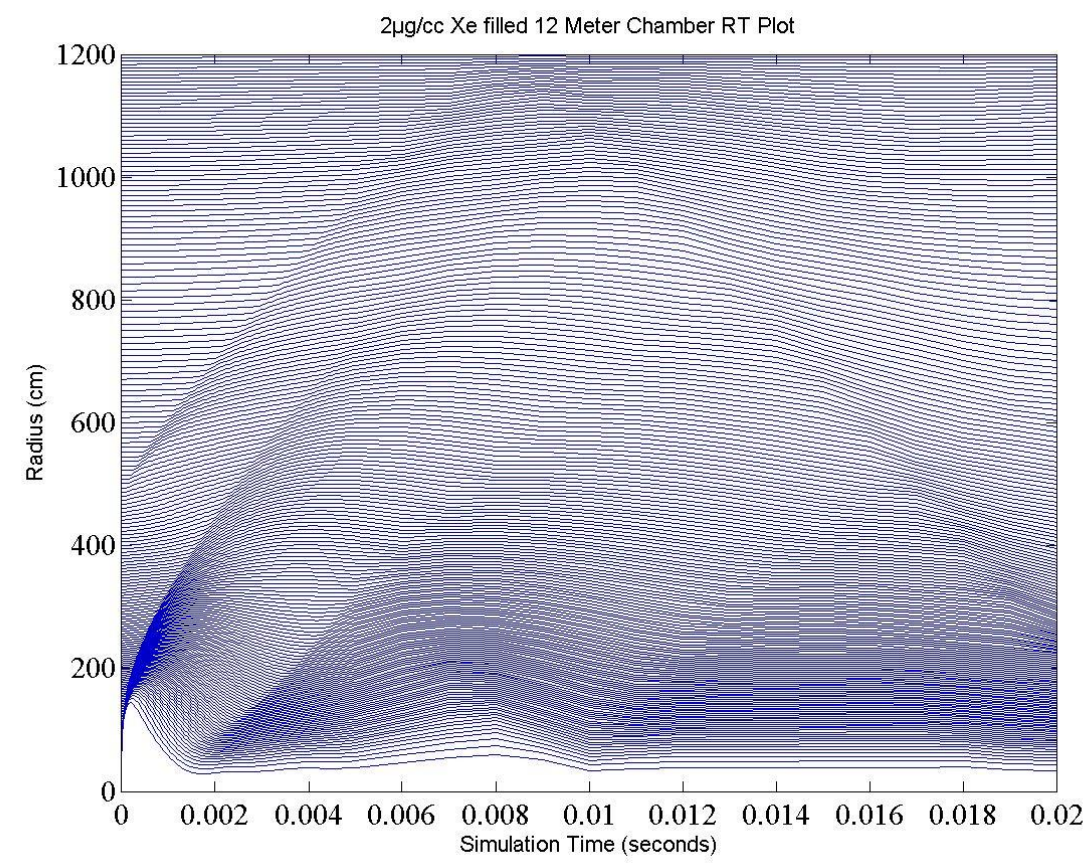

Figure 51: RT plot of the $2 \mu \mathrm{g} / \mathrm{cc}$ Xe filled chamber with 12 meter radius. The double shock starts at $\sim 500 \mathrm{~cm}$. The outer shock arrives at $\sim 7.75 \mathrm{~ms}$ but the inner shock is lost in the rebound of the outer shock.

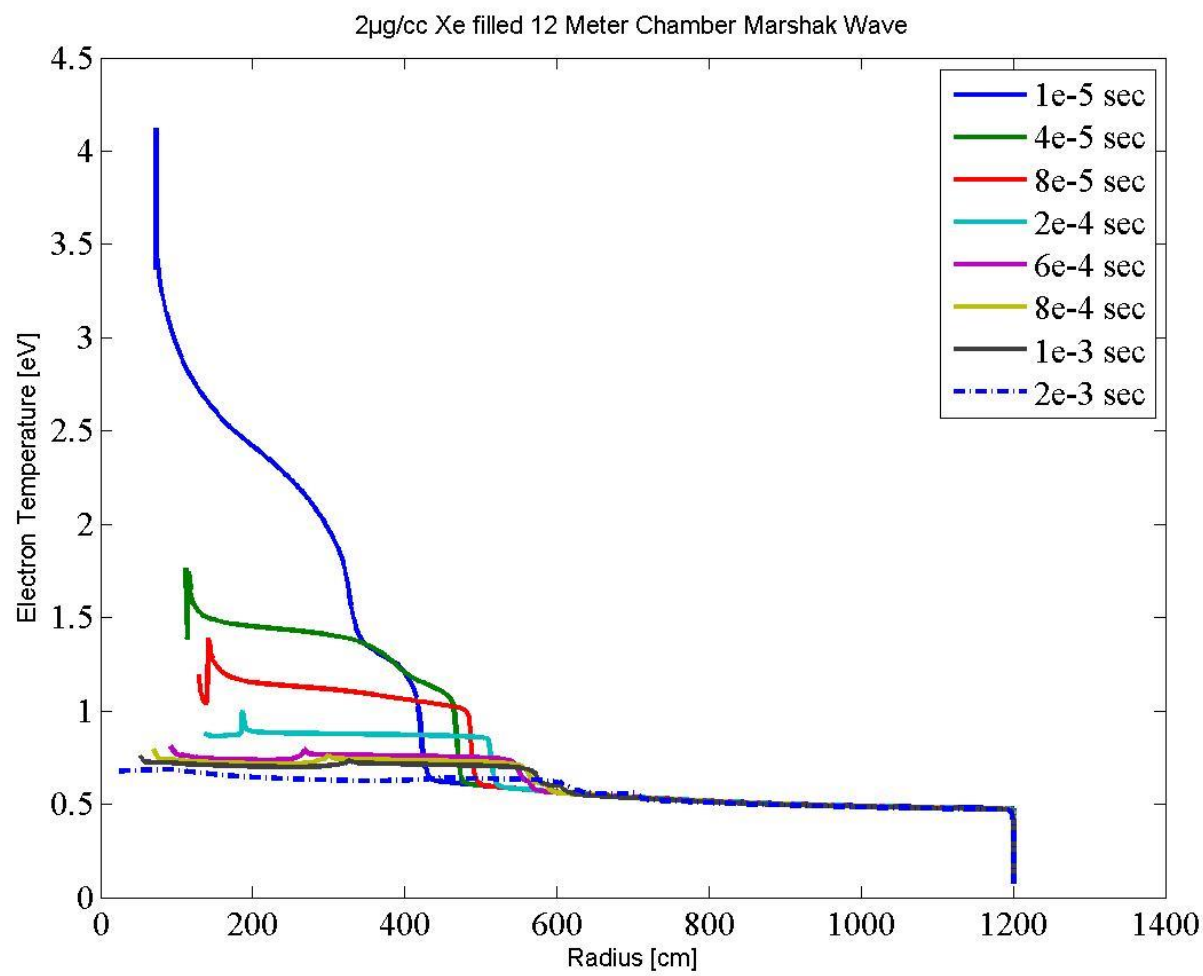

Figure 52: Marshak Wave for 12 meter $2 \mu \mathrm{g} / \mathrm{cc}$ Xe filled chamber. The wave dissipates at about $530 \mathrm{~cm}$. 


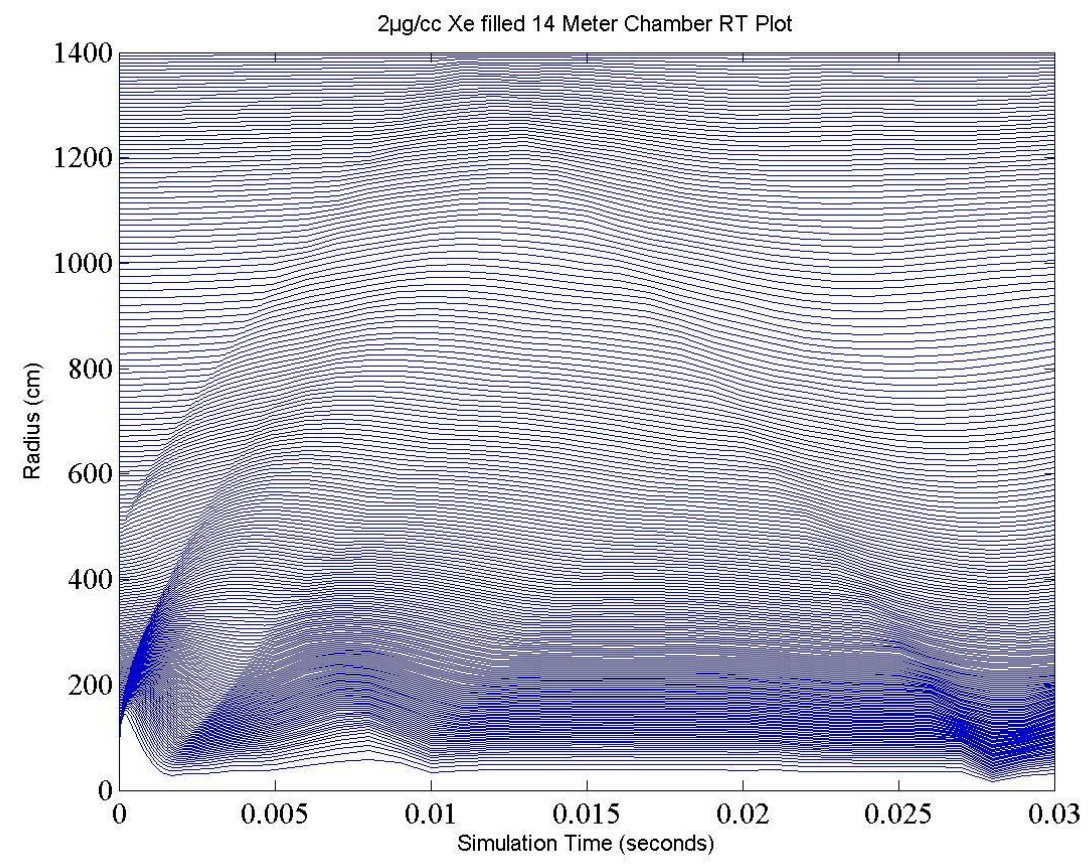

Figure 53: RT plot of the $2 \mu \mathrm{g} / \mathrm{cc}$ Xe filled chamber with 14 meter radius. The double shock starts at $\sim 500 \mathrm{~cm}$. The outer shock arrives at $\sim 12 \mathrm{~ms}$ but the inner shock is lost in the rebound of the outer shock.

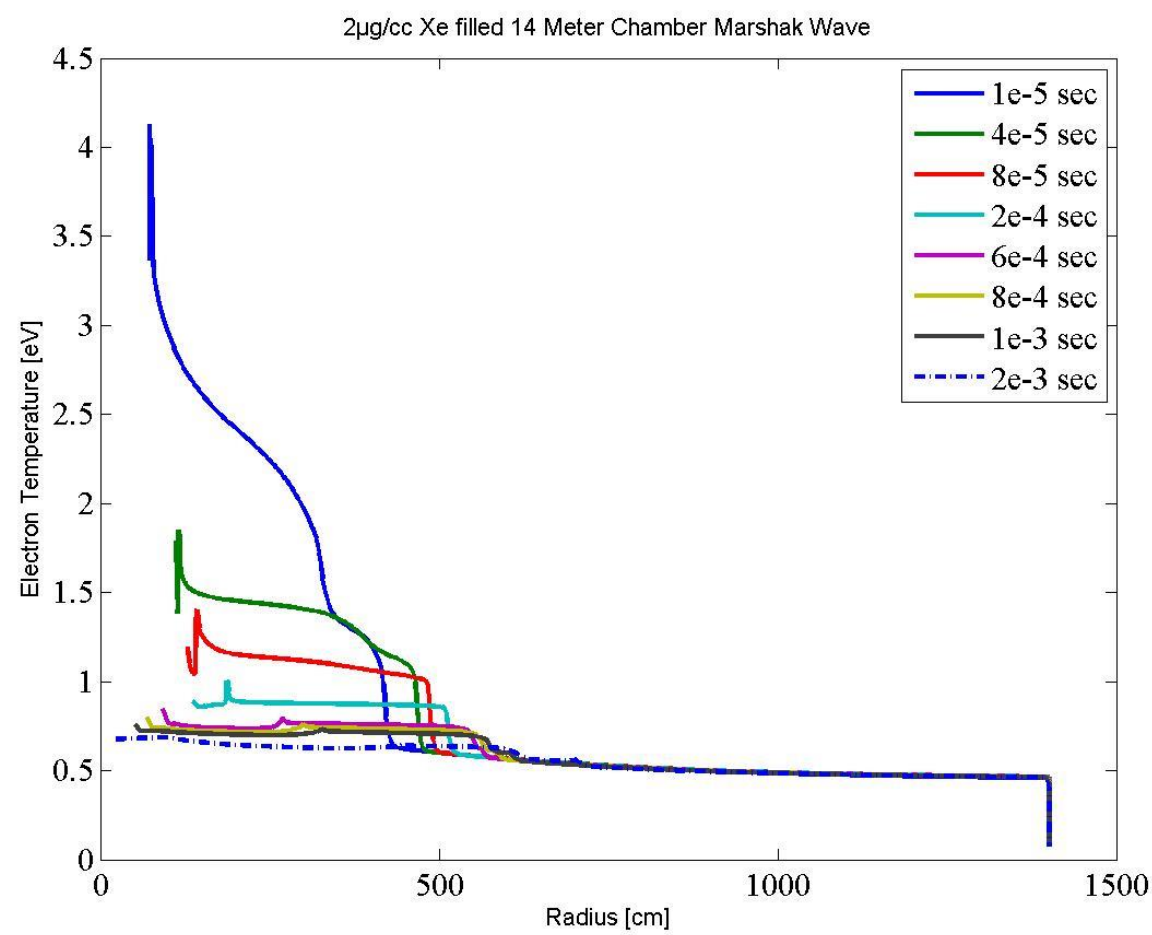

Figure 54: Marshak Wave for 14 meter $2 \mu \mathrm{g} / \mathrm{cc}$ Xe filled chamber. The wave dissipates at about $530 \mathrm{~cm}$. 


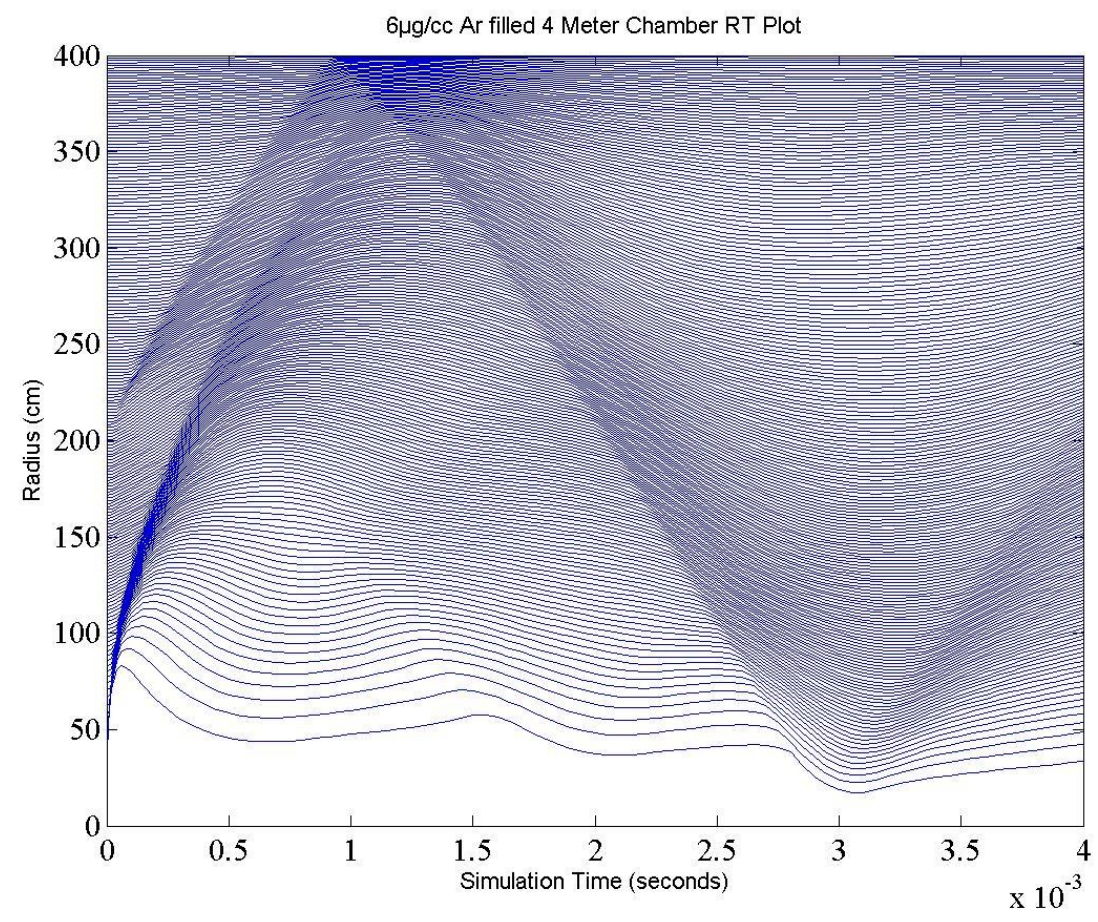

Figure 55: RT plot of the $6 \mu \mathrm{g} / \mathrm{cc}$ Ar filled chamber with 4 meter radius. The double shock starts at $\sim 230 \mathrm{~cm}$ and shocks arrive at the wall at $\sim 1 \mathrm{~ms}$ and $\sim 1.75 \mathrm{~ms}$.

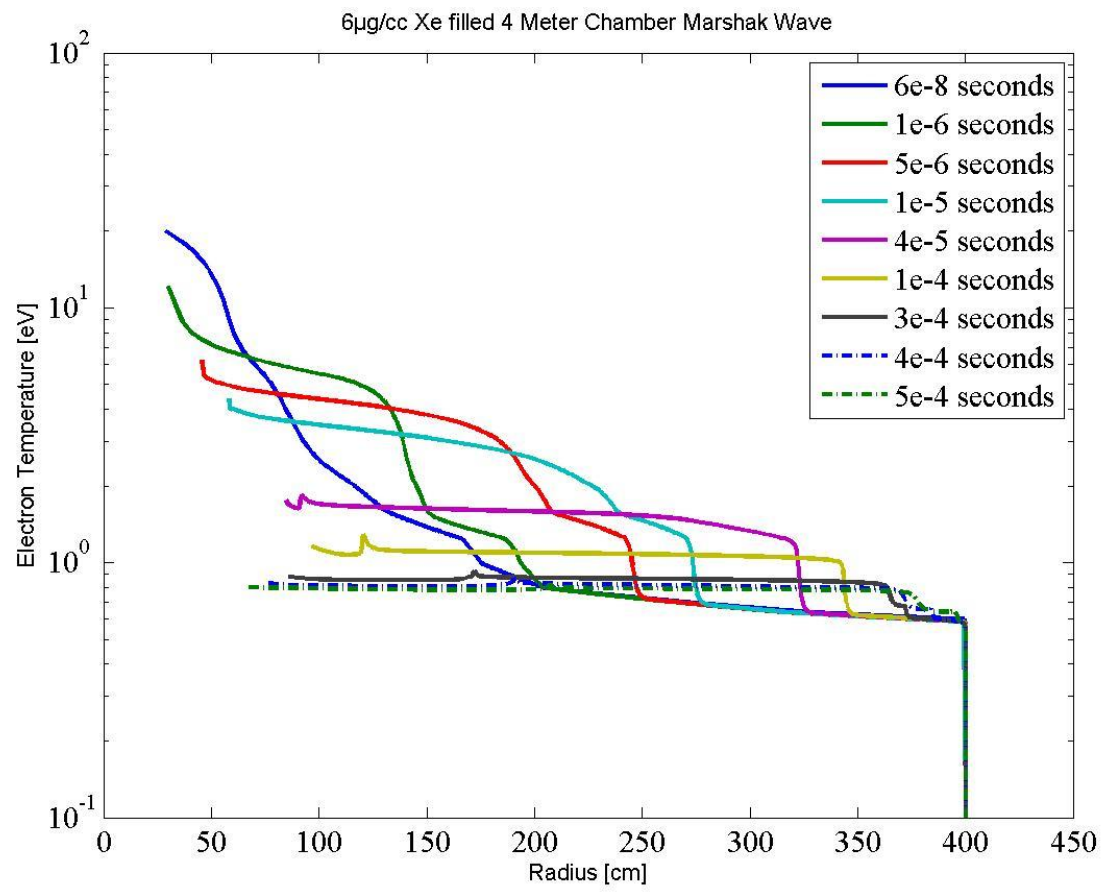

Figure 56: Marshak Wave for 4 meter $2 \mu \mathrm{g} / \mathrm{cc}$ Xe filled chamber. The wave dissipates at about $230 \mathrm{~cm}$. 


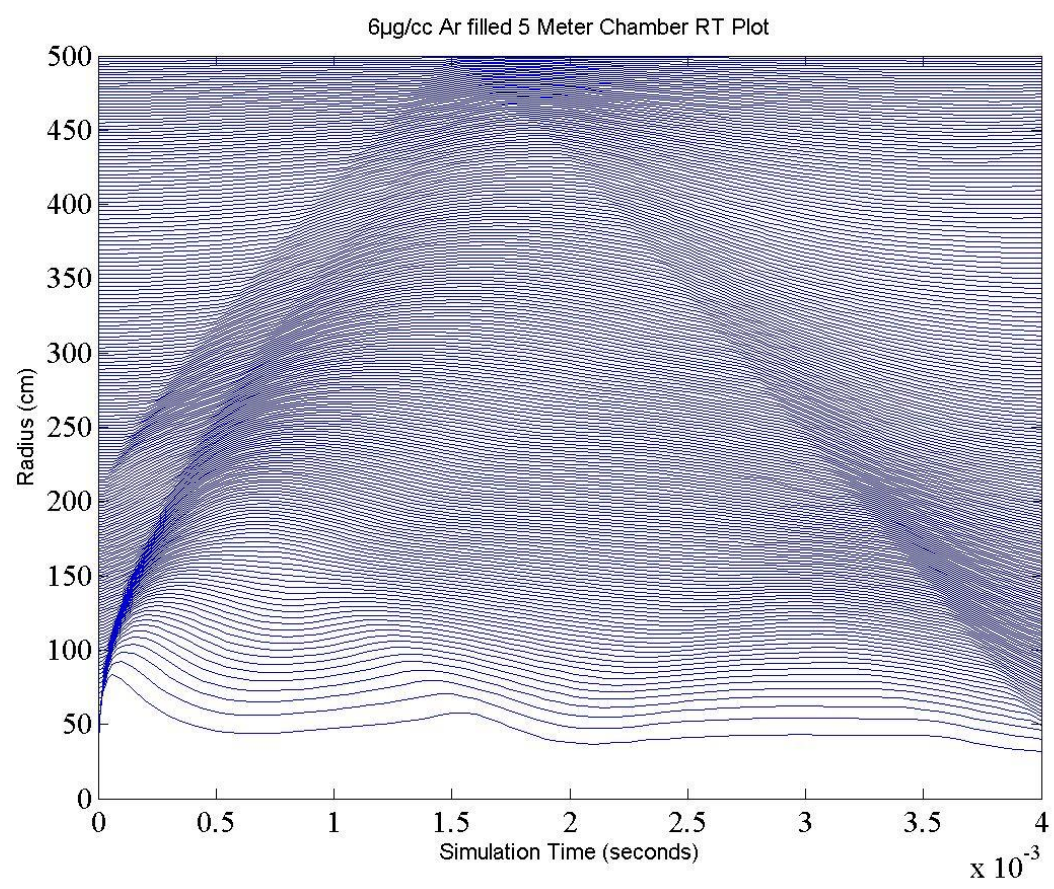

Figure 57: RT plot of the $6 \mu \mathrm{g} / \mathrm{cc}$ Ar filled chamber with 5 meter radius. The double shock starts at $\sim 230 \mathrm{~cm}$ and shocks arrive at the wall at $\sim 1.5 \mathrm{~ms}$ and $\sim 2 \mathrm{~ms}$.

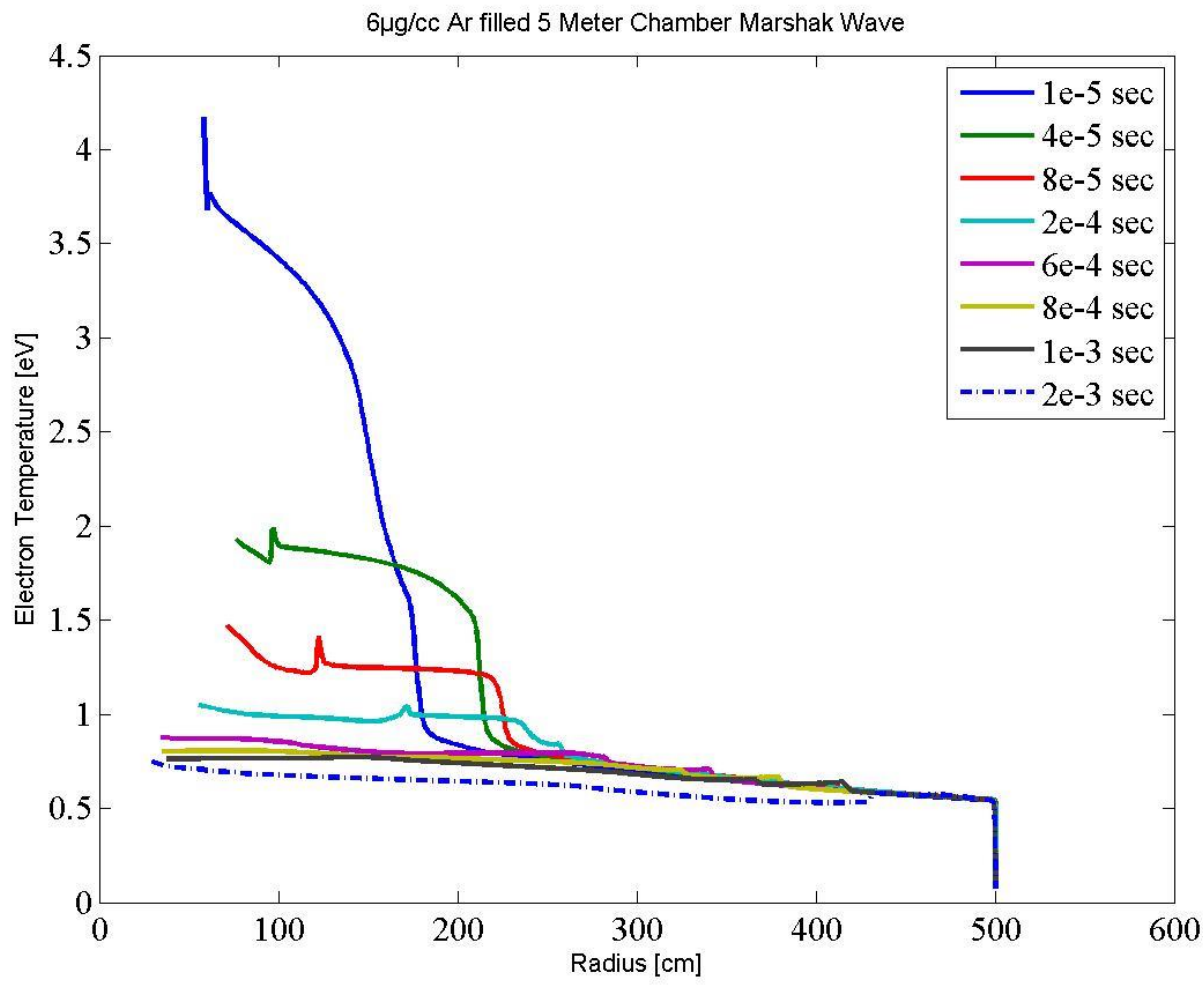

Figure 58: Marshak Wave for 5 meter $2 \mu \mathrm{g} / \mathrm{cc}$ Xe filled chamber. The wave dissipates at about $230 \mathrm{~cm}$. 


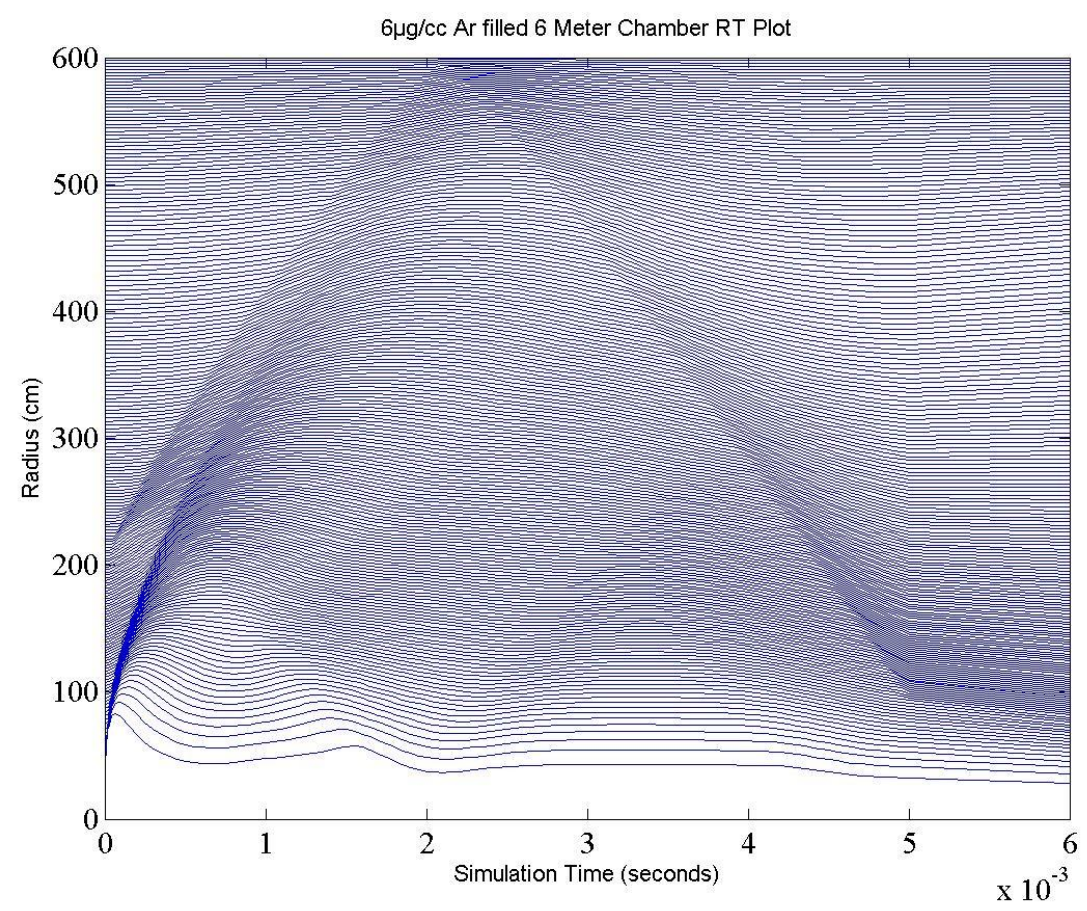

Figure 59: RT plot of the $6 \mu \mathrm{g} / \mathrm{cc}$ Ar filled chamber with 6 meter radius. The double shock starts at $\sim 230 \mathrm{~cm}$. The outer shock arrives at $\sim 2.25 \mathrm{~ms}$ but the inner shock is lost in the rebound of the outer shock.

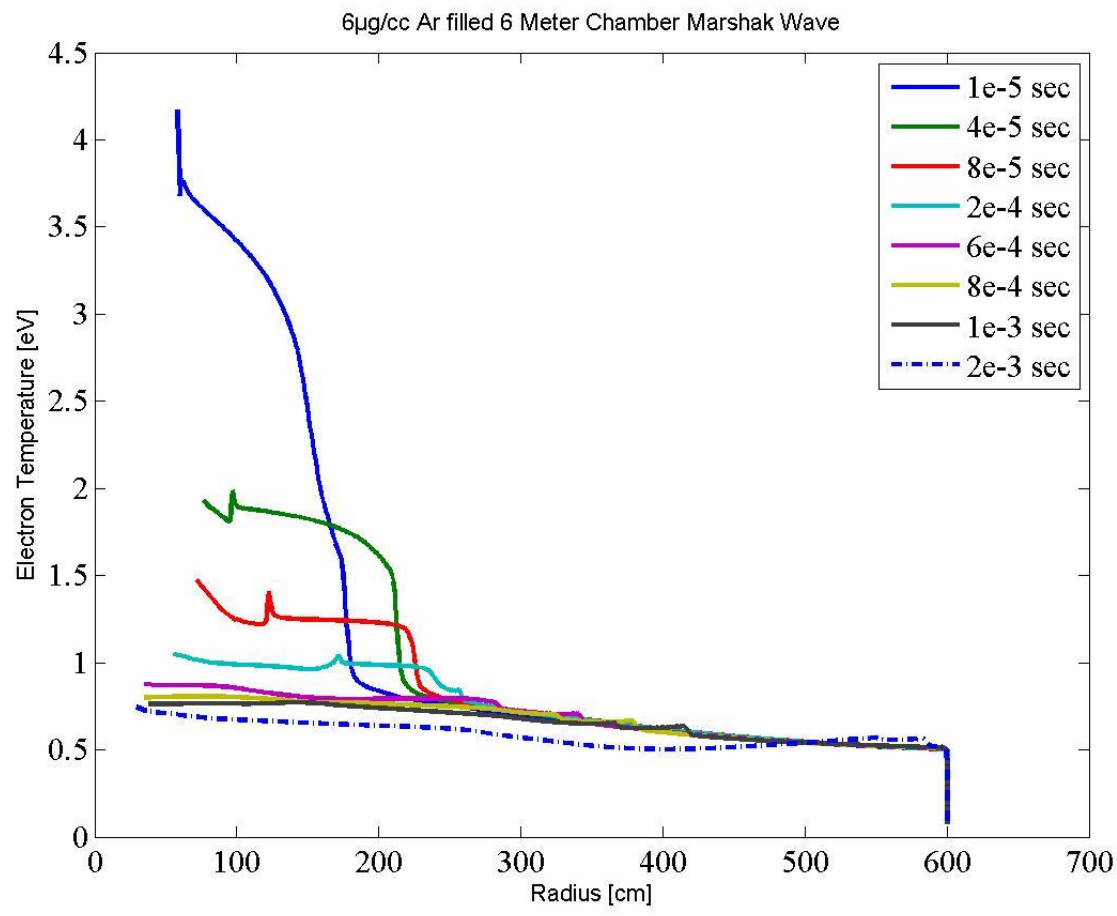

Figure 60: Marshak Wave for 6 meter $2 \mu \mathrm{g} / \mathrm{cc}$ Xe filled chamber. The wave dissipates at about $230 \mathrm{~cm}$. 


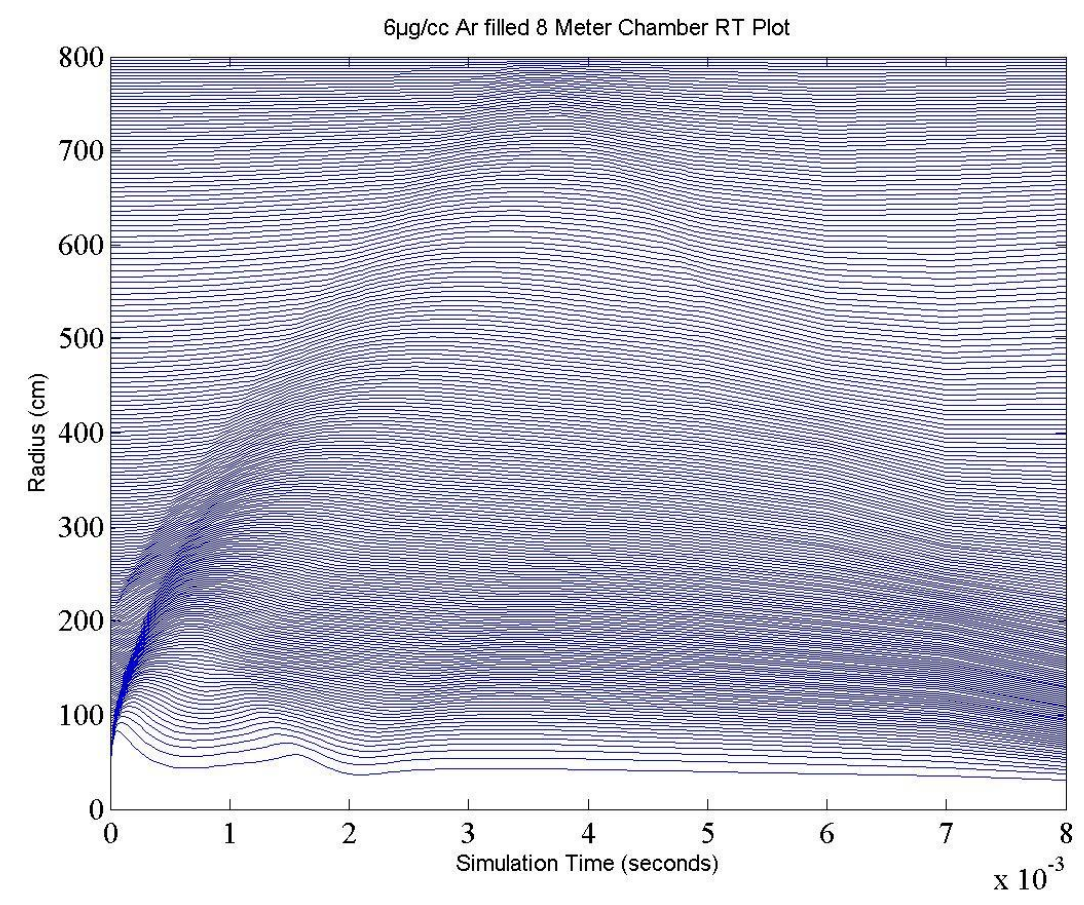

Figure 61: RT plot of the $6 \mu \mathrm{g} / \mathrm{cc}$ Ar filled chamber with 8 meter radius. The double shock starts at $\sim 230 \mathrm{~cm}$. The outer shock arrives at $\sim 3.25 \mathrm{~ms}$ but the inner shock is lost in the rebound of the outer shock.

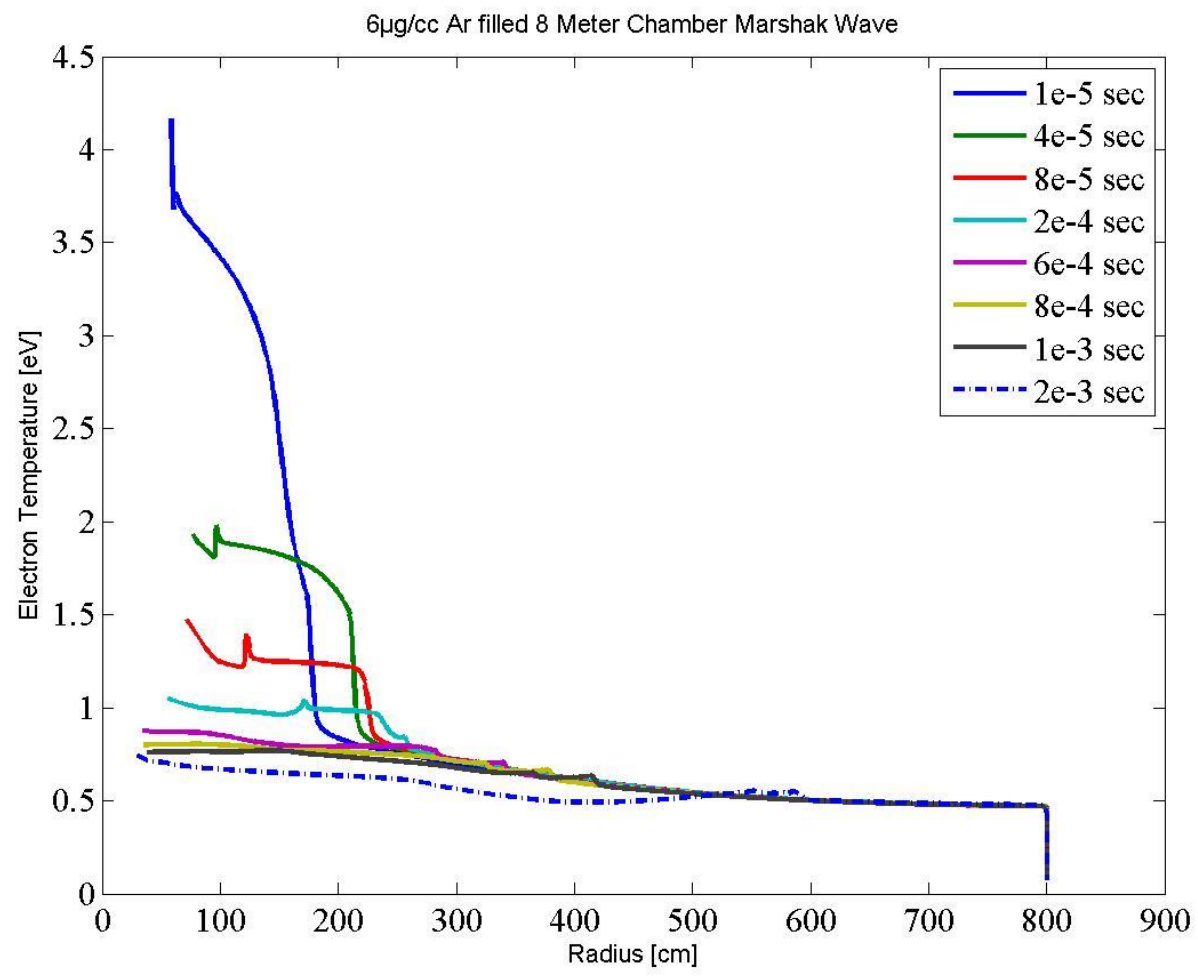

Figure 62: Marshak Wave for 8 meter $2 \mu \mathrm{g} / \mathrm{cc}$ Xe filled chamber. The wave dissipates at about $230 \mathrm{~cm}$. 


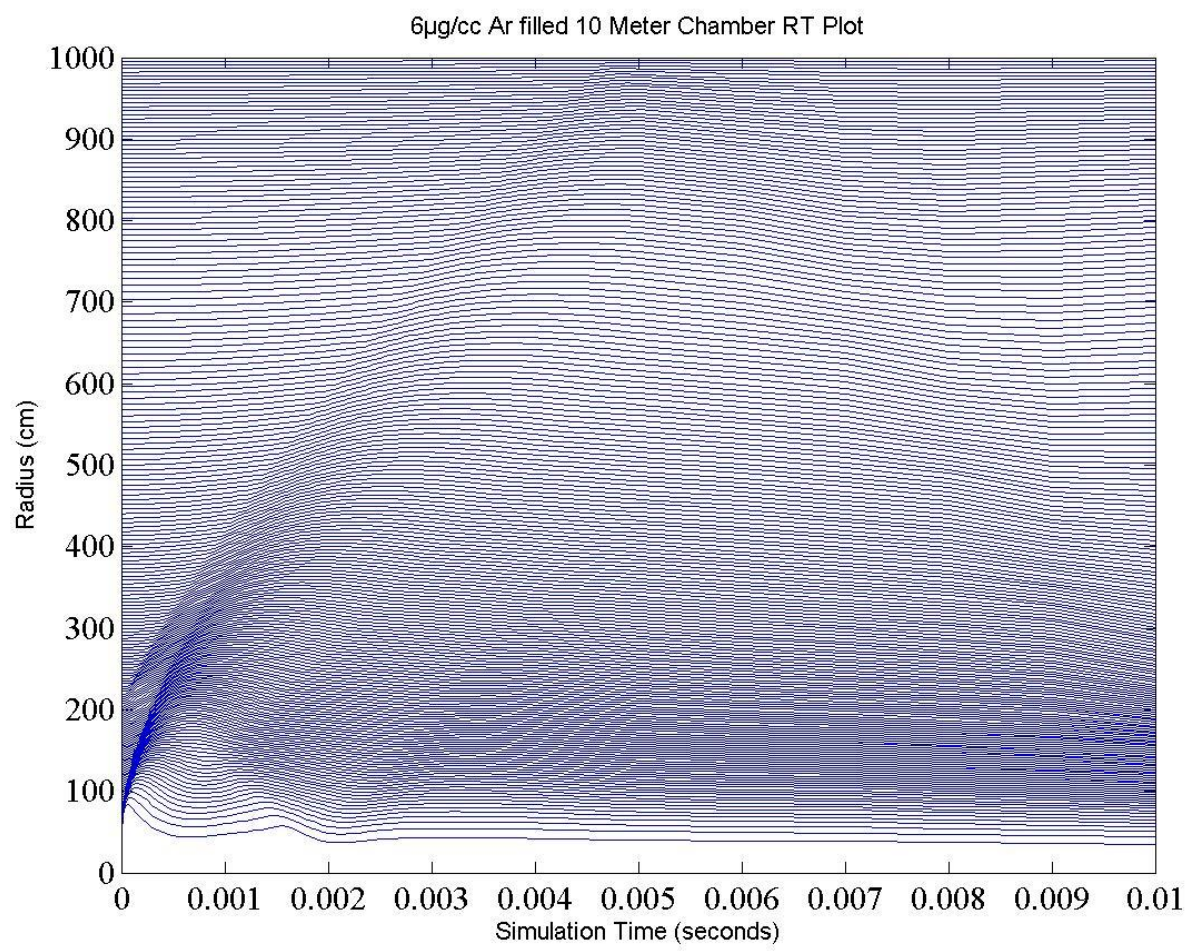

Figure 63: RT plot of the $6 \mu \mathrm{g} / \mathrm{cc}$ Ar filled chamber with 10 meter radius. The double shock starts at $\sim 230 \mathrm{~cm}$. The outer shock arrives at $\sim 4.75 \mathrm{~ms}$ but the inner shock is lost in the rebound of the outer shock.

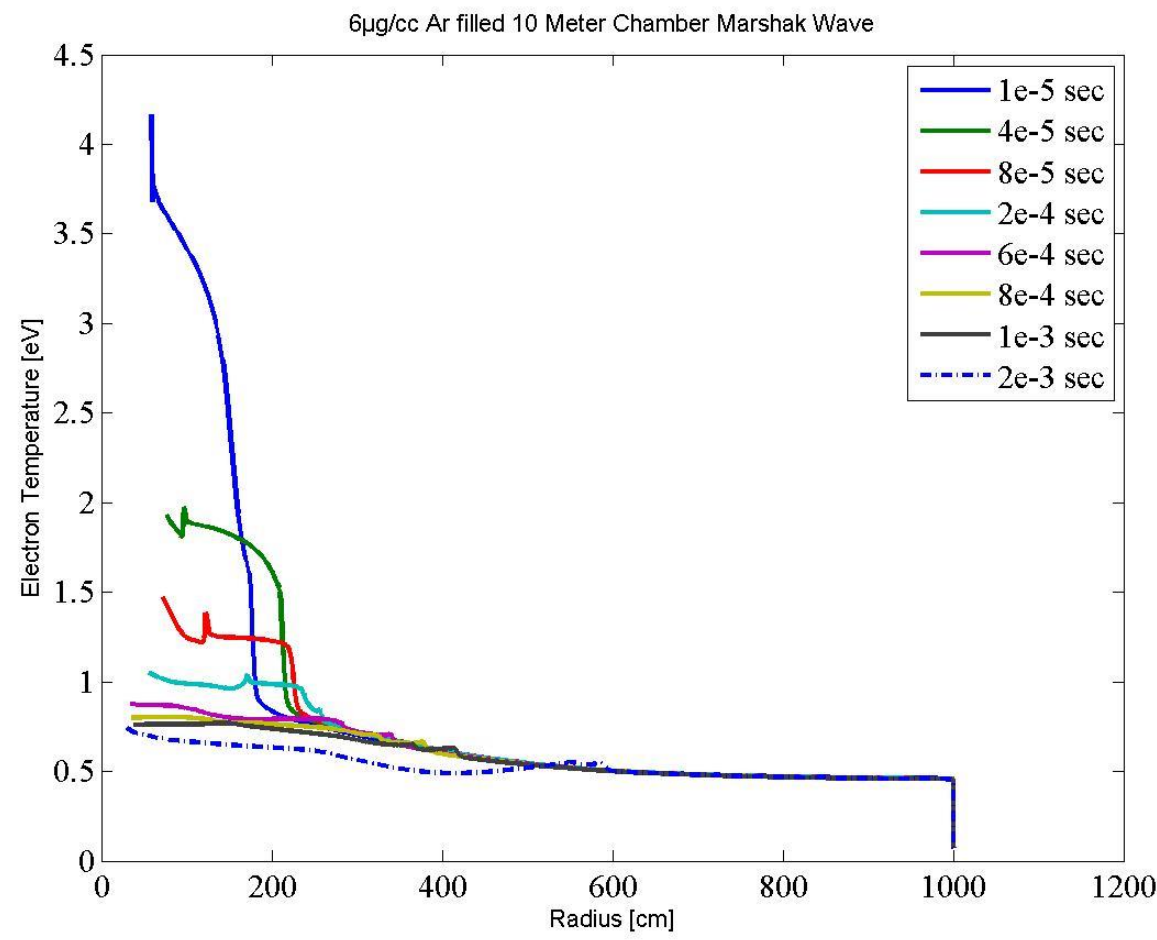

Figure 64: Marshak Wave for 10 meter $2 \mu \mathrm{g} / \mathrm{cc}$ Xe filled chamber. The wave dissipates at about $230 \mathrm{~cm}$. 


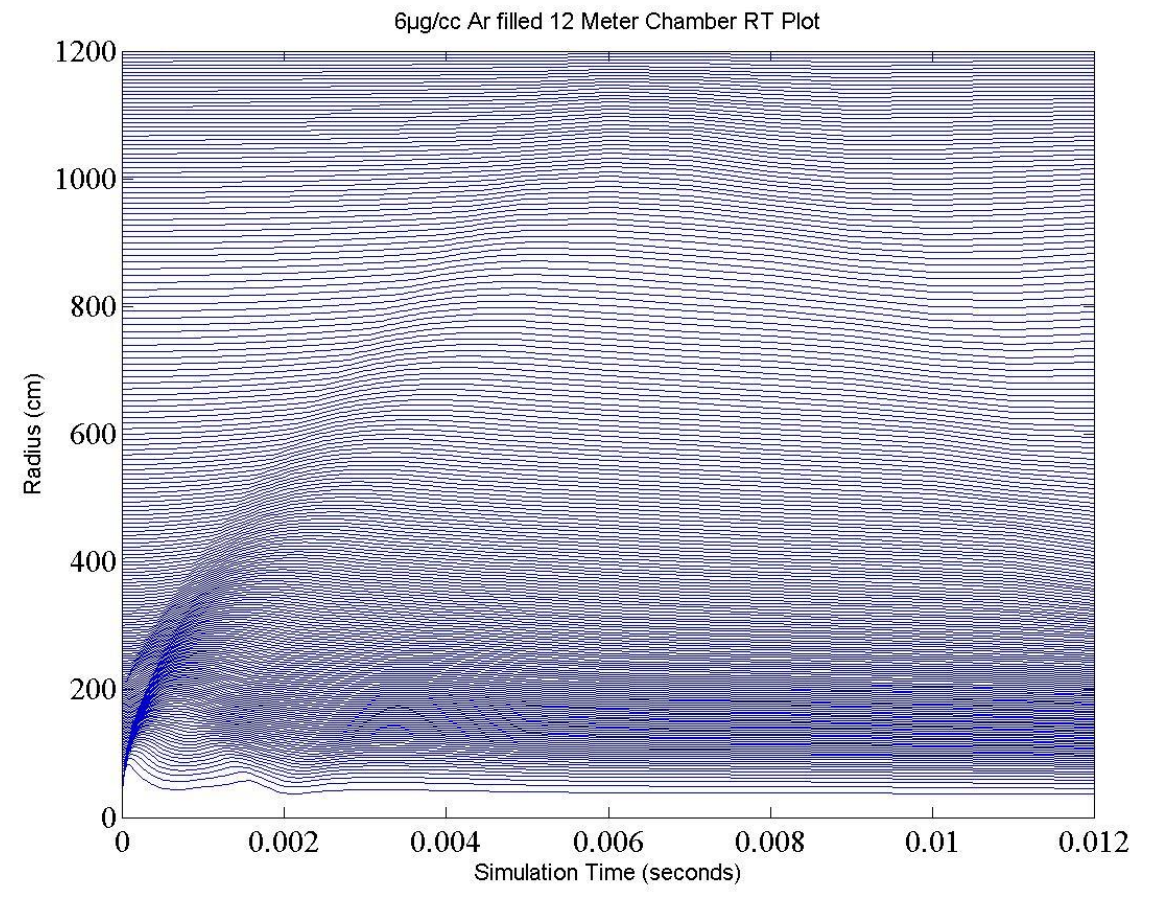

Figure 65: RT plot of the $6 \mu \mathrm{g} / \mathrm{cc}$ Ar filled chamber with 12 meter radius. The double shock starts at $\sim 230 \mathrm{~cm}$. The outer shock arrives at $\sim 6 \mathrm{~ms}$ but the inner shock is lost in the rebound of the outer shock.

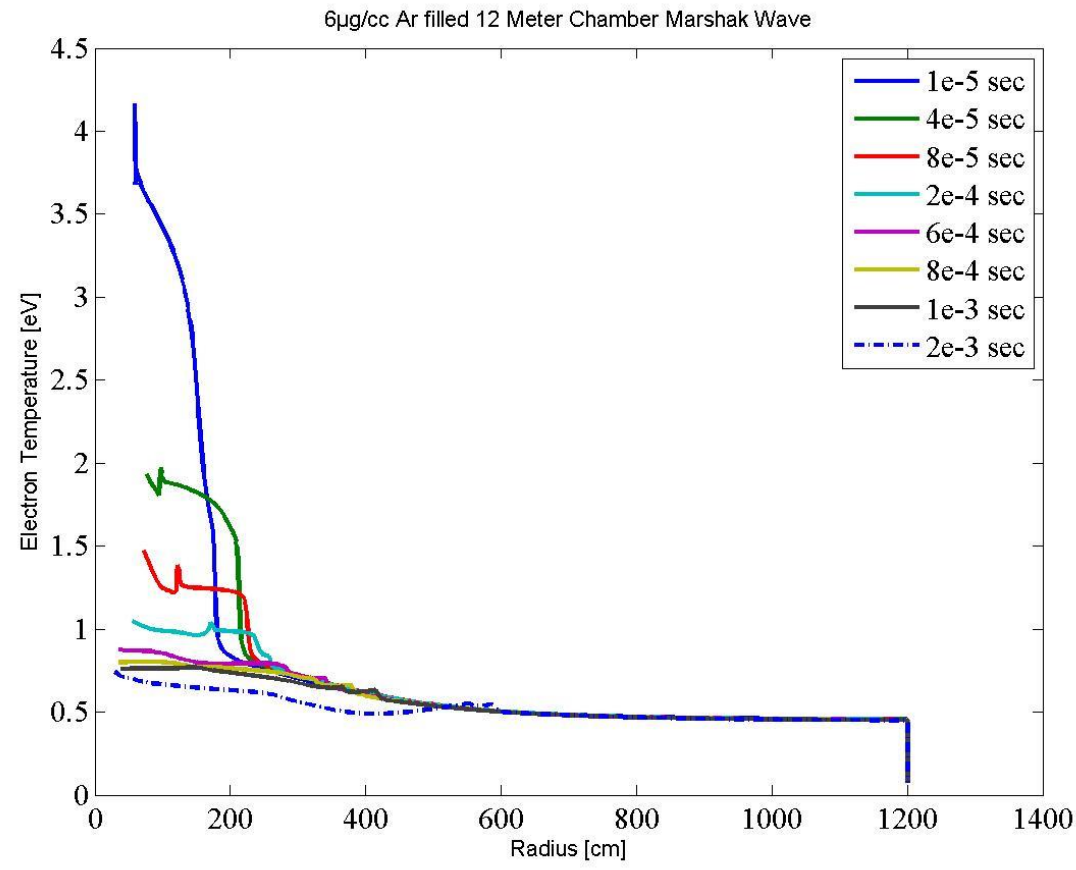

Figure 66: Marshak Wave for 12 meter $2 \mu \mathrm{g} / \mathrm{cc}$ Xe filled chamber. The wave dissipates at about $230 \mathrm{~cm}$. 


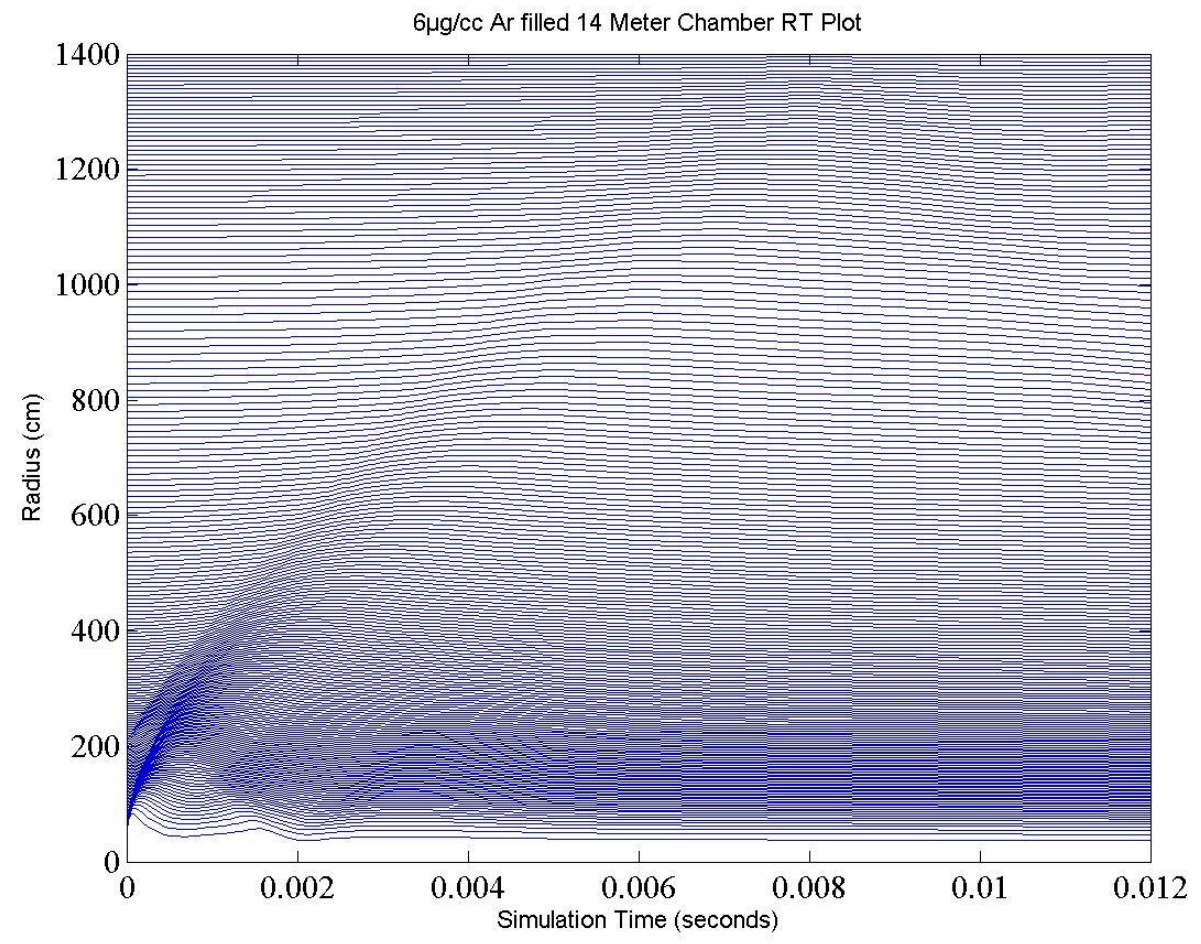

Figure 67: RT plot of the $6 \mu \mathrm{g} / \mathrm{cc}$ Ar filled chamber with 14 meter radius. The double shock starts at $\sim 230 \mathrm{~cm}$. The outer shock arrives at $\sim 7.5 \mathrm{~ms}$ but the inner shock is lost in the rebound of the outer shock.

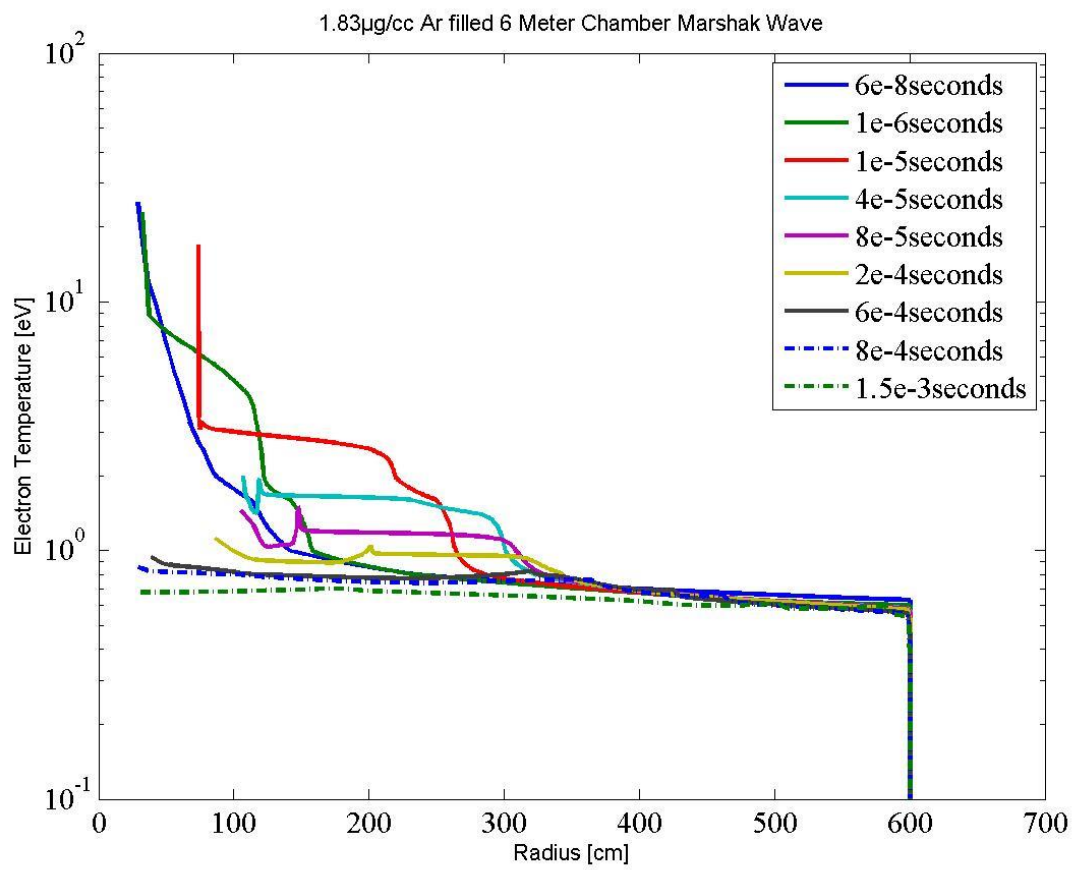

Figure 68: Marshak Wave for 14 meter $2 \mu \mathrm{g} / \mathrm{cc}$ Xe filled chamber. The wave dissipates at about $230 \mathrm{~cm}$. 


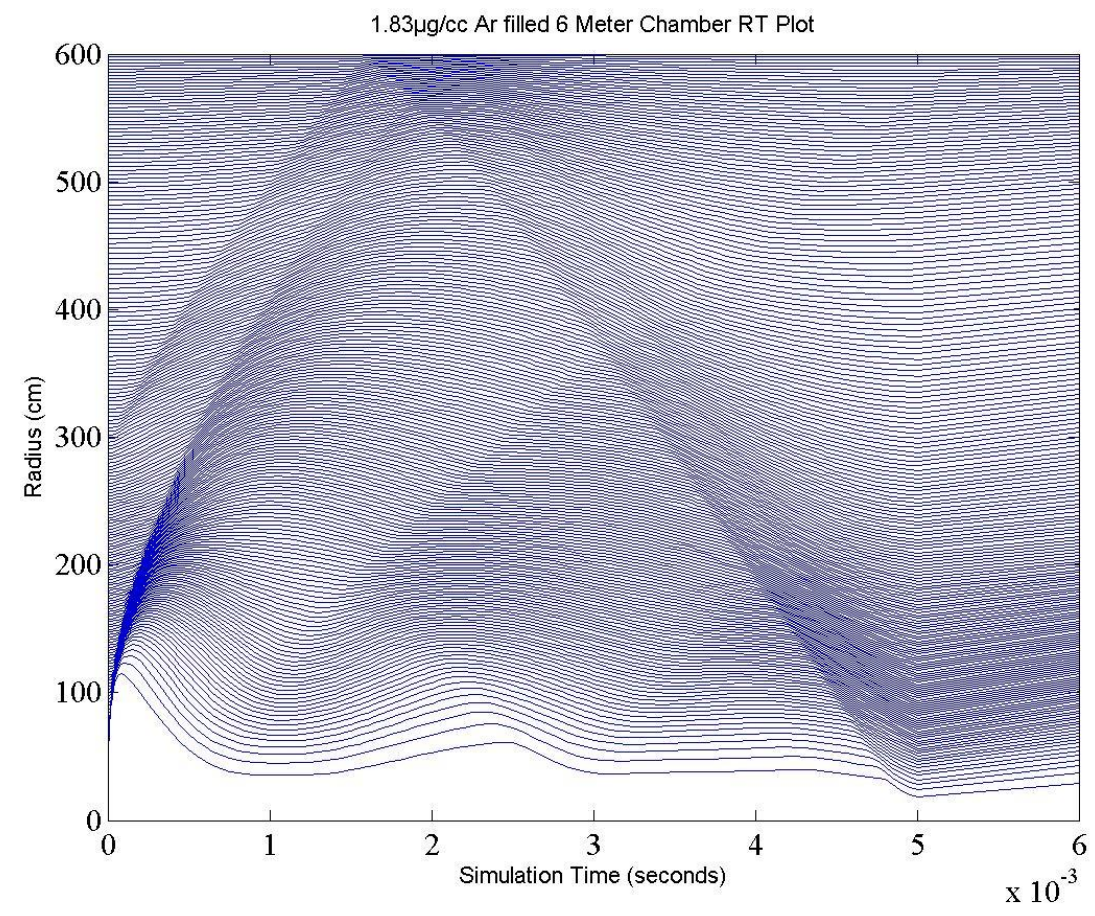

Figure 69: RT plot of the $1.83 \mu \mathrm{g} / \mathrm{cc}$ Ar filled chamber with 6 meter radius. The double shock starts at $\sim 300 \mathrm{~cm}$ and shocks arrive at the wall at $\sim 1.5 \mathrm{~ms}$ and $\sim 2.25 \mathrm{~ms}$.

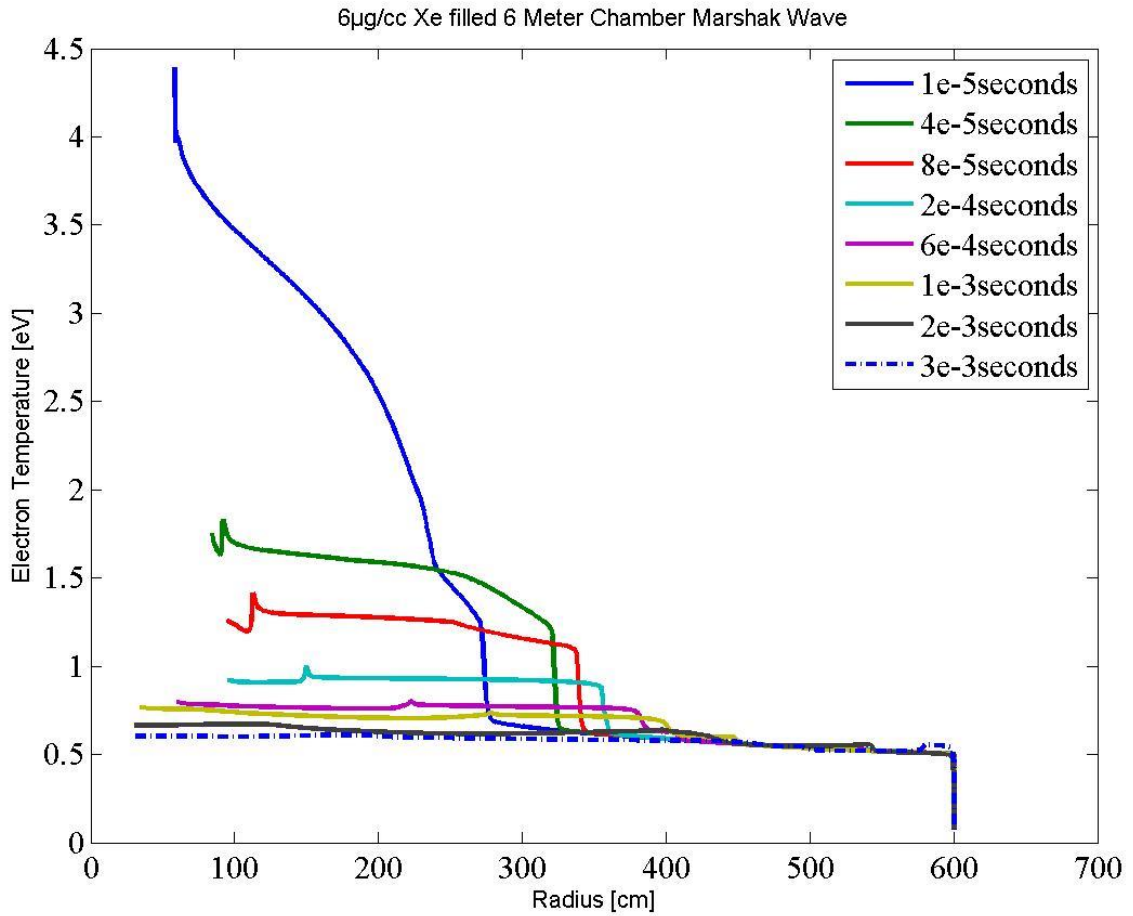

Figure 70: Marshak Wave for 6 meter $1.83 \mu \mathrm{g} / \mathrm{cc}$ Xe filled chamber. The wave dissipates at about $330 \mathrm{~cm}$. 


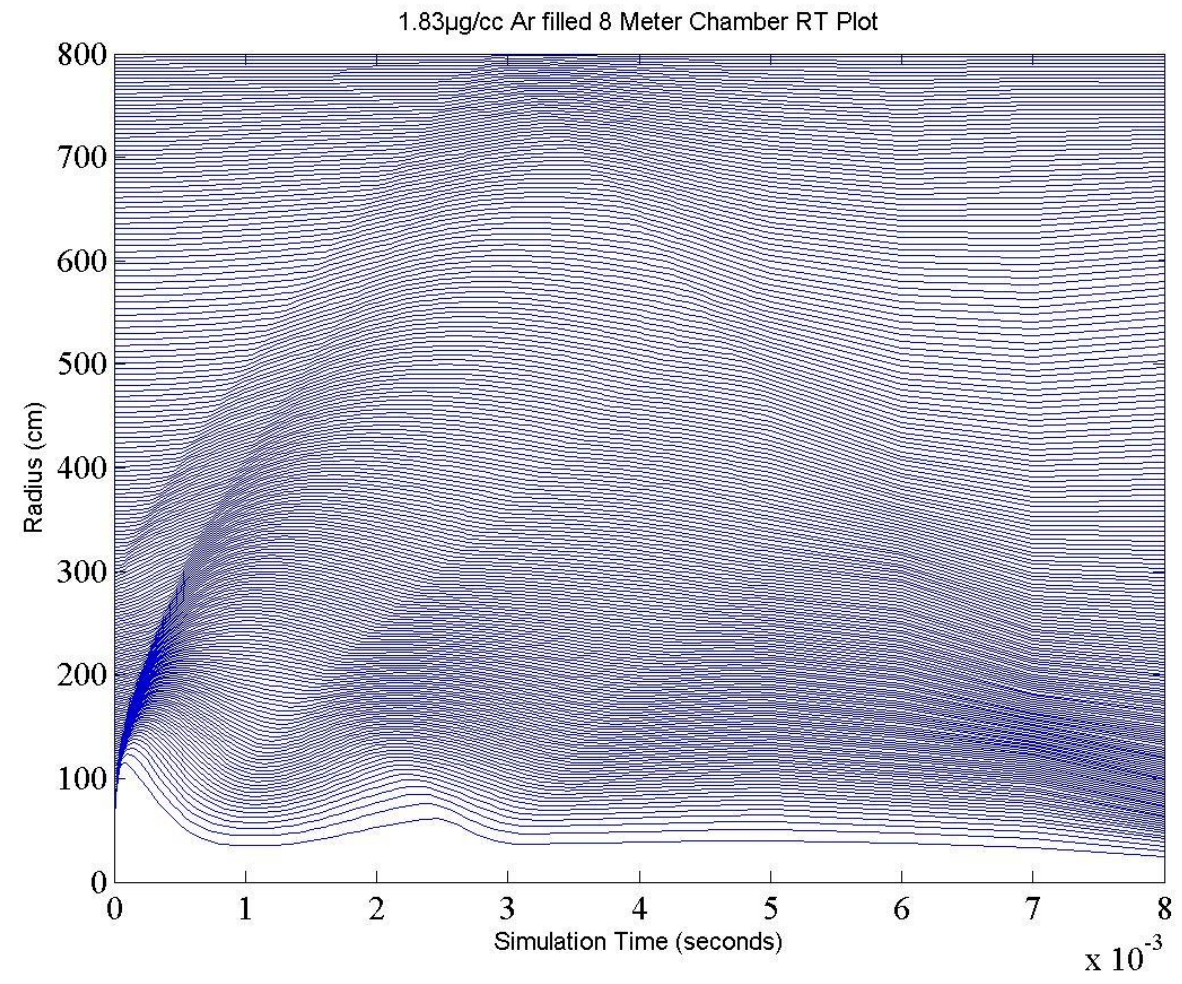

Figure 71: RT plot of the $1.83 \mu \mathrm{g} / \mathrm{cc}$ Ar filled chamber with 8 meter radius. The double shock starts at $\sim 300 \mathrm{~cm}$ and shocks arrive at the wall at $\sim 3 \mathrm{~ms}$ and $\sim 3.75 \mathrm{~ms}$.

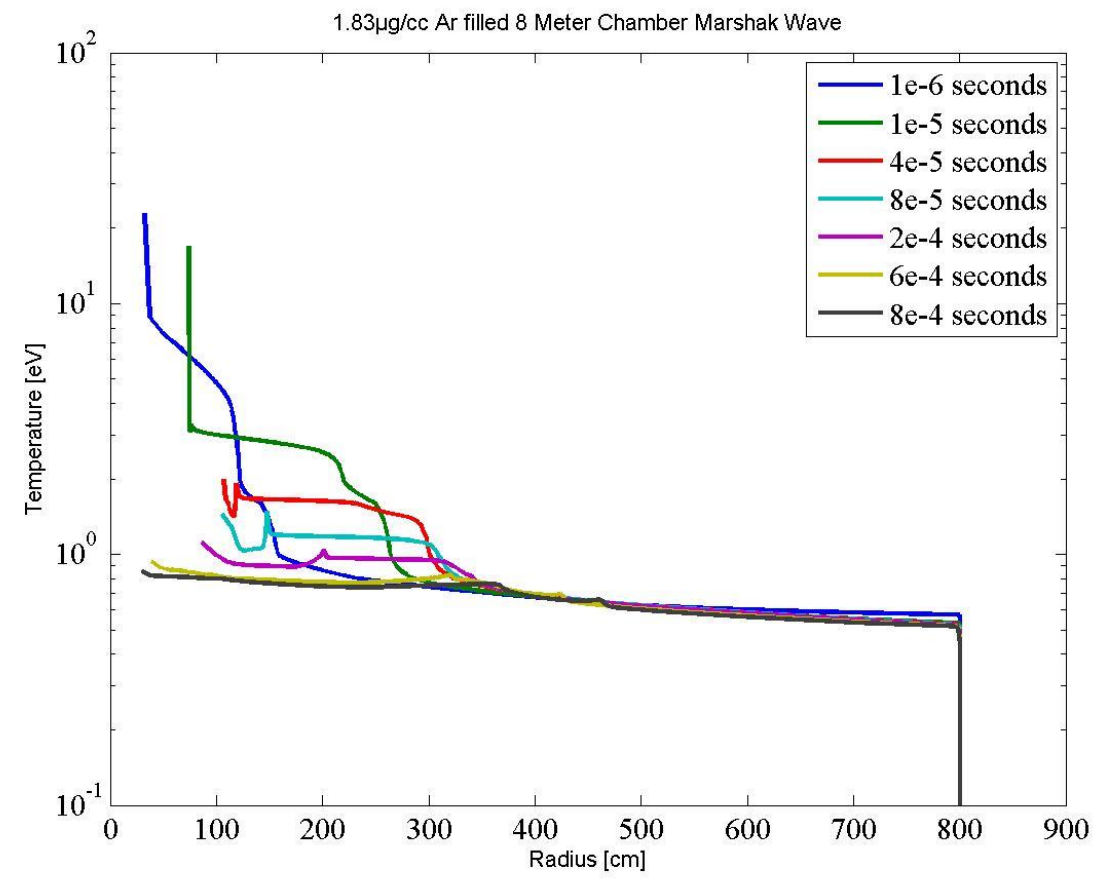

Figure 72: Marshak Wave for 8 meter $1.83 \mu \mathrm{g} / \mathrm{cc}$ Xe filled chamber. The wave dissipates at about $330 \mathrm{~cm}$. 


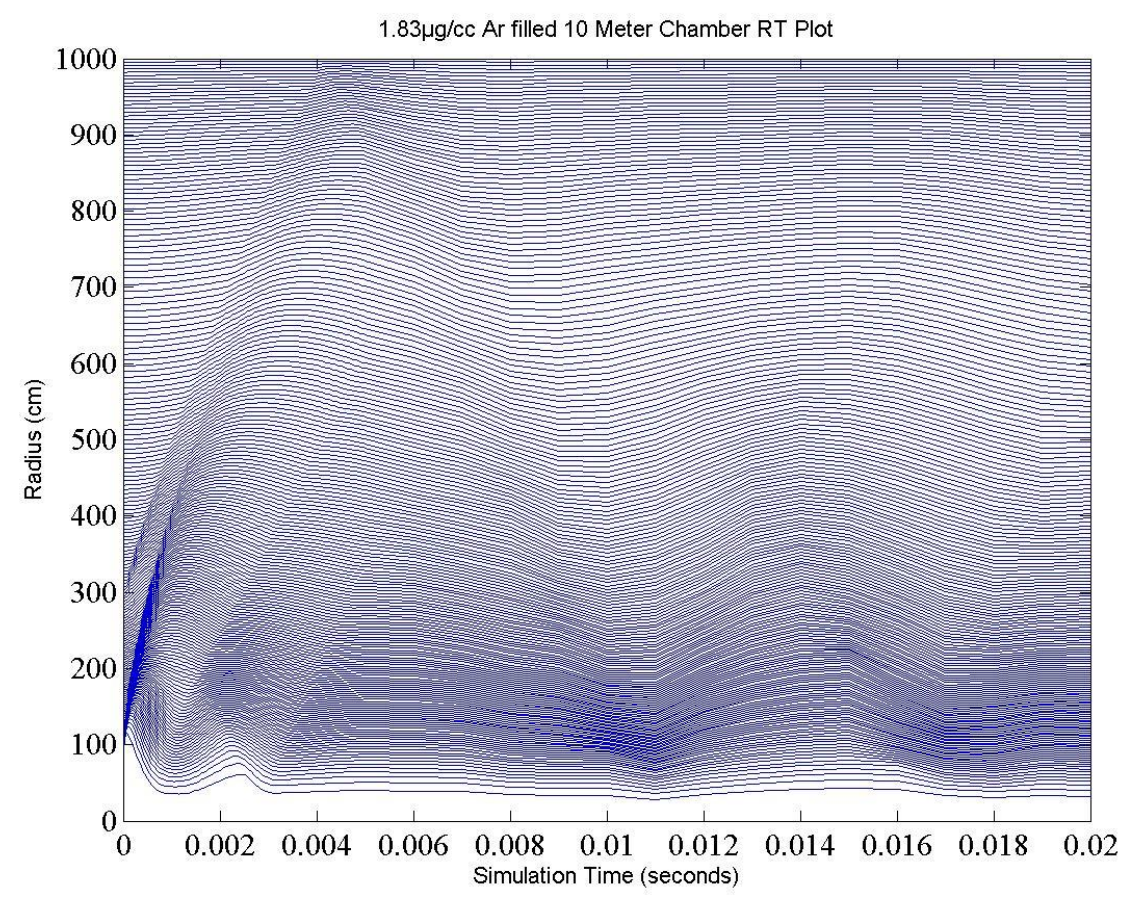

Figure 73: RT plot of the $1.83 \mu \mathrm{g} / \mathrm{cc}$ Ar filled chamber with 10 meter radius. The double shock starts at $\sim 300 \mathrm{~cm}$. The outer shock arrives at $\sim 4.5 \mathrm{~ms}$ but the inner shock is lost in the rebound of the outer shock.

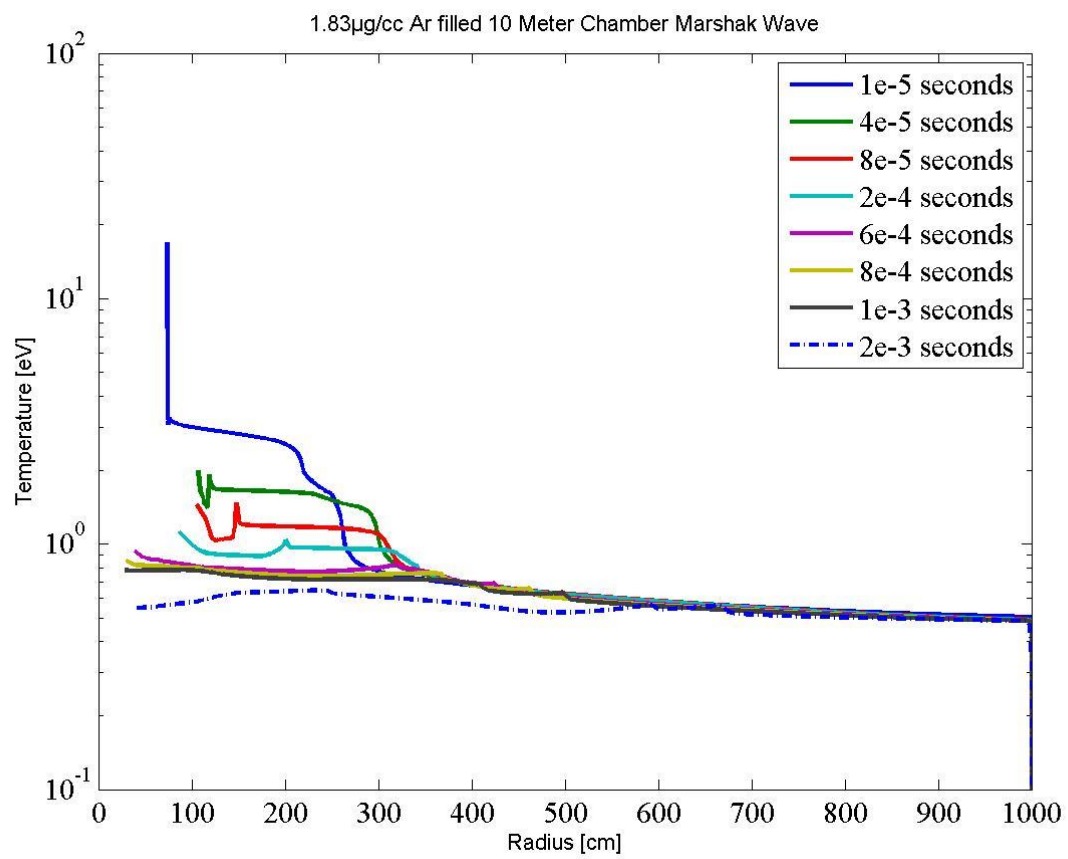

Figure 74: Marshak Wave for 10 meter $1.83 \mu \mathrm{g} / \mathrm{cc}$ Xe filled chamber. The wave dissipates at about $330 \mathrm{~cm}$. 


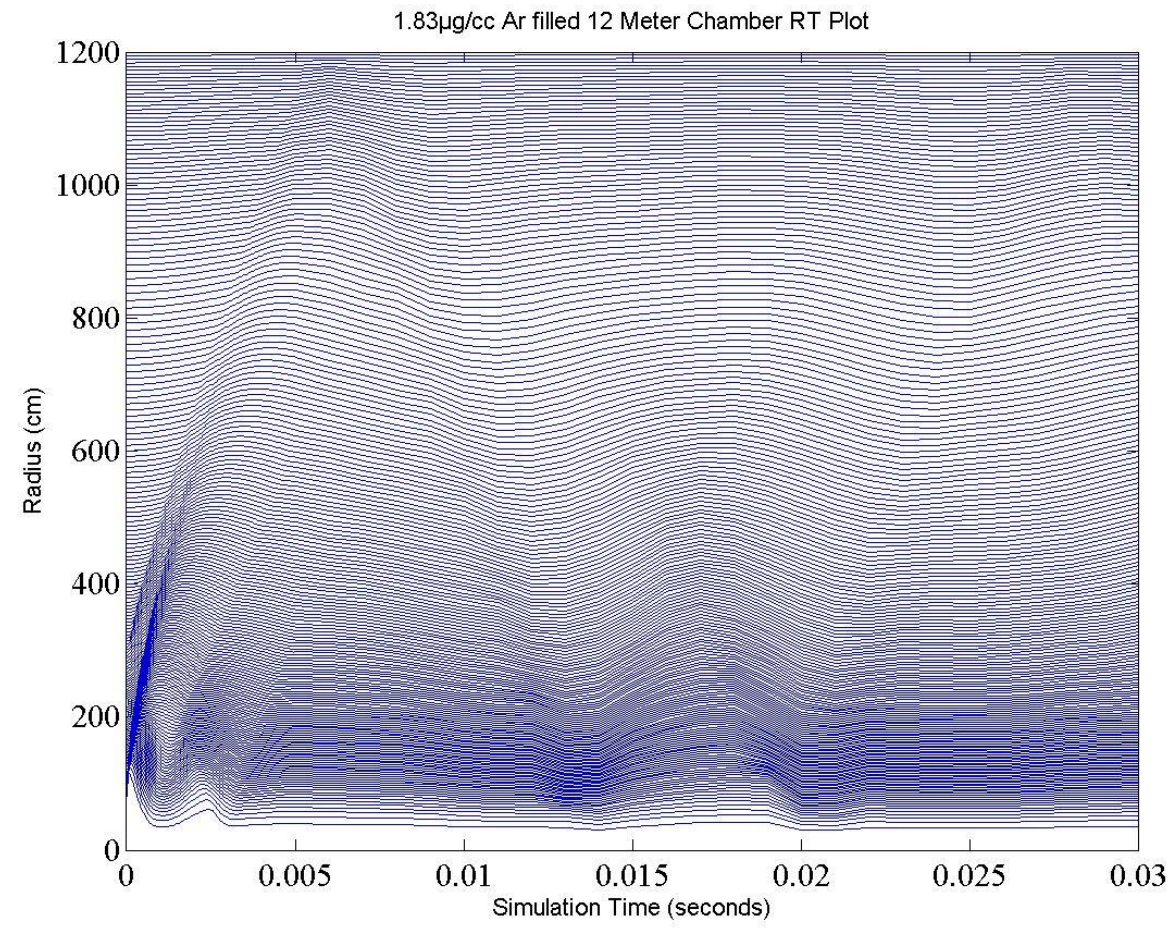

Figure 75: RT plot of the $1.83 \mu \mathrm{g} / \mathrm{cc}$ Ar filled chamber with 12 meter radius. The double shock starts at $\sim 300 \mathrm{~cm}$. The outer shock arrives at $\sim 5.5 \mathrm{~ms}$ but the inner shock is lost in the rebound of the outer shock.

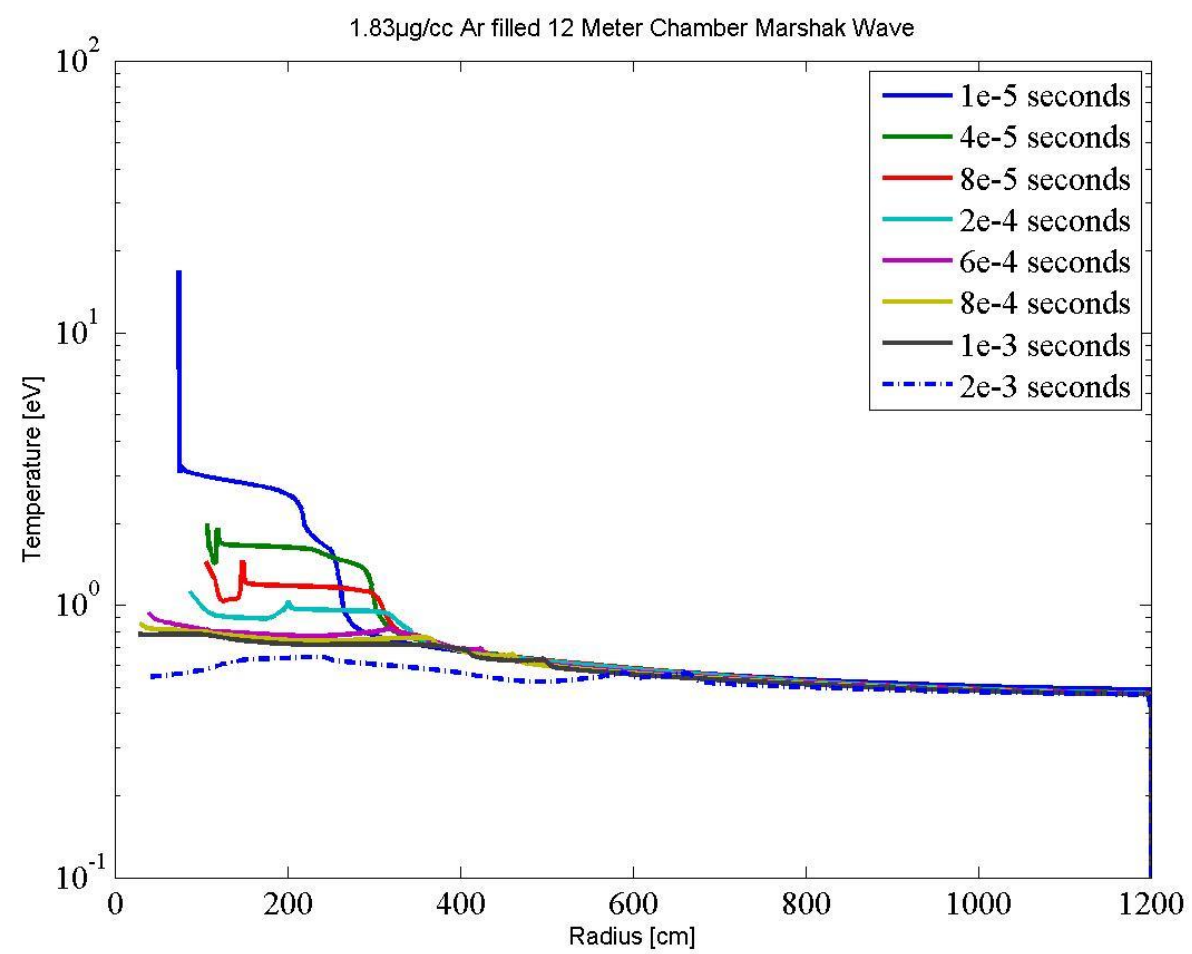

Figure 76: Marshak Wave for 12 meter $1.83 \mu \mathrm{g} / \mathrm{cc}$ Xe filled chamber. The wave dissipates at about $330 \mathrm{~cm}$. 


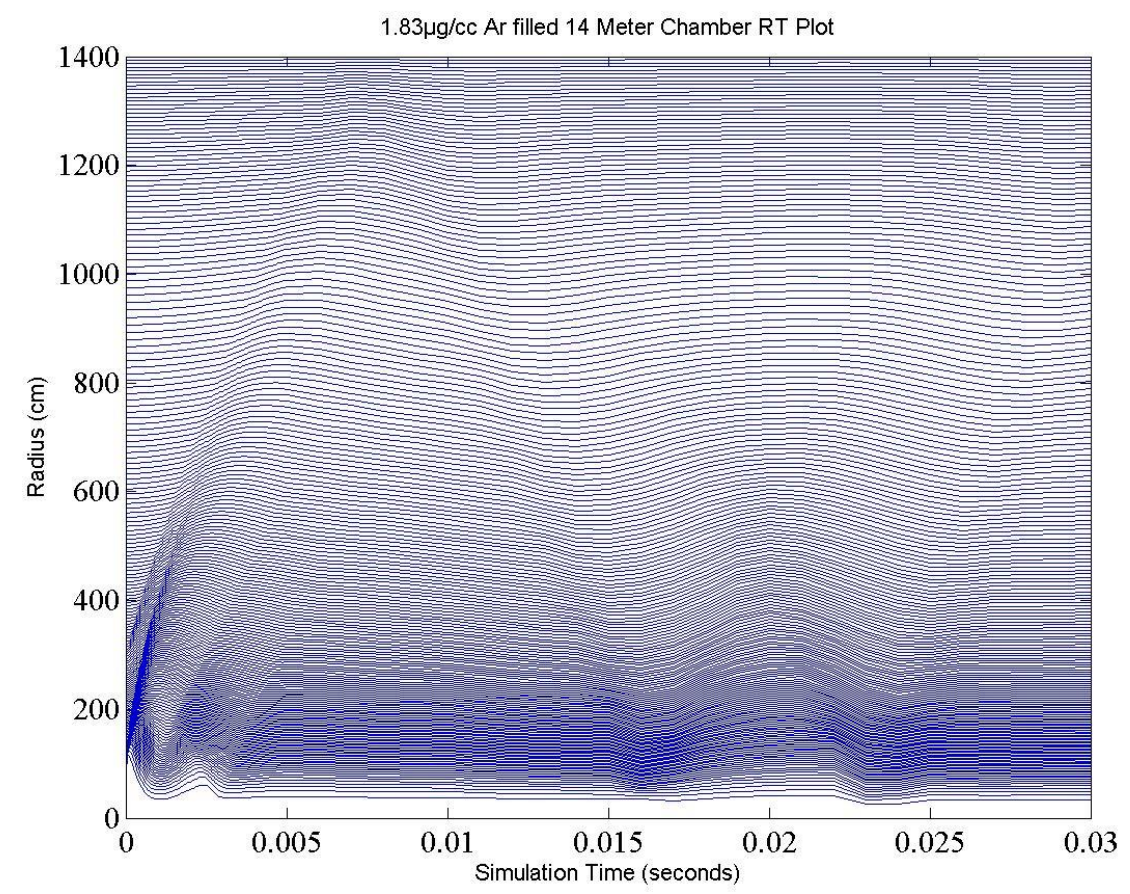

Figure 77: RT plot of the $1.83 \mu \mathrm{g} / \mathrm{cc}$ Ar filled chamber with 14 meter radius. The double shock starts at $\sim 300 \mathrm{~cm}$. The outer shock arrives at $\sim 7 \mathrm{~ms}$ but the inner shock is lost in the rebound of the outer shock.

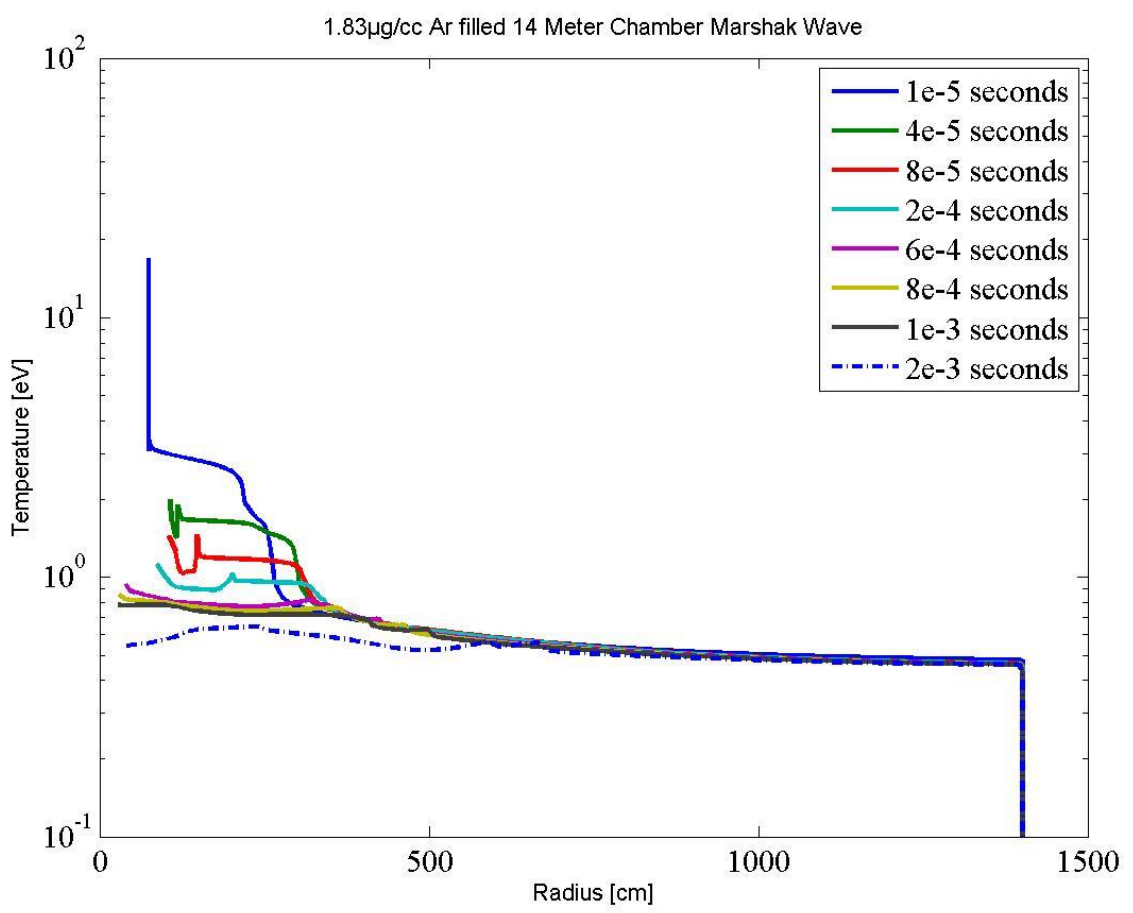

Figure 78: Marshak Wave for 14 meter $1.83 \mu \mathrm{g} / \mathrm{cc}$ Xe filled chamber. The wave dissipates at about $330 \mathrm{~cm}$. 


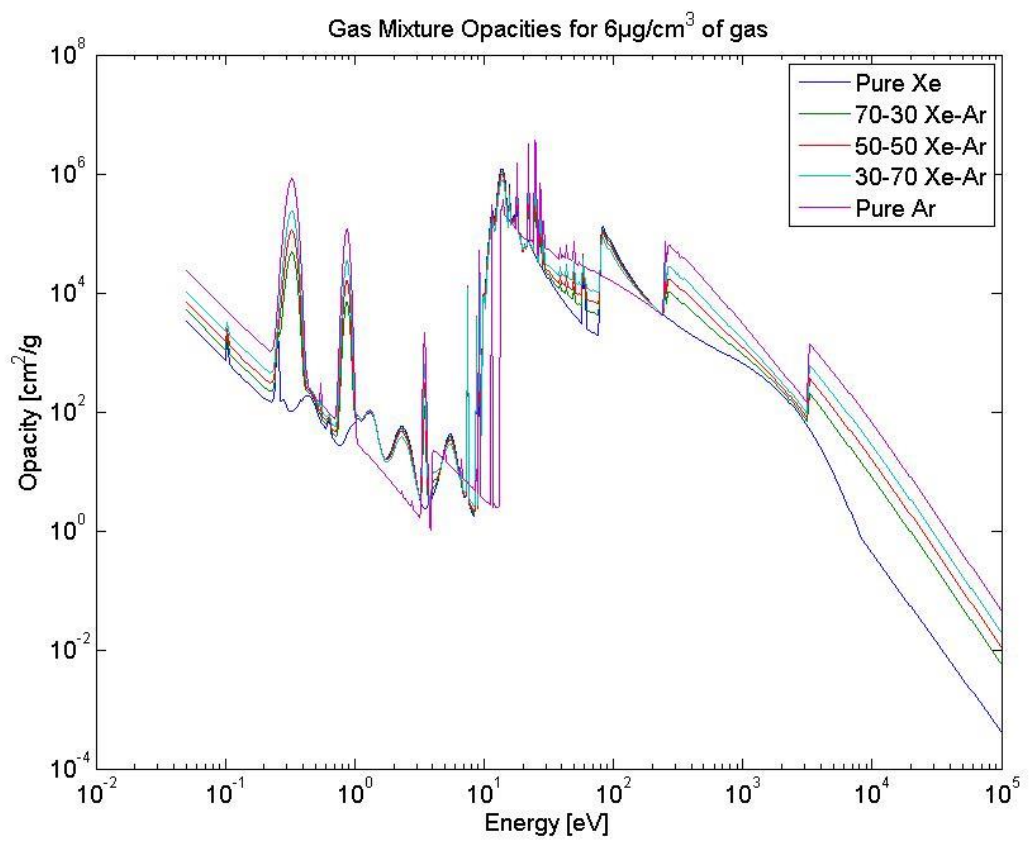

Figure 79: Opacity values for $6 \mu \mathrm{g} / \mathrm{cm}^{3}$ gas mixtures of Xe and Ar. The temperature of the gas is $1 \mathrm{eV}$ and the mixing was done via the CRETIN code with atomic data tables provided by Howard Scott. 